Reactivity of a Tuff-Bearing Concrete:

CL-40 CON-14

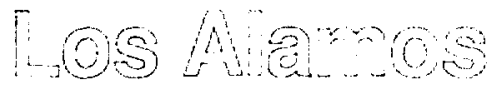

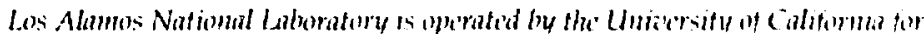

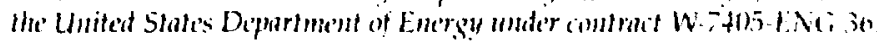


This work was supported by the Yucca Mountain Project Office as part of the Civilian Radioactive Waste Management Program. This Project is managed by the US Department of Energy, Neonda Operations Office.

An Affirmative Action/Equal Oppurtunity Employer

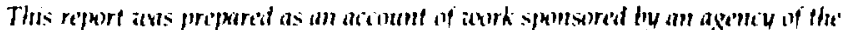

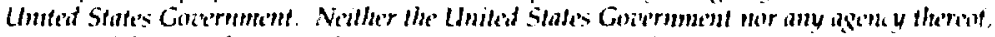

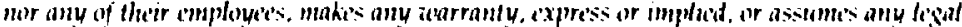

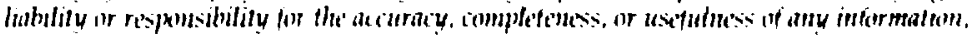

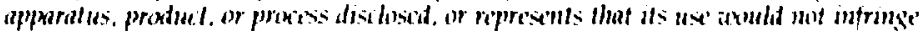

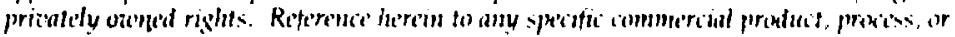

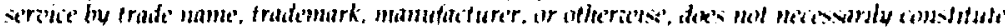

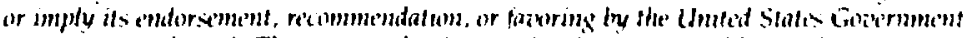

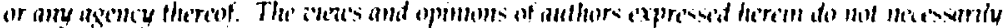

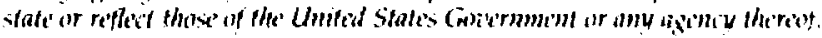


Reactivity of a Tuff-Bearing Concrete:

$C L-40$ CON-14

Barry E. Silleetz*

Della M. Koy*

* Consultant at Los Alamos. Materiais Research Laboratory. Pentisylzamia State University, University Park, PA 16802 (under contract 9-X54-M2894-1 for Los Alamos National Laboratory). 


\section{CONTENTS}

ABSTRACT . . . . . . . . . . . . . . . . . . 1

1. INTRODLCTION .................... 1

1.1 Background ..................... 2

2. EXPERIMENTAL .................... 2

2.1 Characterization of Starting Materials . . . . . . . . . . . . . . 3

2.1.1 Fly Ash . . . . . . . . . . . . . . . . . . . . . . . . 3

2.1.2 Fine Aggregate . . . . . . . . . . . . . . . 5

2.1.3 Coarse Aggregate (CL-40G 1/2-Inch Fraction) . . . . . . . j

2.1.4 CON-14 . . . . . . . . . . . . . . . . . . 6

2.1.4.1 X-ray Phase Determination . . . . . . . . 6

2.1.4.2 Porosity and Pore Size Distribution . . . . . . . . . 6

2.1.5 Petrographic Description of Concrete Components . . . . . $\quad$ s

2.1.5.1 Sand . . . . . . . . . . . . . . . . . . . 8

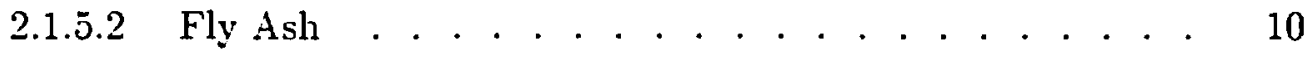

2.1.5.3 Coarse Aggregate . . . . . . . . . . . . . . . . 10

2.2 Experimental Design of Geochenical Reactivity/Durability Testing · 11

2.2.1 Static Expcriments . . . . . . . . . . . . . 12

2.2.1.1 Disc Sample Preparation . . . . . . . . . . . . . . 12

2.2.1.2 Static Hydrothermal Experiments With Powders . . . 12

2.2.1.3 Vapor Phase Reactions . . . . . . . . . . . . . . 15

2.2.2 Agitated Experiments . . . . . . . . . . . . . . . 15

2.2.2.1 Disc Samples/Agitated Hydrothermal Reaction Vessel . 15

2.2.2.2 Rocking Autoclave . . . . . . . . . . . 15

2.2.2.3 Parr Vessel . . . . . . . . . . . . . . . . . . . . 16

2.3 Analytical Procedures . . . . . . . . . . . . . . . . . . . . . 17

2.4 Analysis of J-13 Groundwater . . . . . . . . . . . . . 17 
3. DISCUSSION OF RESULTS . . . . . . . . . . . . . . . . . 18

3.1 Crushed Samples . . . . . . . . . . . . . . . . . . . 18

3.1.1 Rocking Autoclave . . . . . . . . . . . . . . . . . . . 18

3.1.1.1 LANL-T-1 . . . . . . . . . . . . . . . . 18

3.1.1.1.1 Phase Determination by XRD . . . . . . . 18

3.1.1.1.2 Cation Determination by DCP . . . . . . . . 18

3.1.1.1.3 Solids Characterization (SEM/EDX) . . . . . 18

3.1.1.2 LANL-T-2 . . . . . . . . . . . . . . . . . . . . . 19

3.1.1.2.1 Phase Determination by XRD . . . . . . . 20

3.1.1.2.2 Cation Determination in Liquid by DCP . . . . 20

3.1.1.2.3 Solids Characterization by SEM/EDX . . . . . 20

3.1.2 Parr Vessel . . . . . . . . . . . . . . . . 23

3.1.2.1 Solid Phase Characterization by XRD . . . . . . . . 23

3.1.2.2 Solids Characterization by SEM/EDX . . . . . . . . 23

3.1.3 Static Hydrothermal Studies . . . . . . . . . . . . . 25

3.1.3.1 Solid Phase Characterization by XRD . . . . . . . . 26

3.1.3.2 Cation Determination by DCP . . . . . . . . . . . 26

3.2 Disc Samples/Agitated Hydrothermal Experiments . . . . . . . . 27

3.2.1 Optical and SEM Surface Characterization . . . . . . . 27

3.2.2 Chemical Profiling . . . . . . . . . . . . . . . . 34

3.2.3 Aggregate/Matrix Alterations . . . . . . . . . . . . . . 45

3.2.4 Solution Characterization . . . . . . . . . . . . . . . 46

$3.3 \quad$ Vapor Phase Alteration of $\mathrm{CON}-14$. . . . . . . . . . . . . . . 49

3.3.1 Characterization of Solid Surfaces by Optical and

SEM Microscopy . . . . . . . . . . . . . . . . . . . . 49

4. CONCLUSIONS .................... 63

REFERENCES . . . . . . . . . . . . . . 65 
APPENDIX A Chemical Analysis of Three Tuff Samples . . . . . . . . . . 67

APPENDIX B XRD Pattern of CL-40 CON-14 Before

Geochemical Testing . . . . . . . . . . . . . . . . 69

APPENDIX C XRD Pattern of CL-40 CON-14 After

Geothermal Testing DCLASLT1 (LANL-T-1),

76 hours, Rocking Autoclave . . . . . . . . . . . . . . . . 73

APPENDIX D X-ray Data (Energy-Dispersive Counts) for Chemical

Profile Across Surface of Starting Material (CON-14) . . . . . 77

APPENDIX.E X-ray Data (Energy-Dispersive Counts) for Representative

Chemical Profile Through Disc 1A Treated Hydrothermally

for 1 Week . . . . . . . . . . . . . . . . . . . . . . . . 79

APPENDIX F X-ray Data (Energy-Dispersive Counts) for Representative

Chemical Profile Through Disc 1D Treated Hydrothermally

for $>4$ Weeks . . . . . . . . . . . . . . . . . . . . . 81

APPENDIX G Symbols and Formulas . . . . . . . . . . . . . . . . . . 83 


\title{
REACTIVITY OF A TUFF-BEARING CONCRETE: CL-40 CON-14
}

\author{
by
}

Barry E. Scheetz and Della M. Roy

\begin{abstract}
Samples of a tuff-bearing concrete have been altered in $\mathrm{J}$ 13 groundwater and in the vapor phase over deionized water at $200^{\circ} \mathrm{C}$. Crushed and intact discs of the concrete have been studied. The glassy tuff component of the tuff was more extensively reacted than the welded devitrifled tuff. The original concrete was formulated to be expansive on curing through the formation of the calcium alumino-sulfate hydrate phase, ettringite. An $x$-ray diffraction examination of the altered crushed samples shows that the ettringite is no longer present. The original, poorly crystalline calcium-silicate-hydrate has recrystallized to tobermorite. In the rocking autoclave experiments with crushed material, which are the experiments expected to have the fastest reaction rates, the tobermorite has been replaced by a mineral of the gyrolite-truscottite group at the longer reaction times. The disc experiments in $\mathrm{J}-13$ groundwater are characterized by prominent dissolution of the tuff aggregate. Alteration in the vapor phase experiments is primarily in the form of overgrowths on the discs.
\end{abstract}

\section{INTRODUCTION}

The study reported here represents a systematic attempt to evaluate the durability of proposed sealing material designed for taff formations at the Nevada Test Site (NTS). The experiments were performed with both discs and powder samples. In the former case, the studies were designed to evaluate the behavior of concrete, CL-40 CON-14, prepared by the US Army Engineer Waterways Experiment Station (WES) at conditions that represented the exposure of the concrete to conditions anticipated as the maximum limits in a geological repository in Yucca Mountain. These tests were conducted at $200^{\circ} \mathrm{C}$ and $1000 \mathrm{psi}(6.8 \mathrm{MPa})$ in water that was recovered from well J-13 on the N'TS. Alternatively; sample discs were exposed to conditions that simulated an unsaturated hydrogeological environment at $200^{\circ} \mathrm{C}$. Finally, a series of studies was conducted with mixtures of powders and indigenous groundwater at the elevated temperature in order to evaluate resultant 
phase assemblage and groundwater compositions that might be anticipated as a result of extensive hydrothermal alteration of the sealing material.

\subsection{Background}

The concrete formulation prepared, designated by IVES as CL-40 and sample CON14, was mixed during July 1982. The sample that was used in this experimental program was a 3-inch-diameter by 6 -inch-long cylinder that was one of 39 consecutively numbered samples prepared from this mixture. The concrete referred to herein as CON-14 represents the fourteenth specimen in the WES series.

The concrete was formulated to possess slightly expansive properties and to include indigenous NTS sand and aggregate components from G-tunnel on the NTS (Fernandez and Wong, in preparation) for the purpose of providing a sealing material that is compatible. with the host rock. A shrinkage-compensating cement (Chem-comp) that relies upon the formation of the calcium alumino-sulfate hydrate phase, ettringite, for its expansive behavior was selected by WES as the base cement. A high-calcium, class-C, fly ash, coarse aggregate from the Grouse Canyon member of the Belted Range Tuff from G-tunncl, and fine aggregate (NTS concrete sand) were included in the final formulation (Table I).

\section{EXPERIMENTAL}

As part of the geochemical stability experiments conducted in this study, a detailed characterization of the starting materials was carried out. Details in the following section represent the results of the characterization studies at The Pennsylvania State Lniversity (PSU) and, where possible, include relevant data supplied by WES. The cement chemist's notation used to designate cement phases and representative compositions for minerals mentioned in thi: report are given in Appendix G. 


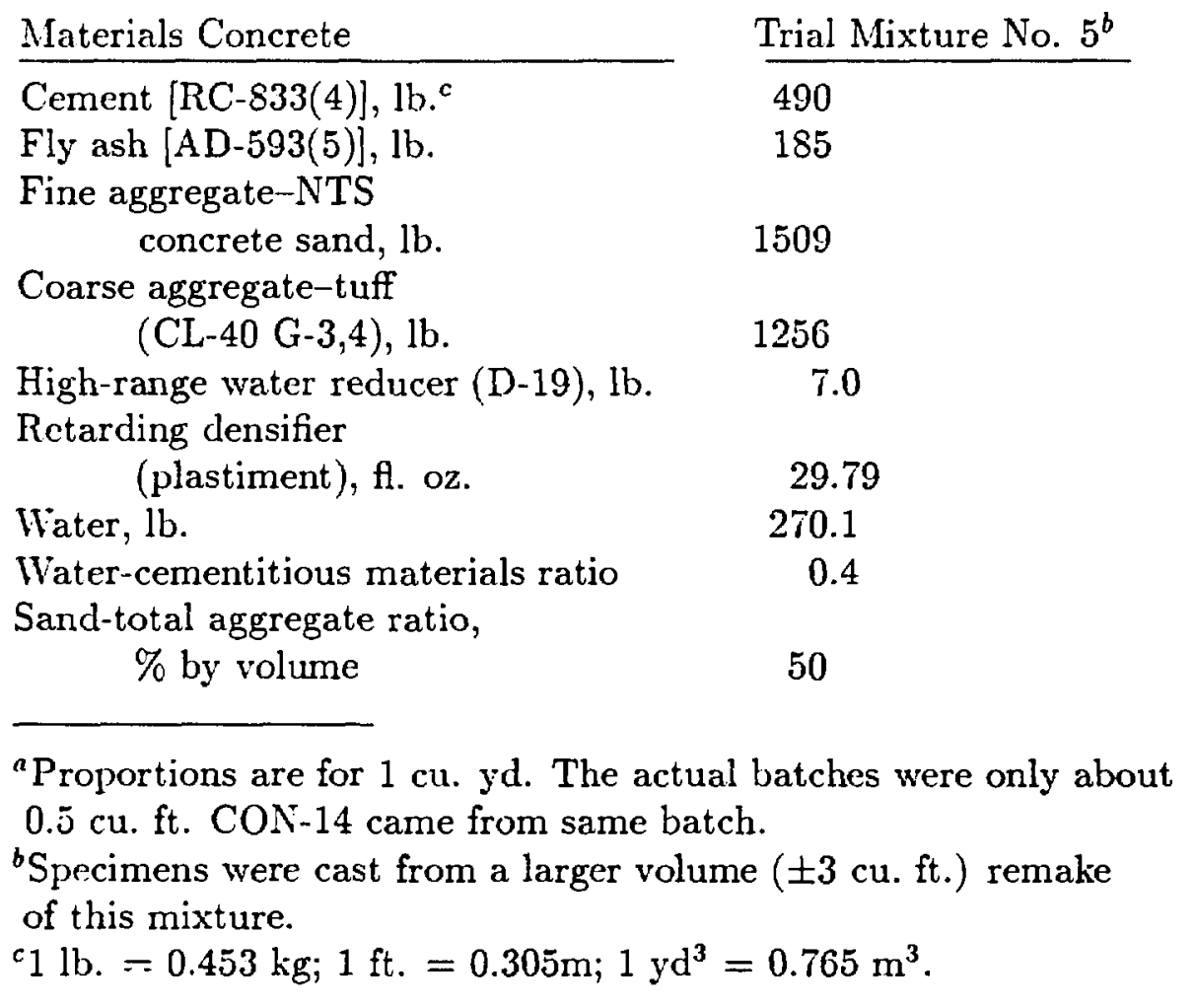

\subsection{Characterization of Starting Materials}

\subsubsection{Fly Ash}

The fly ash designated AD-592(5) is a product of the Southwest Power Co. of Amarillo, Texas, produced at its Harrington plant, and is readily available on the commercial market. Bulk chemical analyses for this ash are available from a number of samples that span the time frame before and after that reported for the acquisition of this sample by WES. These samples provide a measure of the chemical variability of the ash from a single power plant. Table II is a tabulation of the cinemical analyses performed at PSU on a number of different samples of Harrington Plant fly ash and the analysis reported by Fernandez and Wong (in preparation). 
TABLE II

BULK CHEMICAL COMPOSITIONS OF AD-592(5) AND RELATED FLY ASHES ${ }^{a}$

MRL/PSU number

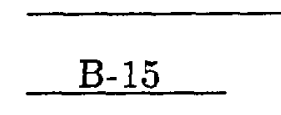

$\mathrm{SiO}_{2}$

$\mathrm{Al}_{2} \mathrm{O}_{3}$

$\mathrm{TiO}_{2}$

$\mathrm{Fe}_{2} \mathrm{O}_{3}$

$\mathrm{MgO}$

$\mathrm{CaO}$

$\mathrm{MnO}$

$\mathrm{Na}_{2} \mathrm{O}$

$\mathrm{K}_{2} \mathrm{O}$

$\mathrm{P}_{2} \mathrm{O}_{5}$

$\mathrm{SO}_{3}$

$\left(\mathrm{CO}_{2}\right)^{c}$

$\mathrm{BaO}$

$\mathrm{SrO}$

Totals

Date:
40.6

17.4

1.24

5.05

3.58

26.86

0.026

0.96

0.72

0.65

1.40

$(0.17)$

0.58

0.23

99.77

14 May 80

\begin{tabular}{c} 
B-26 \\
\hline 33.2 \\
17.6 \\
1.55 \\
6.03 \\
5.07 \\
29.91 \\
0.034 \\
1.03 \\
0.41 \\
0.95 \\
2.77 \\
$(0.22)$ \\
0.84 \\
0.37
\end{tabular}

100.20

5 Aug 80

\begin{tabular}{c} 
B-44 \\
\hline 37.8 \\
20.2 \\
1.44 \\
5.79 \\
4.51 \\
25.2 \\
0.018 \\
1.43 \\
0.56 \\
$\mathrm{NA}^{d}$ \\
1.75 \\
$(0.07)$ \\
$\mathrm{NA}$ \\
$\mathrm{NA}$
\end{tabular}

99.43

23 Mar 82
WES $^{b}$

$\underline{\mathrm{AD}-592(5)}$

31.2

21.2

18.1

1.55

6.21

4.74

27.83

0.039

1.22

0.41

0.94

1.90

NA

0.30

0.60

101.19

01 Nov 82
97.3

08 Apr 81

${ }^{a}$ Values are in weight percent.

${ }^{b}$ After Fernandez and Wong (in preparation).

${ }^{c}$ Not included in totals.

${ }^{d} \mathrm{NA}=$ not analyzed.

This fly ash typically contains about $29 \% \mathrm{CaO}, 19 \% \mathrm{Al}_{2} \mathrm{O}_{3}$, and $33 \% \mathrm{SiO}_{2}$, with the remaining $19 \%$ of the composition partitioned between oxides of alkali metals, alkaline earth elements and transition metals, most notably iron, and $\mathrm{SO}_{3}$. The high calcia and alumina content is frequently utilized in the design of concrete matrices for the formation of the phase ettringite $\left[3 \mathrm{CaO} \cdot \mathrm{Al}_{2} \mathrm{O}_{3} \cdot 3 \mathrm{CaSO}_{4} \cdot 32 \mathrm{H}_{2} \mathrm{O}\right]$, which generates expansion in cements.

Phase characterization by $x$-ray diffraction (XRD) techniques and selective etching (Scheetz et al., 1982) identified quartz, brownmillerite $\left(\mathrm{Ca}_{4} \mathrm{Al}_{2} \mathrm{Fe}_{2} \mathrm{O}_{10}\right)$, anhydrite, periclase $(\mathrm{MgO})$, and $\mathrm{CaO}$, plus an $\mathrm{x}$-ray amorphous component, as summarized in Table III. 


$\begin{array}{lr}\text { Mineral } & \text { JCPDS }^{a} \text { File \# } \\ \text { Anhydrite } & 6-226 \\ \text { Periclase } & 4-829 \\ \text { Quartz } & 5-490 \\ \text { Brownmillerite } & 11-125 \\ \mathrm{CaO} & 4-777 \\ \text { X-ray amorphous component } & \end{array}$

a Joint Committee on Powder Diffraction Standards.

\subsubsection{Fine Aggregate}

NTS concrete sand (Fernandez and Wong, in preparation) was utilized as the sand component of the concrete formulation. This sand consisted of coarse grains of both a dark brown-black fraction and a lighter brown fraction. The sand was separated manually into two populations, based upon these color distinctions, and each population was characterized by XRD.

The darker fraction was composed primarily of quartz, calcite, and a layer silicate that most nearly matched a $2 \mathrm{M}_{2}$ polymorphic form of illite with minor amounts of $\mathrm{K}$-feldspar and chamosite. The presence of a sodic-plagioclase feldspar, dolomite, and magnetite are suggested, but because of overlapping XRD peaks and the low concentration, positive identification of these phases is questionable. Quartz, calcite, and dolomite were the only phases found in the lighter fraction of this sand. Table IV summarizes the XRD data.

\subsubsection{Coarse Aggregate (CL-40G 1/2-Inch Fractional)}

A small sample of graded aggregate was received along with the sand and fly ash for characterization. The aggregate is made up of moderately welded to unwelded tuff from the Grouse Canyon member of the Belted Range Tuff taken from G-tunnel on the NTS (Fernandez and Wong, in preparation). 
Phase characterization, by XRD, of this sample identified a sodic-plagioclase feldspar, K-feldspar, a zeolite (the XRD pattern most nearly matclies heulandite), and a possible trace presence of dolomite. Table V summarizes these observations. Appendix A contains a bulk chemical analysis of a similar tuff.

\subsubsection{CON-14}

\subsubsection{X-ray Phase Determination}

The XRD characterization of the phases in the cured concrete has identified 10 components from the cement paste, sand, fly ash, and coarse aggregate. Ettringite and portlandite are components of the cement paste; quartz and brownmillerite of the fly ash; K-feldspar, Na-plagioclase feldspar, calcite, and illite from both the sand and the coarse aggregate; and finally heulandite, K-feldspar, and dolomite in the coarse aggregate. Amorphous calcium-silicate-hydrate (C-S-H) from the paste is present as background. Separated matrix showed possible residual $\mathrm{Ca}_{3} \mathrm{SiO}_{5}$ or $\mathrm{Ca}_{2} \mathrm{SiO}_{4}$ as well. These findings are detailed in Table VI. Normal x-ray powder diffraction techniques can identify the presence of a phase in a complex mixture of phases at 2-5 wt\%. Therefore, minor phases in any of the components of the concrete that fall below this range in the final mixture of phases will normally not be observed. XRD patterns of the concrete matrix are given in Appendix B.

\subsubsection{Porosity and Pore Size Distribution}

Connected porosity of pores greater than $18 \AA$ radius was determined by mercury intrusion porosimetry. CON-14 concrete exhibited a bimodal distribution of pore sizes with peaks at about $1000-2000 \AA$ and at about $175-200 \AA$. The porosity determined in this manner is $14.5 \%$. The critical radii of the CON-14 pore distributions are similar to those for the aggregate used in this concrete formulation (Fig. 1). Although the heights of the peaks are lower, the tuff aggregate in this figure exhibits a similar bimodal pore size distribution at the two values described above. The tuff aggregate exhibits a single value at about $1000 \AA$ compared to two peaks in the region for the concrete, and its total porosity as measured by mercury porosimetry is $20 \%$. However, the tuff aggregate and concrete 
TABLE IV

PHASES IN NTS SAND DETERMINED BY XRD

Dark Fraction

Lighter Fraction

Positive Identification

\begin{tabular}{lrlr} 
Quartz & $5-490^{a}$ & Quartz & $5-490$ \\
Calcite & $5-586$ & Calcite & $5-586$ \\
Illite & $24-495$ & Dolomite & $11-078$ \\
Chamosite & $13-029$ & & \\
Orthoclase & $19-931$ & & \\
& & & \\
& & & \\
& Questionable or Trace & \\
\hline
\end{tabular}

$\begin{array}{ll}\text { Dolomite } & 11-078 \\ \text { Magnetite } & 29-629 \\ \text { Na-plagioclase } & 10-539\end{array}$

${ }^{a}$ JCPDS file card number.

TABLE V

PHASE COMPOSITION OF CL-40G, COARSE AGGREGATE AS DETERMINED BY XRD

\begin{tabular}{l}
\multicolumn{1}{c}{ Mineral } \\
\hline Heulandite \\
Orthoclase \\
Na-plagioclase \\
Quartz (possible) \\
Dolomite
\end{tabular}

${ }^{a}$ Best fit for heulandite; may be clinoptilolite. ${ }^{b}$ Absolute identification is difficult because of compositional variations within the feldspars.
JCPDS File No.

$25-144$

$19-931$

$10-539(9-456)^{b}$

$5-490$

11-078 


\section{TABLE VI}

PHASE COMPOSITION OF CON-14 DETERMINED BY XRD

Source

\begin{tabular}{|c|c|c|c|c|c|}
\hline Phase & JCPDS File No. & Cement & Fly Ash & Sand & Coarse Aggregate \\
\hline $\mathrm{K}$-feldspar & $19-931$ & & & & $\mathrm{x}$ \\
\hline Na-plagioclase & $10-539$ & & & $?$ & $\mathrm{x}$ \\
\hline Illite & $24-495$ & & & $x$ & \\
\hline Calcite & $5-586$ & & & $x$ & \\
\hline Dolomite & $11-078$ & & & $x$ & $?$ \\
\hline Brownmillerite & $11-124$ & & $\mathrm{x}$ & & \\
\hline Ettringite & $9-414$ & $\mathrm{x}$ & & & \\
\hline Portlandite & $4-733$ & $\mathrm{x}$ & & & \\
\hline Heulandite $^{a}$ & $25-144$ & & & & $\mathrm{x}$ \\
\hline Quartz & $5-400$ & & $x$ & $\mathrm{x}$ & $x$ \\
\hline
\end{tabular}

a Heulandite and clinoptilolite yield similar XRD patterns and are typically difficult to distinguish. Heulandite is reported here, although the phase snay be intermediate between the two.

differ in the development of slight shoulders on the main pore size distribution at about $200 \AA$. The concrete has more very small pores than does the tuff, which are probably contributed by the cement paste component. The similarity of the pore size distributions suggests that the bulk of the porosity is due to the aggregate.

\subsubsection{Petrographic Description of Concrete Components}

Both thin section and small quantities of bulk materials for each of the components of the CON-14 concrete were supplied by Los Alamos (LANL). The following are detailed petrographic descriptions and phase identifications from these thin sections.

\subsubsection{Sand}

Particles of four different mineralogies were recognized in the sand. Quartz was present as polycrystalline grains and a smaller number of single-crystal grains, usually well rounded. Some polycrystalline grains have carbonate cement. Calcite grains, the second 


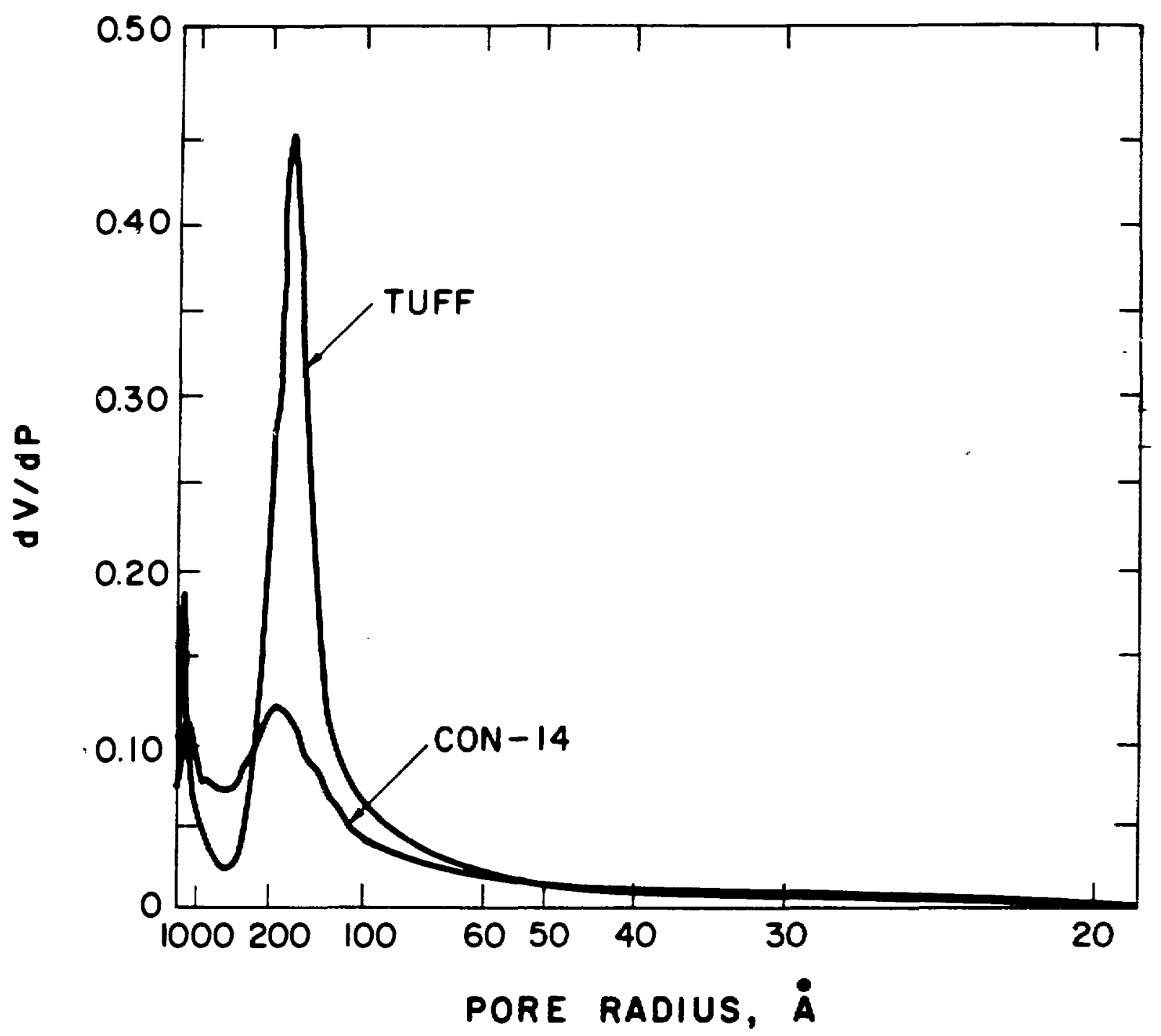

Fig. 1. Comparison of the critical pore distribution of CON-14 tuff-bearing concrete and a tuff aggregate. 
mineral type, exhibit primary sedimentary structures such as "cryptalgal" laminations and are stained with organic matter. Some carbonate-mineral grains show coarsely recrystallized textures and probably are dolomite. Feldspar, commonly displaying albite twinning but occasionally with more complex twins (polysynthetic and scotch-plaid). makes up the third mineralogical group in the sand. There are also a few grains of ycllowish-brown clay-rich material, distinctive in thcir coloring and texture. Accessory minerais in the sand were not positively identified, but appear to include very small grains of an opaque mineral, possibly ilmenite, and a mineral of the chlorite group.

\subsubsection{Fly Ash}

The fly ash is fine grained ( $\sim 16-\mu \mathrm{m}$ average particle diameter) and of nonuniform shades of gray, with uncommon hollow glassy (optically isotropic) spheres. The fly ash has agglomerated into clusters of particles. In contrast to the appeararce of the raw fly ash, when incorporated in the matrix of the cured concrete before the reaction studies, the fly ash appears to be evenly distributed throughout the matrix.

\subsubsection{Coarse Aggregate}

The aggregate designated CL-40G is composed of two distinct types of tuff, which for reference purposes will be referred to as dark and light, according to their body color. The thin sections studied also included sections of each rock type alone, designated as CL-40G-1e (dark) and G-1b (light). The darker tuff has few large phenocrysts and a large percentage of glass shards and is only partially welded, having a more granular and less banded appearance in thin section. The matrix is not deformed around phenocrysts, although the glassy components (yellow in thin section in plane polarized light) are somewhat aligned. This tuff also is zeolitic.

The lighter tuff aggregate is moderately welded and contains very little glass, and its groundmass displays spherulitic recrystallization to feldspars and quartz. It is strongly banded, with the aligned groundmass deformed around the common large phenocrysts of feldspar. There are also deformed, crystallized pumice fragments with remnants of their original porous structure. Some feldspar phenocrysts appear to have 
been partially resorbed. Some feldsinar phenocrysts are surrounded by redidish-brown translucent aggregates of iron oxicles and opaque, lath-like ilmenite crystals.

Individual types of tuff, polycrystalline and single-crystal quartz, feldspar phenocrysts, and carbonate and clay grains are all distinguishable in thin scetions of untreated $\mathrm{CON}-13$ and $\mathrm{CON}-14$. In addition to the calcite present in the fine aggregate, the matrix of CON-14 was extensively carbonated cither before sectioning or during making of thin sections (and, therefore, before the hydrothermal experinents). In contrast, the matrix of CON-13 in thin section is not carbonated. However, the XRD studies of CON-14 showed that extensive portlandite (calcium hydroxide) was present, so that much noncarbonated material is present. The presence of carbonated anci noncarbonated consecutive samples (CON-14 vs. CON-13) suggests that carbonate may late been introduced during sample landling. Such sample alteration can introduce cxperimental artifacts that could persist and alter the distribution of reaction products. As an cxample, the persistence of calcite in the hydrothermal experiments removes some calcium from the solutions.

\subsection{Experimental Design of Geochemical Reactivity/Durability Testing}

Three sets of experiments were conducted. The first set consisted of $\mathrm{CON}$-14 samples prepared as discs of approximately 2.54 -cm diameter that were placed in J-13 groundwater at $200^{\circ} \mathrm{C}$ and approximately $6.9 \mathrm{MPa}$ for $1,2,3$, and $>4$ weeks. The solution phase in contact with the concrete was recovered and chemically analyzed. The second set of experiments, designed to acclerate the alteration of CON-14 concrete, was performed with $-20+30$ mesh ( $840-$ to $590-\mu \mathrm{m}$ ) powders of the concrete. These experiments were conducted on powdered samples in three types of hydrothermal vessels, a static cold-sealtype, a Parr vessel, and a rocking autoclave for varying times up to 20 wceks at pressure and temperature conditions similar to the above experiment. Both of these types of experiments were designed to evaluate the alteration/interaction products under accelerated conditions. A third set of experiments was conducted to simulate the behavior of CON-14 concrete discs in an environment in which the repository rock is not saturated with water. The conditions of these tests were maintained at $200^{\circ} \mathrm{C}$ at a saturated steam pressure and with 
the test specimens (2.54-cm-diam. discs) suspended in the wapor phase above deionized water.

\subsubsection{Static Experiments}

This set of experiments was designed to evaluate the derelopment of solid alteration products and/or the selective dissolution of various components of this concrete. This method allowed sefore and after comparisons to be made on the same area of the specimen.

\subsubsection{Disc Sample Preparation}

The saniple CON-14 as received from WES was a single cylindrical sample 3 inches in diameter by 6 inches long. The specimen was tightly wrapped in transparent plastic food wrap and taped slut. All subsequent handling of the sample retained this packaging. The cylinder was stored in a controlled humidity chamber at $38^{\circ} \mathrm{C}$ and a relative humidity of $>90 \%$.

In preparation for the hydrothermal experiments, two slices were taken from the top one-third of the cylinder. The two slices were cut to approximately a $0.5-\mathrm{cm}$ thickness. From each of these larger discs, four smaller discs were removed for experimental samples. Each of the cight discs was polished to a $3-\mu \mathrm{m}$ finish and cleaned with alcohol in an

ultrasonic clcaner; photomosaics were prepared with the clectron backscattering (EES) imaging capability of the scanning electron microscope (SEM). A photomosaic of each disc is presented in Figs. 2 and 3.

A third slice that represented approximately onc-lialf of the remaining cylinder was cut and ground. The sieve fractions $-20+30(840$ to $590 \mu \mathrm{m})$ were used in subsequent hydrothermal experiments.

\subsubsection{Static Hydrothermal Experiments With Powders}

Small-scale cold-seal hydrothermal experiments were conducted at conditions similar to the above-described hydrothermal disc experiments. Samples of approximately 50 to $150 \mathrm{mg}$ of 75 - to $150-\mu \mathrm{m}$ powdered concrete were scaled into gold tubes with a weight ratio of 10:1 J-13 groundwater to sample. Two to five replicates at each tine interval were 


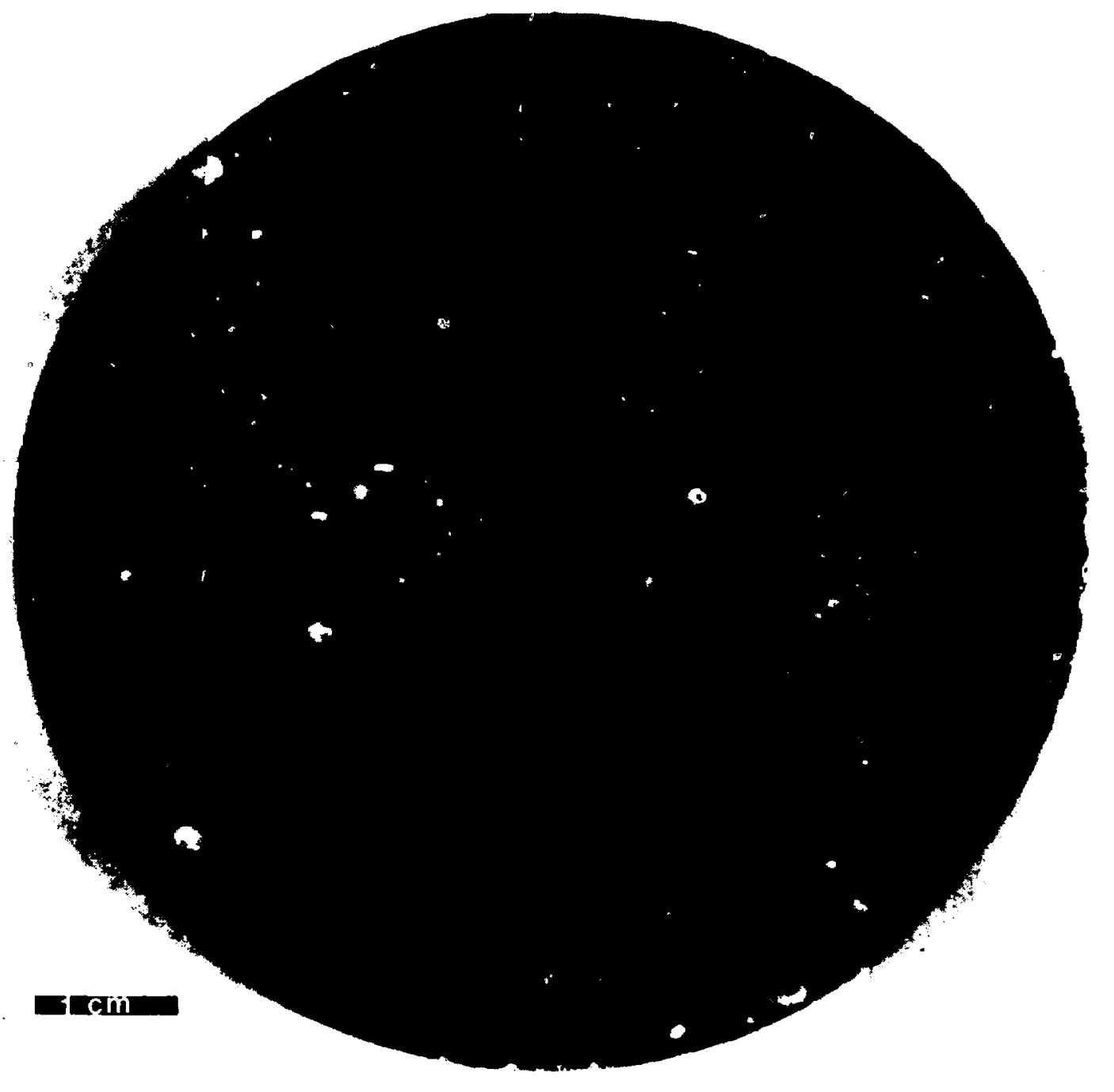

Fig. 2. Photomosaic of starting sample No. 1 of CON-14. 


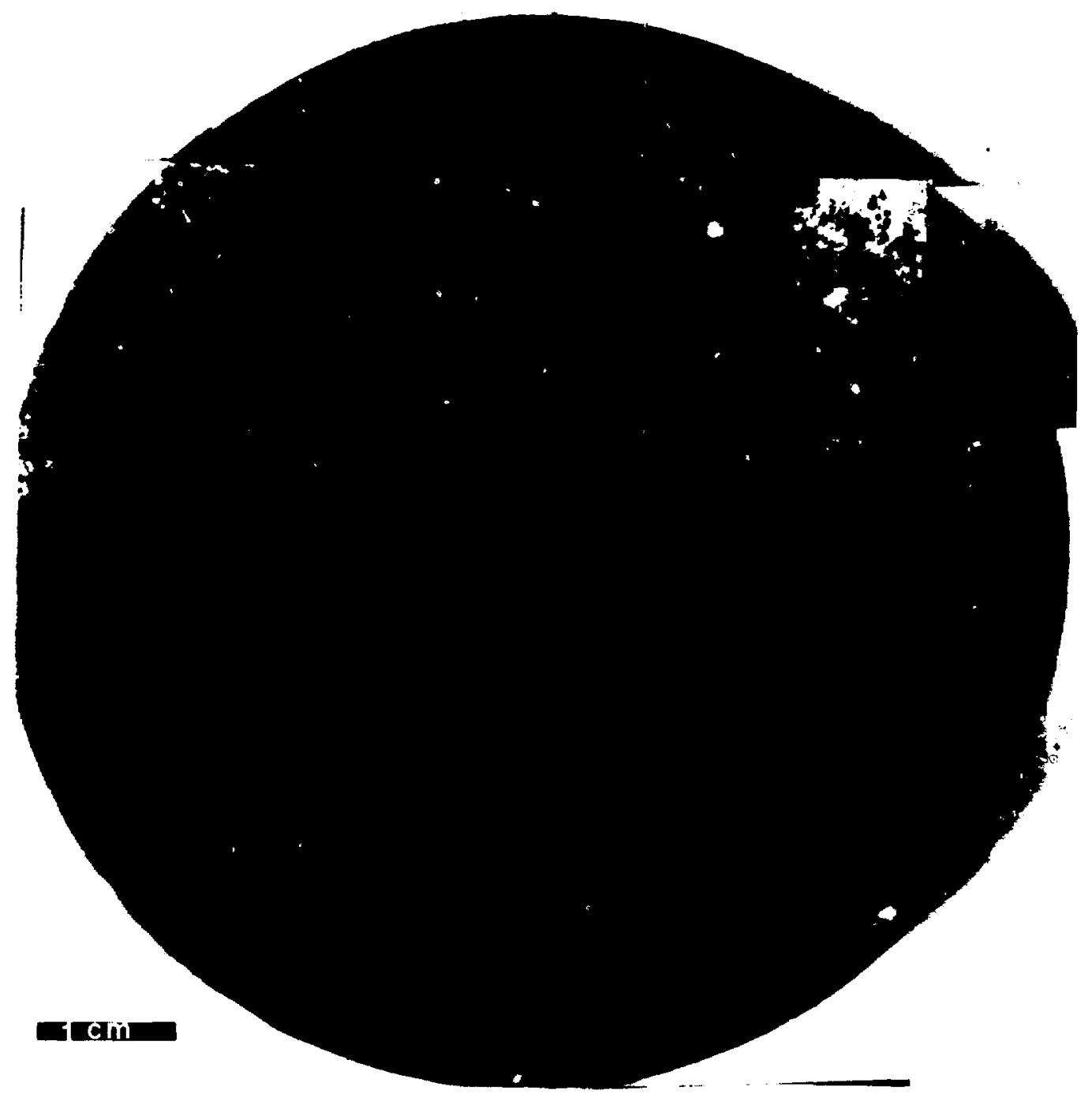

Fig. 3. Photomosaic of starting sample No. 2 of CON-14. 
analyzed for phase nineralogy by standard XRD techniques. The solution was recorered and analyzed for major cations. Sampling intervals for these experiments were 1, 2, 4. 12 , and 20 weeks.

\subsubsection{Vapor Phase Reactions}

A set of discs was exposed to water vapor over deionized water for durations of 1 , 2,3 , and $>4$ months at saturated steam pressure at $200^{\circ} \mathrm{C}$. This was accomplished by suspending the disc with a chromel wire in the cool (up) end of a Bridgman-scal-type autoclave (Balln an and Laudise, 1963). The water compositions in the bottom of the autoclave were not characterized.

\subsubsection{Agitated Experiments}

Accelerated chemical reactions at a given temperature can be achieved in laboratory experiments by either decreasing particle size (increasing surface area of reactions) and/or homogenizing the fluid. For the subsequent experiments (disc samples/agitated hydrothermal reaction vessel and rocking autoclave), both of these techniques were utilized. Coarse powders of CON-14 were used and homogenization of the fluid was achieved by either stirring or reciprocal rocking of the reaction vessels.

\subsubsection{Disc Samples/Agitated Hydrothermal Reaction Vessel}

A 1-L Parr internally stirred vessel was chosen for the $200^{\circ} \mathrm{C}$ experiments. However, due to the abrasive character of the concrete/solvent system, problems were encountered because the seal for the shaft that entered the vessel through the cap could not be maintained for more than 1 week. To facilitate the completion of the experimental program, the disc sample experiments for all durations greater than or equal to 2 weeks were conducted in a Bridgman-seal-type autoclave following the initial 1-week exposure in the Parr vessel.

\subsubsection{Rocking Autoclave}

Agitation of the hydrothermal fluid during an experiment aids in the homogenization of the fluids by minimizing the boundary diffusion layer about the reactants. A rocking 
autoclave with a $300-\mathrm{mL}$ capacity was one of the two types of apparatus used in these experiments to accelerate the alteration of CON-14.

The rocking autoclave pivots about a point located at the mid-point of the length of the cylindrical vessel. The pivot is approximately $\pm 20^{\circ}$ from the horizontal at a frequency of 30 cycles/minute. A sample of sieved CON-14 that passed a No. 20 sicve screen ( $840 \mu \mathrm{m}$ ) and was retained on a No. 30 screen $(590 \mu \mathrm{m})$ was chosen. To minimize the dispersion and self-abrasion of solids, the charge was placed in a stainless steel bag made from No. 80 sieve screening, and this bag was placed in the vessel. The liquid from this experimental run was sampled at temperature, and then the vessel was allowed to cool to room temperature and was sampled again. Botl experimental runs were maintained at $200^{\circ} \pm 5^{\circ} \mathrm{C}$ and at a pressure of 1200 to $1600 \mathrm{psi}$. The water-to-solid ratio was maintained at approximately $50: 1$ to $40: 1$.

\subsubsection{Parr Vessel}

The Parr hydrothermal vessel is a 1-L reactor designed with an impeller driven by a belt-driven pulley system that uses an external 1725-rpm electric motor. By the nature of the vessel design, its upper working temperature and pressure ranges are limited, but the $200^{\circ} \mathrm{C}$ and 1200 - to 1600 -psi conditions chosen are safely within its operational range. The vessel is designed with an impeller containing two sets of vanes located approximately equidistant from the top and bottom of the vessel and from each other. The initial experimental design called for the charge of reactants to be placed directly into the vessel with the fluid. Any subsequent sampling would take place by cooling the vessel and removing the cap. The very fine, dispersed, highly abrasive powder reactant was too severe an environment for the seal system that is utilized with the impeller shaft. The damage caused by this initial experiment caused repeated leaks in the system. This was not recognized immediately and additional attempts to perform the experiment met with failure caused by leakage. A modification of the Parr vessel was made to accommodate a similar stainless steel bag as used in the rocking autoclave. From five runs that were attempted in the Parr vessel, only solids from one of these have been salvaged, and, because of the nature of the leaks, no fluid samples have been recovered. 


\subsection{Analytical Procedures}

Solutions that formed from reactions of the water that was in contact with the concrete were recovered and chemically analyzed, primarily by DCP (DC plasma) emission spectrometry for the major cations and by precipitation techniques or ion-specific electrodes for selected anions.

\subsection{Analysis of J-13 Groundwater}

Two S-L containers of water were received from Los Alamos that were recovered from well $J-13$. These waters were analyzed at the Materials Research Laboratory/The Pennsylvania State University (MRL/PSU) to verify the composition and compare analyses with those supplied by Los Alamos. The chemical data for these analyses are presented in Table VII.

TABLE VII

CHEMICAL COMPOSITION OF J-13 GROUNDWATER ${ }^{a}$

\begin{tabular}{|c|c|c|c|}
\hline & LANL & Bottle No. 1 & Bottle No. 2 \\
\hline $\mathrm{Al}$ & 0.025 & $0.03 \pm 0.01$ & $\ldots$ \\
\hline $\mathrm{Ba}$ & 0.001 & - & - \\
\hline $\mathrm{Ca}$ & 11.5 & $12 \pm 1$ & $16 \pm 1$ \\
\hline $\mathrm{Fe}$ & 0.011 & $0.01 \pm 0.01$ & $L^{-12}$ \\
\hline K & 5.26 & $5 \quad \pm 1$ & $6 \pm 1$ \\
\hline $\mathrm{Li}$ & 0.060 & - & - \\
\hline $\mathrm{Mg}$ & 1.76 & $2 \pm 1$ & $2 \pm 1$ \\
\hline $\mathrm{Mn}$ & 0.012 & - & - \\
\hline $\mathrm{Na}$ & 45.1 & $45 \pm 2$ & $35 \pm 2$ \\
\hline $\mathrm{Si}$ & 31.8 & $32 \pm 2$ & $30 \pm 2$ \\
\hline $\mathrm{Sr}$ & 0.039 & $0.04 \pm 0.01$ & $0.04 \pm 0.01$ \\
\hline $\mathrm{Ti}$ & 0.028 & $\ldots$ & $\ldots$ \\
\hline $\mathrm{V}$ & 0.021 & $\longrightarrow$ & - \\
\hline $\mathrm{F}$ & 2.1 & & \\
\hline $\mathrm{Cl}$ & 6.4 & & \\
\hline $\mathrm{PO}_{4}$ & 0.1 & & \\
\hline $\mathrm{NO}_{3}$ & 10.1 & & \\
\hline $\mathrm{SO}_{4}$ & 18.1 & & \\
\hline $\mathrm{HCO}_{3}$ & 142 & & \\
\hline
\end{tabular}




\section{DISCUSSION OF RESULTS}

\subsection{Crushed Samples}

\subsubsection{Rocking Autoclave}

\subsubsection{LANL-T-1}

The initial experiment designated LANL-T-1 was run in the rocking autoclave at $200^{\circ} \mathrm{C}$ and approximately 1600 psi $(10.9 \mathrm{MPa})$ for 32 days. The water-to-solids ratio was $20: 1$. At the termination of the experiment, the heat was removed and the vessel was allowed to cool to ambient temperature while rocking. At this time, a liquid and solid sample were recovered for analysis.

\subsection{Phase Determination by XRD}

Analysis of the XRD of a finely ground powder mount of the reacted concrete revealed the presence of coarse aggregate phases, heulandite, dolomite, and plagioclase feldspar, although the XRD peaks were slightly less intense than in the original diffractogram. The K-feldspar, calcite, and perhaps quartz appear to be relatively unaffected by the hydrothermal treatment. The cement matrix phase calcium-silicate-hydrate (C-S-H) appears to have crystallized to $11 \AA$ tobermorite. Illite, portlandite, and ettringite were not detected. Details of the $\mathrm{x}$-ray diffractogram are presented in Appendix $\mathrm{C}$.

\subsection{Cation Determination by DCP}

A 5-mL portion of clear fluid was removed from the experiment LANL-T-1 and analyzed by DCP emission spectrometry for 20 cations. The analysis is presented in Table VIII.

\subsection{Solid Characterization (SEM/EDX)}

All grains were coated and there appeared to be very little differentiation among the grains examined, as characterized by energy dispersive x-ray (EDX) analysis. All of the surfaces were heavily coated with about the same chemistry in the same relative 


$\begin{array}{lc}\text { Element } & \mathrm{mg} / \mathrm{L}^{a} \\ \mathrm{Al} & \\ \mathrm{B} & 1.0 \pm 0.1 \\ \mathrm{Ca} & 1.6 \pm 0.1 \\ \mathrm{Cr} & 140 \pm 5 \\ \mathrm{Fe} & 0.1 \pm 0.1 \\ \mathrm{~K} & 1.0 \pm 0.1 \\ \mathrm{Mg} & 23 \pm 2 \\ \mathrm{Mo} & 0.8 \pm 0.1 \\ \mathrm{Na} & 0.9 \pm 0.1 \\ \mathrm{Si} & 105 \pm 5 \\ \mathrm{Sr} & 90 \pm 5 \\ \mathrm{~V} & 0.3 \pm 0.1 \\ & 0.2 \pm 0.1\end{array}$

$a$ The following elements were not found in the resultant solutions and therefore are present at less than $0.1 \mathrm{mg} / \mathrm{L}: \mathrm{Ba}, \mathrm{Co}, \mathrm{Mn}, \mathrm{Ni}, \mathrm{Ti}, \mathrm{Zn}, \mathrm{Zr}$; $\mathrm{Rb}$ was not observed at a detection limit of $0.3 \mathrm{mg} / \mathrm{L}$.

proportions. This coating masked the original chemistry of the concrete. Abundant needlelike growth was observed that corresponded in morphology to hydrothermally grown $11 \AA$ tobermorite that was observed in the paste. Infrequently, areas that have the morphology of platy C-S-H or tobermorite were seen. Both needle-like and platy morphologies are characteristic of tobermorite of slightly different compositions, with aluminum-substitution tobermorite producing a platy morphology.

\subsubsection{LANL-T-2}

This experiment was designed to last approximately 60 days. Because of the limited supply of CON-14, the sieve fraction of $-50+60(250 \mathrm{to} 300 \mu \mathrm{m})$ was used at a water-tosolids ratio of $6: 1$. The experiment was conducted at $200^{\circ} \mathrm{C}$ and 1200 psi for a total of 51 days. 


\subsection{Phase Determination by XRD}

Results of characterization of the reacted concrete by means of standard powder diffraction methods were similar to the T-1 experimental observations. Of the phases initially present, illite, portlandite, and ettringite were not observed in the experimental products. The plagioclase feldspar, dolomite, and heulandite/clinoptilolite continued to be depleted, while quartz, K-feldspar, and calcite appeared to remain relatively unaffected by the hydrothermal treatment. The tobermorite that was observed in the cement matrix in the shorter duration experiments was not observed in these experiments. In its place was another phase with a broad diffraction peak centered at $14.9 \AA$, possibly a member of the gyrolite-reyerite-truscottite (calcium silicate) group.

\subsection{Cation Determination in Liquid by DCP}

As in the previous experiment, a sample of clear fluid was removed from the vessel after it had cooled (while rocking) to room temperature. In addition, a sample of the fluid was removed while the system was at temperature just before the experiment was terminated. This procedure was followed to evaluate the extent of reaction between the solids and the fluid during cooling. The sample retrieved at the elevated temperature did not exhibit any precipitation upon being sampled (Scheetz, 1980) and was immediately acidified to $\mathrm{pH} 1$ with nitric acid. The results from the solution analyses are summarized in Table IX.

\subsection{Solids Characterization by SEM/EDX}

In contrast to the morphology of the surface coating described in sample T-1, T-2 has a surface dominated by the growth of crystals with a rosette or platelet-like morphology (Fig. 4) with occasional flattened needle-like crystals. The predominance of the fibrous tobermorite crystals in T-1 and their replacement in T-2 with platelet-like morphology are consistent with the absence of tobermorite in the XRD patterns of the latter. Truscottite and gyrolite (like some tobermorites) have hexagonal platy crystal habits (Roy et al., 1980; Komarneni et al., 1982). The bulk chemistry of the platelets is dominated by potassium approximately equal to calcium and aluminum with much less, but variable, silicon and 
TABLE IX

ANALYSES OF LANL-T-2 FLUID, SAMPLED AT (a) $200^{\circ} \mathrm{C}$

AND (b) ROOM TEMPERATURE; CRUSHED MATERIAL,

ROCIING AUTOCLAVE (mg/L)

(a)

At-Temperature Sample

Element

LANL-T-2-1

A]

B

$\mathrm{Ba}$

$\mathrm{Ca}$

Co

$\mathrm{Cr}$

$\mathrm{Fe}$

K

$\mathrm{Mg}$

$\mathrm{Mn}$

Mo

$\mathrm{Na}$

$\mathrm{Ni}$

$\mathrm{Si}$

$\mathrm{Sr}$

Ti

$\mathrm{Zn}$

$\mathrm{Zr}$
$2.2 \pm 0.1$

$1.3 \pm 0.1$

$<0.2$

$41 \pm 5$

$<0.2$

$<0.2$

$1.8 \pm 0.1$

$17.5 \pm 0.5$

$2.0 \pm 0.1$

$<0.2$

$1.0 \pm 0.1$

$38 \pm 5$

0.3

$410 \pm 10$

$<0.2$

$<0.02$

$0.8 \pm 0.1$

$<0.2$ (b)

Room Temperature Sample

LANL-T-2-2

$$
\begin{aligned}
& 0.05 \pm 0.01 \\
& 0.54 \pm 0.01 \\
& 0.03 \pm 0.01 \\
& 205 \quad \pm 5 \\
&<0.02 \\
&<0.02 \\
& 0.80 \pm 0.01 \\
& 7.3 \pm 0.1 \\
& 1.38 \pm 0.01 \\
& 0.18 \pm 0.01 \\
& 0.74 \pm 0.01 \\
& 42 \quad \pm 5 \\
&<0.02 \\
& 195 \quad \pm 10 \\
& 0.70 \pm 0.01 \\
&<0.002 \\
&<0.02 \\
& 0.12 \pm 0.01
\end{aligned}
$$

a trace of iron. The occasional flattened needle also exhibits a similar chemistry with only slightly more silicon relative to the aluminum. A mixture of potassium, aluminumsubstituted calcium silicates and truscottite/gyrolite, as well as an aluminum-rich zeolitic phase, is probably present. Also scattered over the surface are anhedral patches apparently rich in silicon, which may represent the products of precipitation during cooling of the hydrothermal vessel.

Another type of euhedral crystal was observed on the surface of the platy crystals. Figure 5 is an SEM image of one of these crystals isolated in the surface scale; other crystals occur as rosettes of similar cubic or pseudocubic symmetry. The major elements in this phase that can be identified in Fig. 5 are potassium, calcium, aluminum, and silicon. 

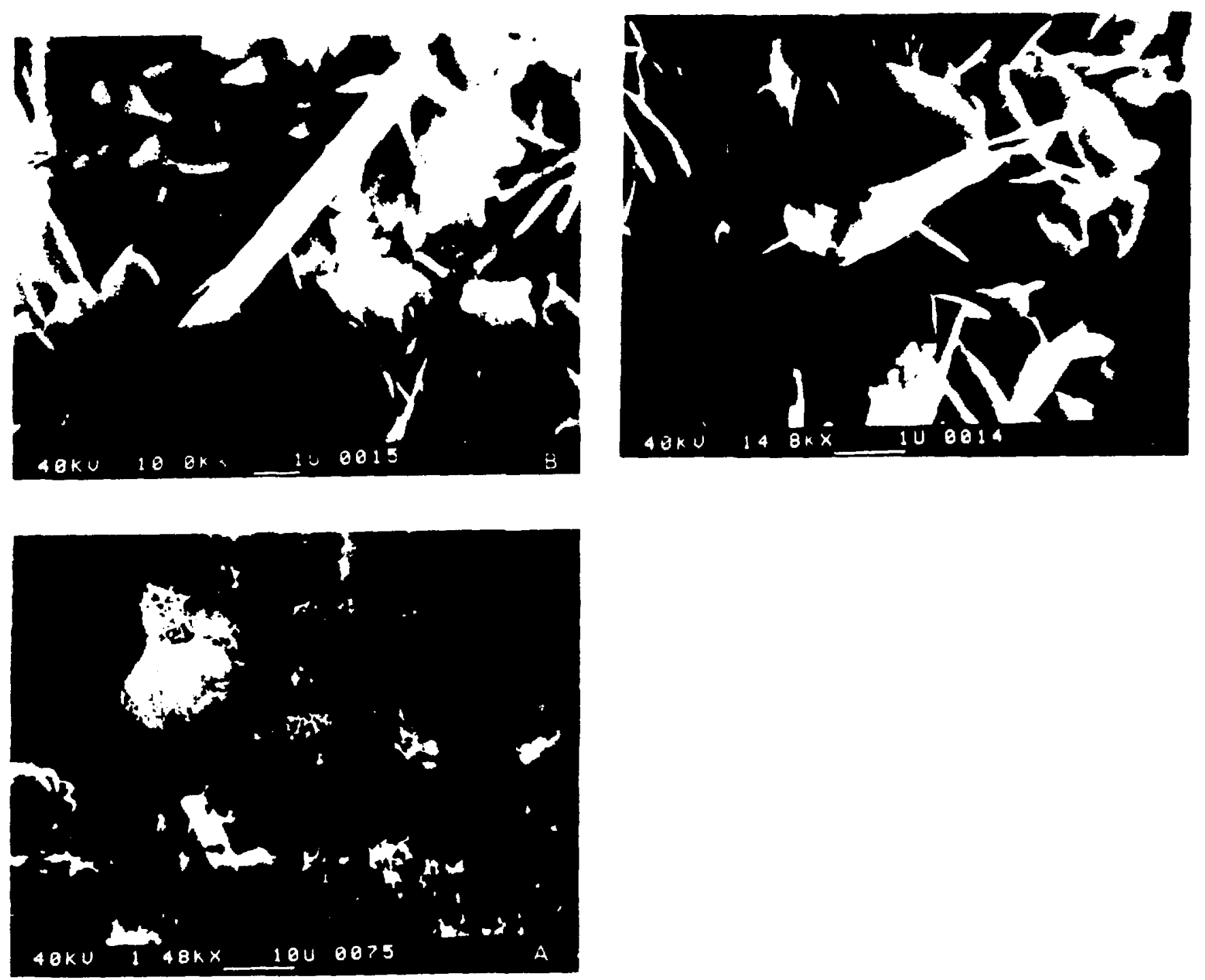

Fin. 4. Clockwise from lower left: (A) low-mangufiention riew of typical surface norphology highlighted ly flattened needle-like crystals. (B) high-magnification inage of the needle-like erystals. (C) high-magnitication image of platelets. 
Positive identification of the phase has not been made, but the chemistry: morphology: and a knowledge of the reaction tenperature suggest that it is the zeolite wairalite. These crystals are present in low abundance, making identification by XRD methods inpractical.

\subsubsection{Parr Vessel}

Only one solid charge was recovered from this set of experiments. This sample, LANL-P-1, was exposed to elevated temperature conditions for approximately 27 hours before the experiment was terminated. The time the sample was exposed to hychothermal conditions before the loss of fluids is undetermined. The initial water-to-solids ratio was 41:1. At the termination of the experiment, it was observed that all of the initial fluid charge had escaped. The remaining solids were loosely welded together and covered with a drusey coating, presumably a result of the rapid precipitation of solids as the fluid evaporated.

\subsubsection{Solid Phase Characterization by XRD}

The XRD characterization of the solid sample showed that the plases ettringite, illite, and portlandite were absent and that the plagioclase feldspar and dolomite were markedly reduced. The XRD pattern of heulandite appears to be slightly reduced in intensity. The amorphous calcium-silicate-hydrate (C-S-H) from the cementitious matrix has begun to crystallize as $11 \AA$ tobermorite $\left(5 \mathrm{CaO} \cdot 6 \mathrm{SiO}_{2} \cdot 5 \mathrm{H}_{2} \mathrm{O}\right.$ ). Calcite, $\mathrm{K}$-feldspar, quartz, and brownmillerite do not appear to have changed significantly.

\subsubsection{Solids Characterization by SEM/EDX}

The surfaces of all of the grains examined are covered with a drusey coating. The coating is composed of subhedral platelets with scattered anhedral masses resting on top of the platelets (Fig. 6). The chemistry of these platelets is dominated by calcium and silicon. The platelets are probably tobermorite. Only traces of aluminum, potassium, titanium, and iron are present. The coatings so dominate the particle surfaces that it is difficult to differentiate betwcen particles composed of cementitious matrix and the aggregates. 


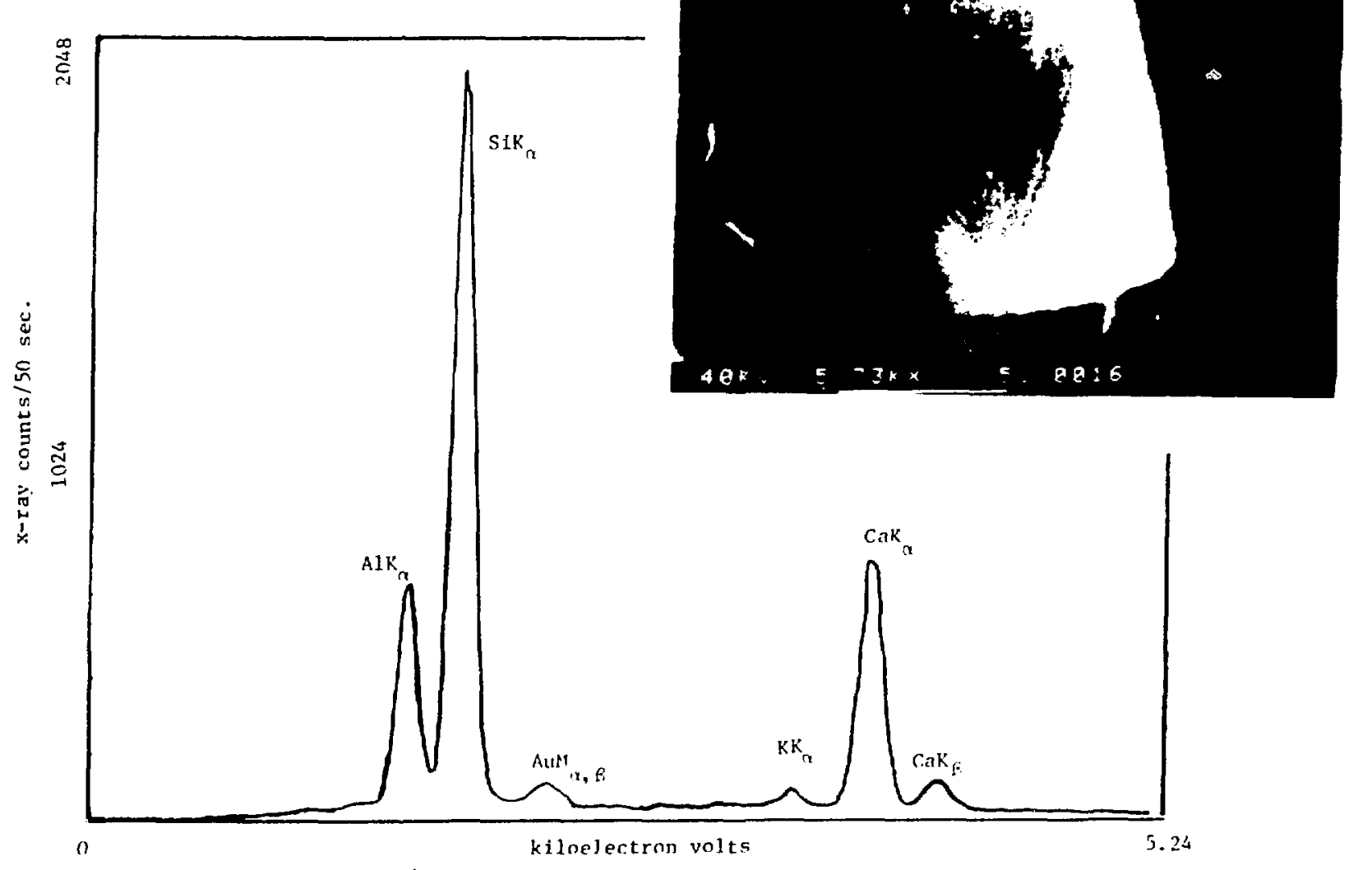

Fig. 5. The EDX chemistry and SEM image of alteration product (possibly the zeolite, wairakite) formed on LANL-T-2 at $200^{\circ} \mathrm{C}$ and $1200 \mathrm{psi}$. 


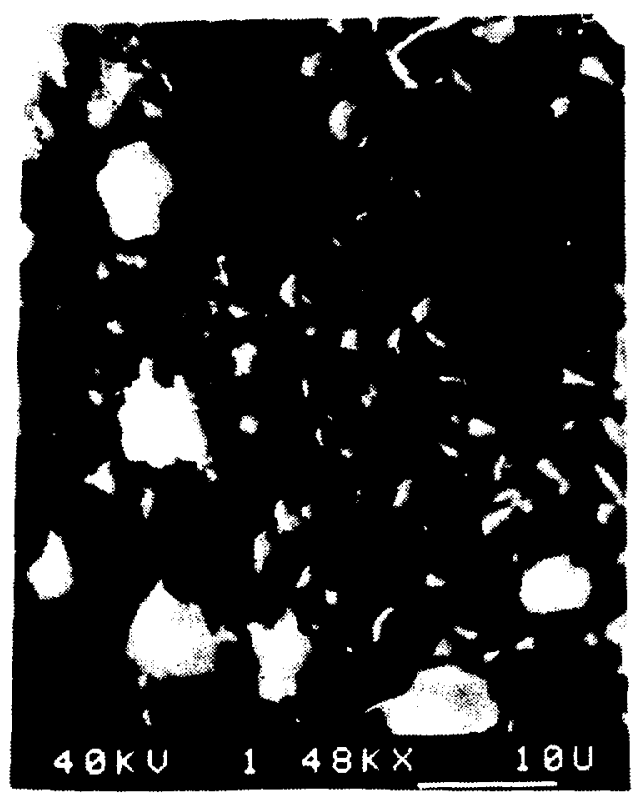

Fig. 6. Surface morphology of LANL-P-1 after hydrothermal exposure to $200^{\circ} \mathrm{C}$ and 1200 psi. The subhedral platelets have a chemistry dominated by calcium and silica. A possible phase identification is tobermorite.

\subsubsection{Static Hydrothermal Studies}

The $\mathrm{x}$-ray characterization of the various sieve fractions revealed some partitioning of the constituent phases of the concrete as a result of the mechanical grinding and sieving. The XRD characterization of the sieve size $-20+30(840$ to $590 \mu \mathrm{m})$ did not reveal any deviation from the reference XRD pattern described in Sect. 2.1.4.1. A slight depletion in $\mathrm{K}$-feldspar was noted for the -200 mesh $(74-\mu \mathrm{m})$ sieve fraction as contrasted to the reference pattern. The $-100+200$ mesh $(149-$ to $74-\mu \mathrm{m})$ sample was consequently slightly enriched in orthoclase relative to the reference pattern. This degree of enrichment/depletion was not considered detrimental to the study.

The 50- to $150-\mathrm{mg}$ sample of powder, along with 10 times its mass of J-13 groundwater, was sealed into thin-walled gold tubing and treated in cold-seal-type pressure 
vessels. The experiments were conducted isobarically while the temperature was raised to $200^{\circ} \mathrm{C}$, after which it was maintained for $1,2,4,12$, or 20 wecks. At the completion of the experiment, the capsules were allowed to return to ambient temperature and the pressure was allowed to decrease following the saturated steam pressure curve. The cooling rate was not monitored for these experiments but is estimated to be about $5^{\circ} \mathrm{C}$ per minute.

\subsubsection{Solid Phase Characterization by XRD}

Charactcrization of the hydrothermal reaction products from these closed-system, static experiments was conducted by standard powder XRD techniques. The results of these studies are summarized in Table $\mathrm{X}$ and Figure 7 . The formation of a smectite $(\approx 15 \AA x$-ray reflection) after 1 week of hydrothermal treatment has been confirmed by the glycolation of the smectite and observation of the subsequent expansion of the basal spacing to $\approx 16.9 \AA$ (Figs. 8 and 9 ). The persistence of tobermorite throughout the 20 weeks of hydrothermal treatment differs from the results of preliminary experiments in the rocking autoclave, which indicates reaction to produce other products by the eighth week. This is probably due to slow reaction caused by diffusion-limited transport of altering cations in the cold-seal vessel experiments.

Ettringite is an abundant phase in the initial concrete and is the phase that was responsible for generating a slight expansion in the initial cementitious formulation. However, at the elevated temperature of these experiments, ettringite is unstable and decomposes (Ogawa and Roy, 1981). Ettringite was not observed in the hydrothermally treated samples; however, neither was any set of phases observed that might reasonably represent the dccomposition products of ettringite. Abundant sulfate should manifest itsclf either in the form of new phase formation or in ligher concentrations in the aqueous fluid. It appears from the XRD characterization that equilibrium has most likely not been achieved in the course of 20 weeks of hydrothermal treatment of the CON-14 concrete.

\subsubsection{Cation Determination by DCP}

After hydrothermal exposure and cooling to room temperature, the fluid phase in contact with the concrete was extracted from the gold tube and analyzed by DCP. Because of the small sample size and the subsequent dilutions that were necessary to bring the 
TABLE X

XRD CHARACTERIZATION OF REACTION PRODUCTS IN STATIC HYDROTHERMAL EXPERIMENTS

\begin{tabular}{|c|c|c|c|c|c|c|}
\hline \multirow[b]{2}{*}{ Phase } & \multicolumn{6}{|c|}{ Time (weeks) } \\
\hline & $\underline{0}$ & $\underline{1}$ & $\underline{2}$ & $\underline{4}$ & 12 & 20 \\
\hline Quartz & $x$ & $\mathrm{x}$ & $\mathrm{x}$ & $\mathrm{x}$ & $\mathrm{x}$ & $\mathrm{x}$ \\
\hline Calcite & $\mathrm{x}$ & $\mathrm{x}$ & $\mathrm{x}$ & $\mathrm{x}$ & $x$ & $\mathrm{x}$ \\
\hline Dolomite & $\mathrm{x}$ & $x$ & $x$ & $\mathrm{x}$ & $\mathrm{x}$ & $\mathrm{x}$ \\
\hline Feldspars & & & & & & \\
\hline K-feldspar & $\mathrm{x}$ & $x$ & $\mathrm{x}$ & $\mathrm{x}$ & $x$ & $\mathrm{x}$ \\
\hline Plagioclase & $\mathrm{x}$ & $\mathrm{x}$ & $\mathrm{x}$ & $\mathrm{x}$ & $\mathrm{x}$ & $\mathrm{x}$ \\
\hline
\end{tabular}

\section{Zeolite}

Heulandite/

Tobermorite

Clinoptilolite

Gyrolite

Smectite

\begin{tabular}{|c|c|c|c|c|}
\hline $\mathrm{x}$ & $x$ & $\mathrm{x}$ & $\mathrm{x}$ & $x$ \\
\hline & $\mathrm{x}$ & $\mathrm{x}$ & $\mathrm{x}$ & $\mathrm{x}$ \\
\hline & & $?$ & $?$ & $?$ \\
\hline & & $x$ & $\mathbf{x}$ & $\mathrm{x}$ \\
\hline
\end{tabular}

sample up to a suitable volume, only cations were determined. Table XI summarizes the DCP analyses of the 16 samples (including replicates) in this data set.

\subsection{Disc Samples/Agitated Hydrothermal Experiments}

The dises were exposed to hydrothermal solutions for 1 week in an agitated Parr vessel and for the remainder of time in a Bridgman seal autoclave, as described in Sec. 2.2.2.1. Comparisons are made between samples before and after hydrothermal treatment.

\subsubsection{Optical and SEM Surface Characterization}

Detailed optical examination of the concrete discs that were $r$ ined from the mild hydrothermal conditions produced several generalizations. Alte $t_{1} ; r_{i, 1}$ of the concrete resulted in the selective dissolution of the larger aggregate (tuff) fraction of the concrete. The dark brown aggregate material was identified in thin section as a glassy, poorly welded tuff. This material exhibited the most extensive alteration, as exhibited by pitting. A light gray-brown tuff aggregate material, which was found to be a more crystalline, welded tuff 


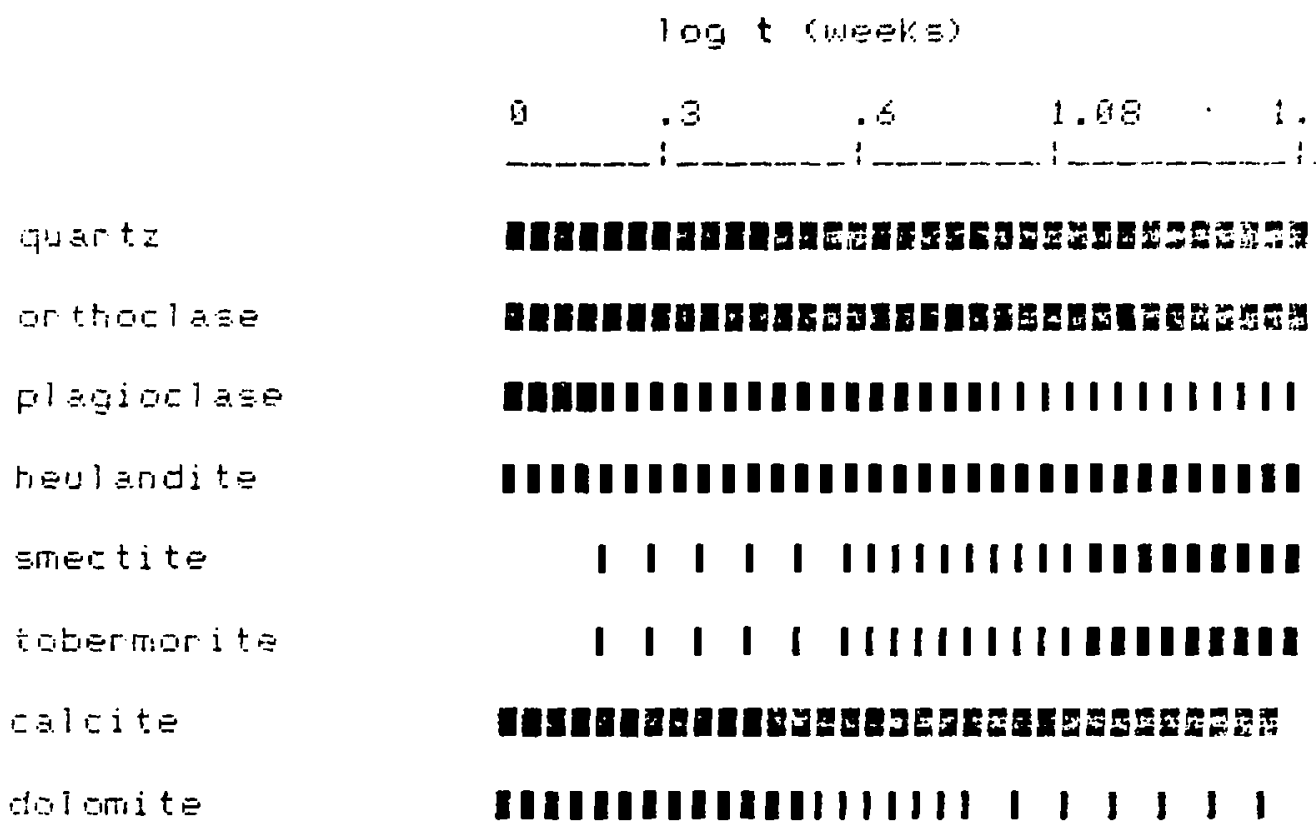

Fig. 7. Paragenesis relationships for the crystalline phases in CON-14 exposed to hydrothermal fluids (static experiments).

fragment, was the second most altered component of the concrete. Inclusions within the tuff aggregate as well as sand-sized particles of quartz added to the concrete as sand were observed to be most resistant to alteration. The extent of alteration of the concrete matrix material was intermediate between the latter two concrete components.

Pairs of photomosaics are presented in Figs. 10(a,b) through 13(a,b) for each disc both before and after exposure to the J-13 groundwater. The mosaics were prepared from photographically reproduced images from EBS SEM microscope images, which were maintained as nearly as possible between 30 and $35 \mathrm{X}$ magnification. Each mosaic contains a marker bar that is equivalent to a length of $500 \mu \mathrm{m}$. The mosaic in Fig. 10(a) (before) reveals important details of the concrete. Cracking had occurred between the aggregate and the cementitious matrix. The cement formulation used in CON-14 is a shrinkage-compensating cement that has been modified by the addition of a Class- $\mathrm{C}$ 


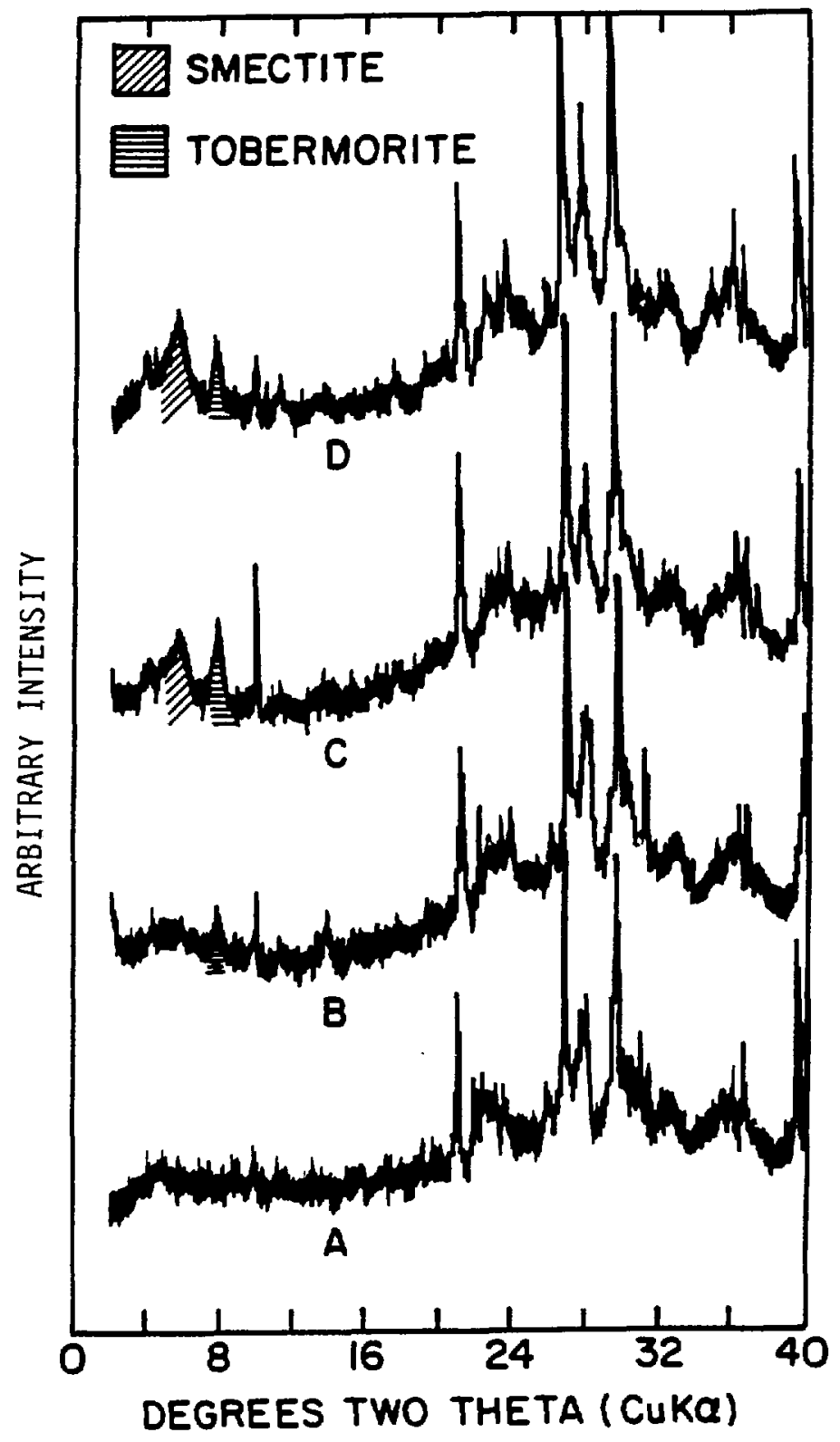

Fig. 8. Portions of $x$-ray diffractograms of untreated and hydrothermally treated CON14 samples with J-13 simulated water: (A) control (untreated); (B) treated for 1 week; (C) treated for 12 weeks; and (D) treated for 20 weeks. 


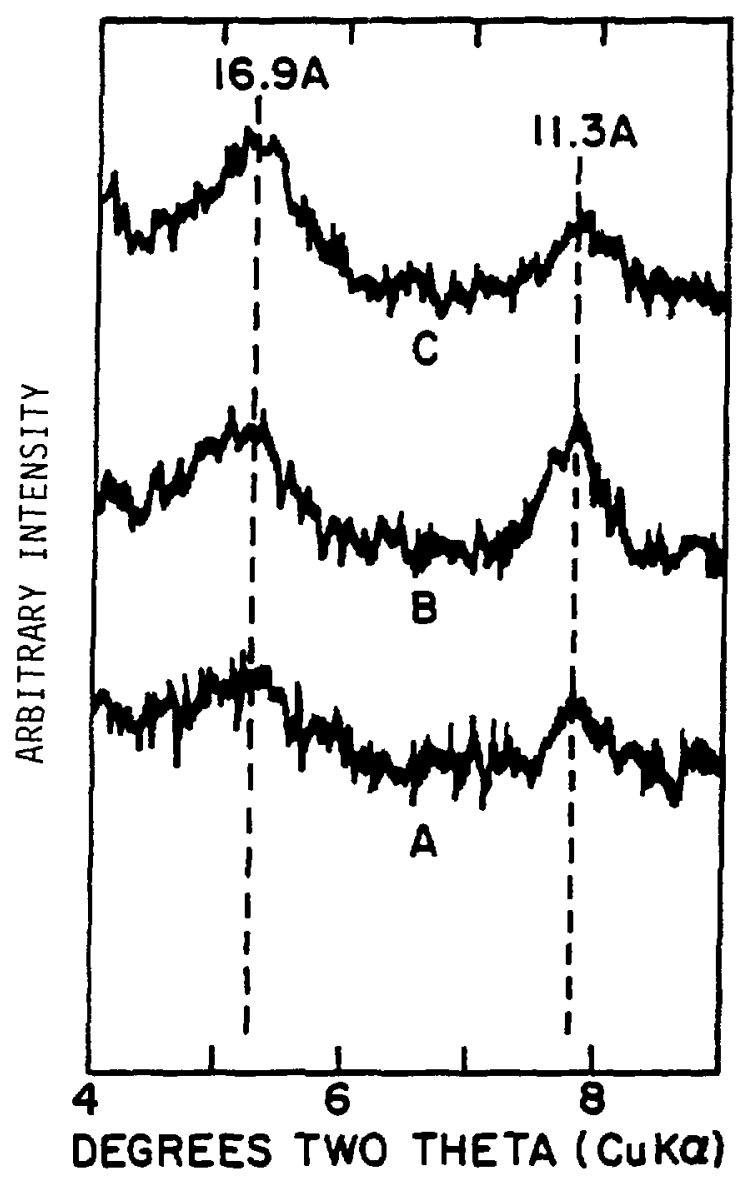

Fig. 9. Portions of $x$-ray diffractograms of ethylene glycol-treated samples showing the

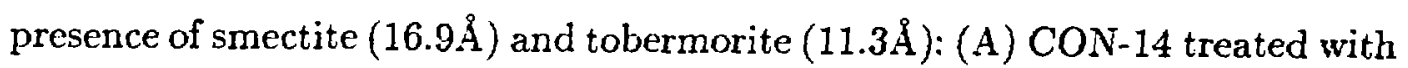
J-13 simulated tuff water for 4 weeks; (B) CON-14 treated with J-13 simulated tuff water for 12 weeks; and (C) CON-14 treated with J-13 simulated tuff water for 20 weeks. 


Time (weeks)

$\mathrm{J}-13$

\begin{tabular}{|c|c|c|c|c|c|c|}
\hline Element & 1 & 2 & 3 & 12 & 20 & Groundwater \\
\hline $\mathrm{Ca}$ & $290 \pm 10^{a}$ & $350 \pm 10$ & $260 \pm 10$ & $380 \pm 10$ & $300 \pm 10$ & 11.5 \\
\hline $\mathrm{Na}$ & $130 \pm 5$ & $125 \pm 5$ & $135 \pm 5$ & $140 \pm 5$ & $137 \pm 5$ & 45.1 \\
\hline $\mathrm{K}$ & $33 \pm 5$ & $17 \pm 5$ & $13 \pm 5$ & $12 \pm 5$ & $11 \pm 5$ & 5.26 \\
\hline $\mathrm{Si}$ & $52 \pm 5$ & $40 \pm 5$ & $70 \pm 5$ & $34 \pm 5$ & $46 \pm 5$ & 31.8 \\
\hline $\mathrm{pH}$ & 5.0 & 5.0 & 5.0 & 4.7 & 4.5 & \\
\hline $\mathrm{n}^{b}$ & 3 & 3 & 3 & 2 & 5 & \\
\hline
\end{tabular}

${ }^{*} \mathrm{Al}, \mathrm{Ba}, \mathrm{Fe}, \mathrm{Li}, \mathrm{Mg}, \mathrm{Mn}, \mathrm{Sr}, \mathrm{Ti}$, and $\mathrm{V}<5 \mathrm{mg} / \mathrm{L}$ in all of the hydrothermal solutions. ${ }^{a}$ Error included both instrumental and estimated experimental.

${ }^{b}$ Number of replicates.

fly ash, which should enhance the expansive characteristics. The expansive behavior of the cement is produced by the formation of the low-density crystalline phase ettringite $\left(3 \mathrm{CaSO}_{4} \cdot \mathrm{Ca}_{3} \mathrm{Al}_{2} \mathrm{O}_{6} \cdot 32 \mathrm{H}_{2} \mathrm{O}\right)$. It is unclear from these observations whether the cracking is a result of the sample preparation and characterization in the SEM (including extensive drying), is a result of carbonation, or is an intrinsic property of the expansive cement in an unconstrained environment, which would not appear in a restrained environment. These microcracks provide active sites for preferential alteration of the surfaces of the discs. The large aggregate grain in the upper half of the mosaic is composed of intergrowth of two fine lath-like phases. Feldspar phenocrysts are contained in the groundmass. The dark gray rounded-to-angular grains found throughout the sample are quartz. The lighter gray grains are feldspars, and the grains identified as opaques in the thin section are dominantly ilmenite. The black object in the lower left quadrant of the mosaic is an air bubble cast.

Figure 10(b) (after) reveals the extensive alteration of the large tuff grain. There has been preferential removal of material from the groundmass, probably the more reactive glass. Most of the other components of the aggregate and matrix of this concrete, including the cementitious matrix, appear to have been etched. The extensive system of 


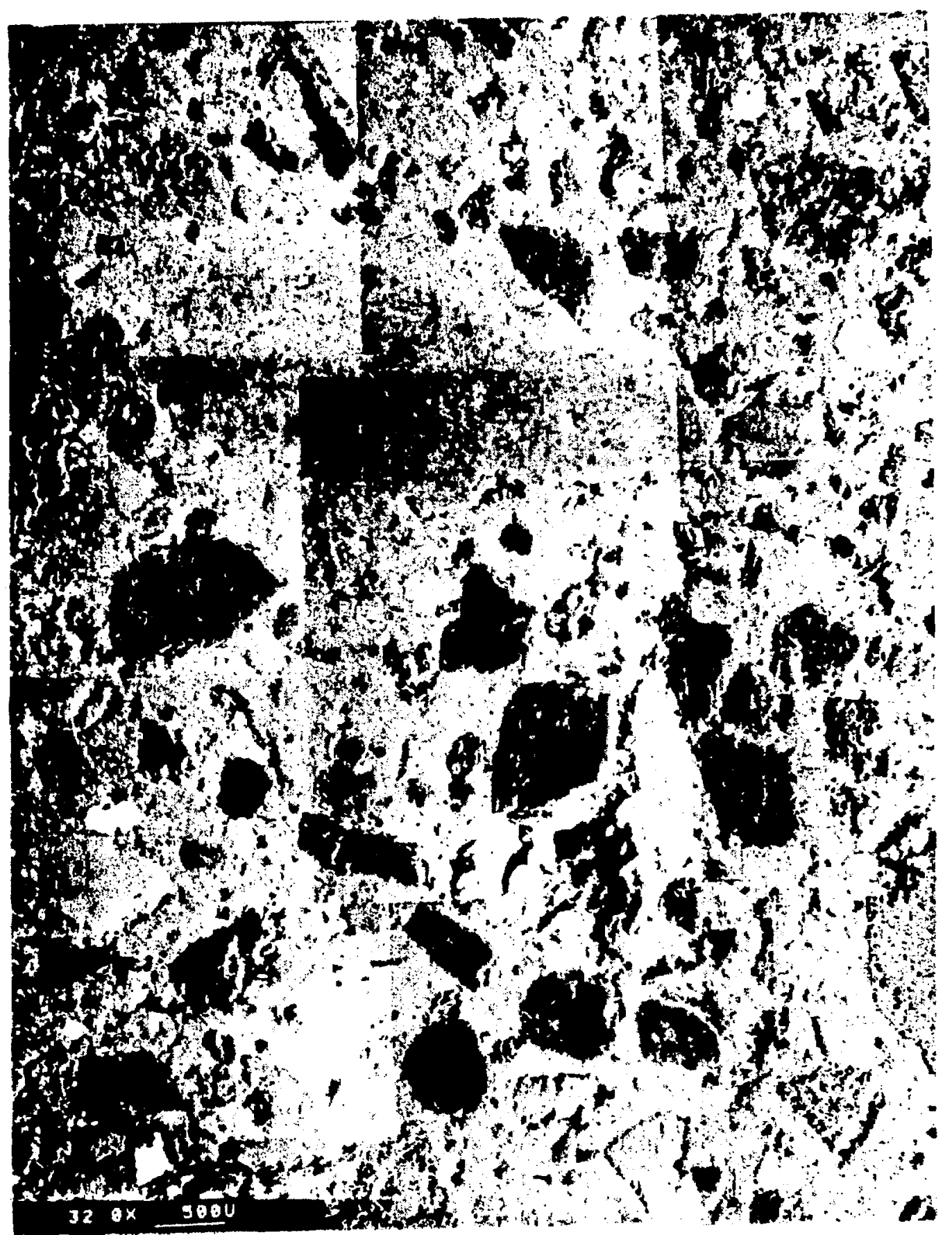

Fig. 10(a). The EBS photomosaic of disc 1A before hydrothermal treatment. 


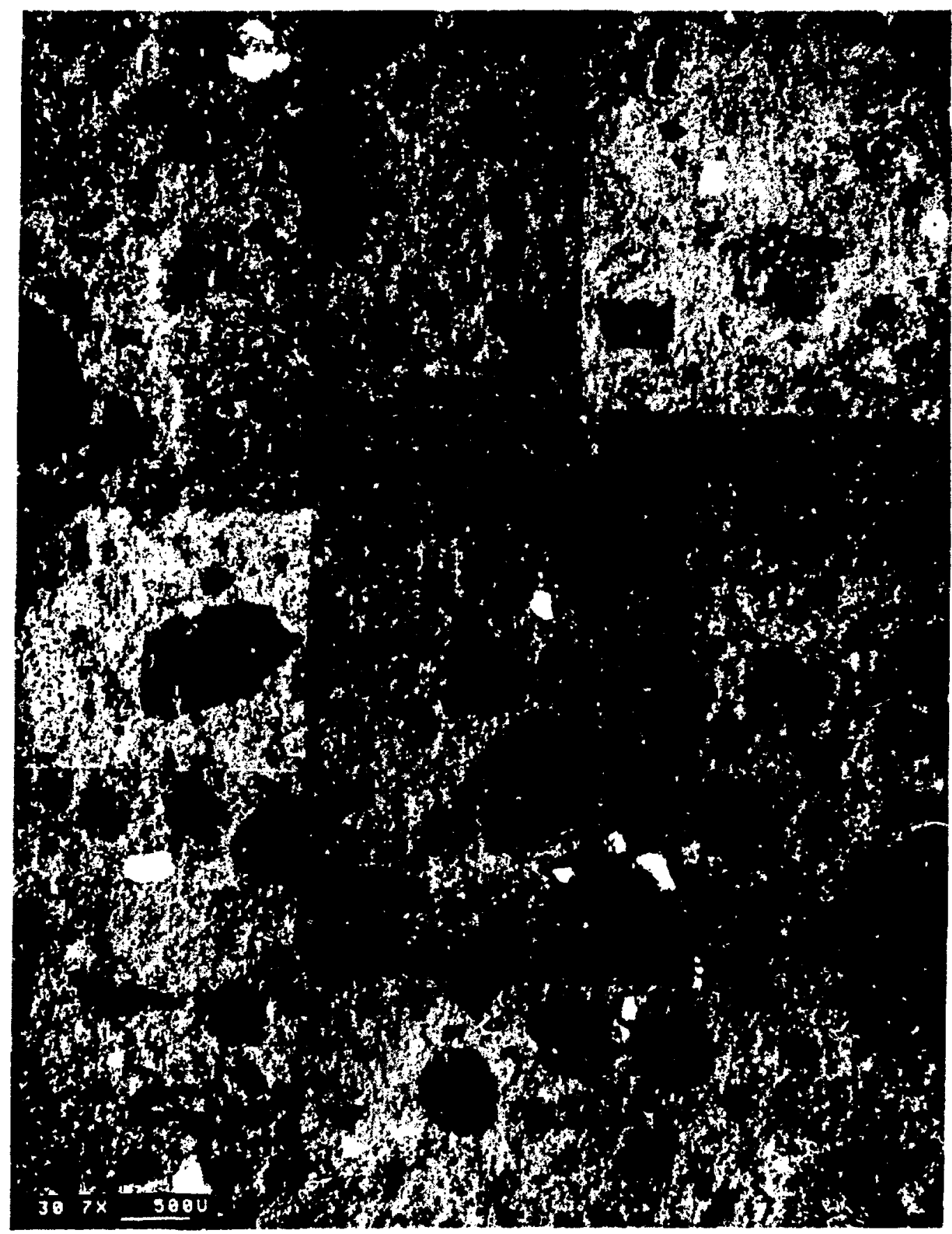

Fig. 10(b). The EBS photomosaic of disc $1 \mathrm{~A}$ after 1 week of hydrothermal treatment. 
aggregate/matrix interfacial cracks appears to be gone, suggesting removal of the surface material. Figure $11(\mathrm{a})$ is composed of a large tuff aggregate with an occluded bubble adjacent to the particle. The network of interfacial cracks and cracks emanating from the bubble casts is also illustrated. External alteration is apparent in Fig. 11(b). Further etching and pitting is shown in 12(b), indicating that after 3 weeks (12b) only the opaque (white) minerals are completely intact. There appears to be complete removal of some grains. Finally, the sample that experienced the longest (4-week) exposure and the largest extent of alteration is illustrated in Fig. 13(b). A tuff fragment is present extending across the center of the mosaic from left to right. Deep removal of material is apparent in this tuff fragment, in contrast to the surrounding cement matrix. Initial attempts to monitor the surface by profiling were of limited quantitative value because the amount of material removed created topological differences on the surface of the discs that were beyond the capabilities of the profilometer.

Characterization of these discs, both optically and with the SEM, showed relatively little deposition of material on the surfaces. This observation suggests that at the water-tosolids ratio $(\approx 100: 1$ to $\approx 400: 1$ ) of this study (Bridgman seal vessel, last 3 weeks), transport of material was from solid to solution, which was probably maintained in an unsaturated condition.

\subsubsection{Chemical Profiling}

Chemical profiling of the cementitious matrix was conducted in an attempt to evaluate the transport of ions between the matrix and the aggregate or between the matrix and solution. Establishment of chemical reaction across the interface of the tuff aggregate would aid in interpretation of the stability of the plug in the borehole.

Profiles across the surface of the starting material CON-14 were made at a spacing of $28 \mu \mathrm{m}$ for a distance of approximately $900 \mu \mathrm{m}$. Figure 14 is a composite of the EBS image and the line profiles for each of the elements monitored ( $x$-ray counts for each datum point are tabulated in Appendix D). Ratios of $x$-ray counts for aluninum/silicon and for calcium/silicon (inclusion of other cations into this ratio does not affect the general trend of the data) were used as a means of minimizing the surface rouglnness effects in the 


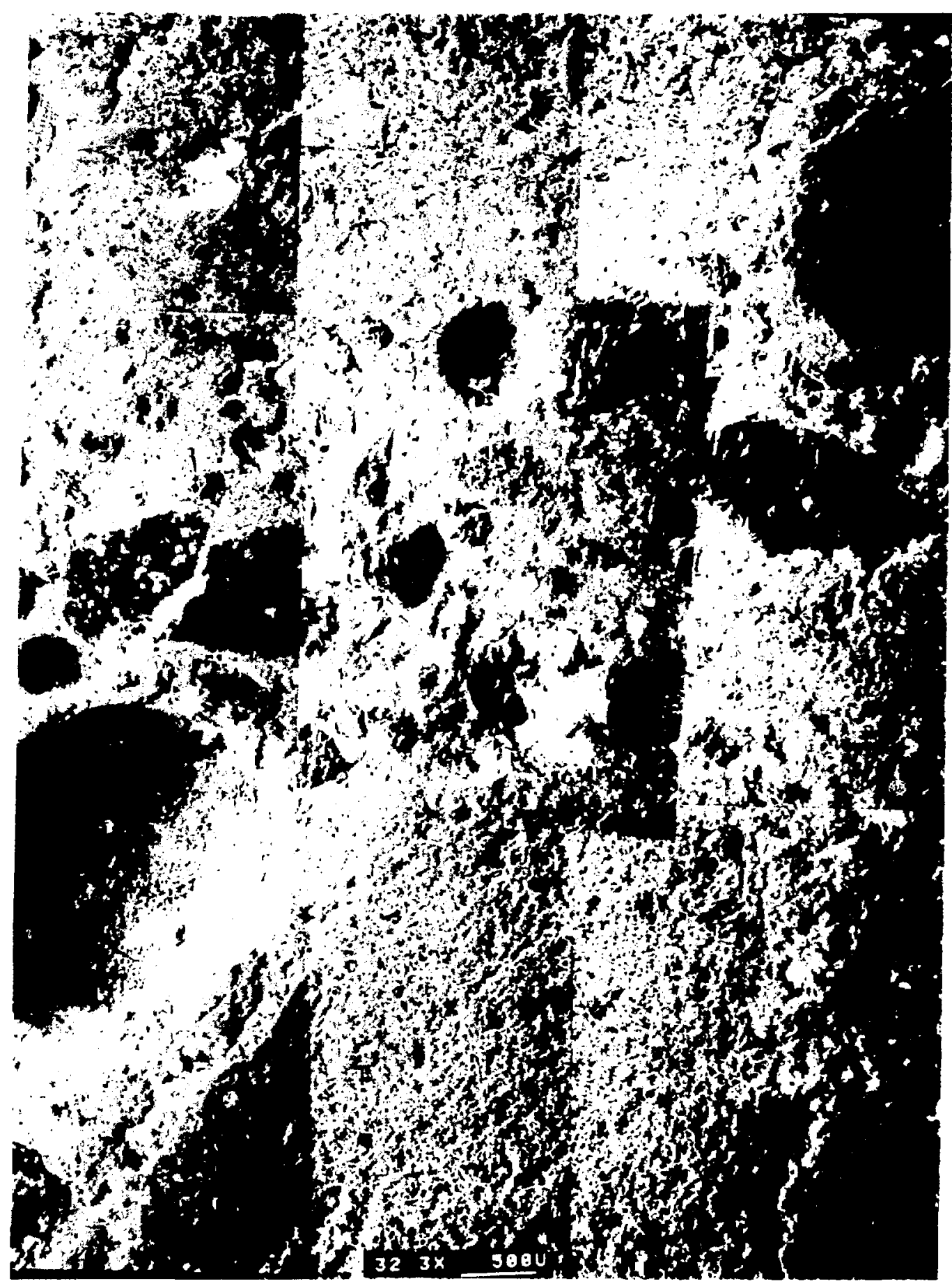

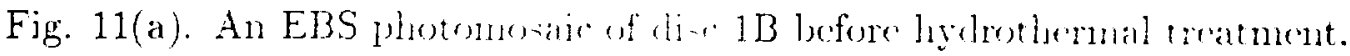




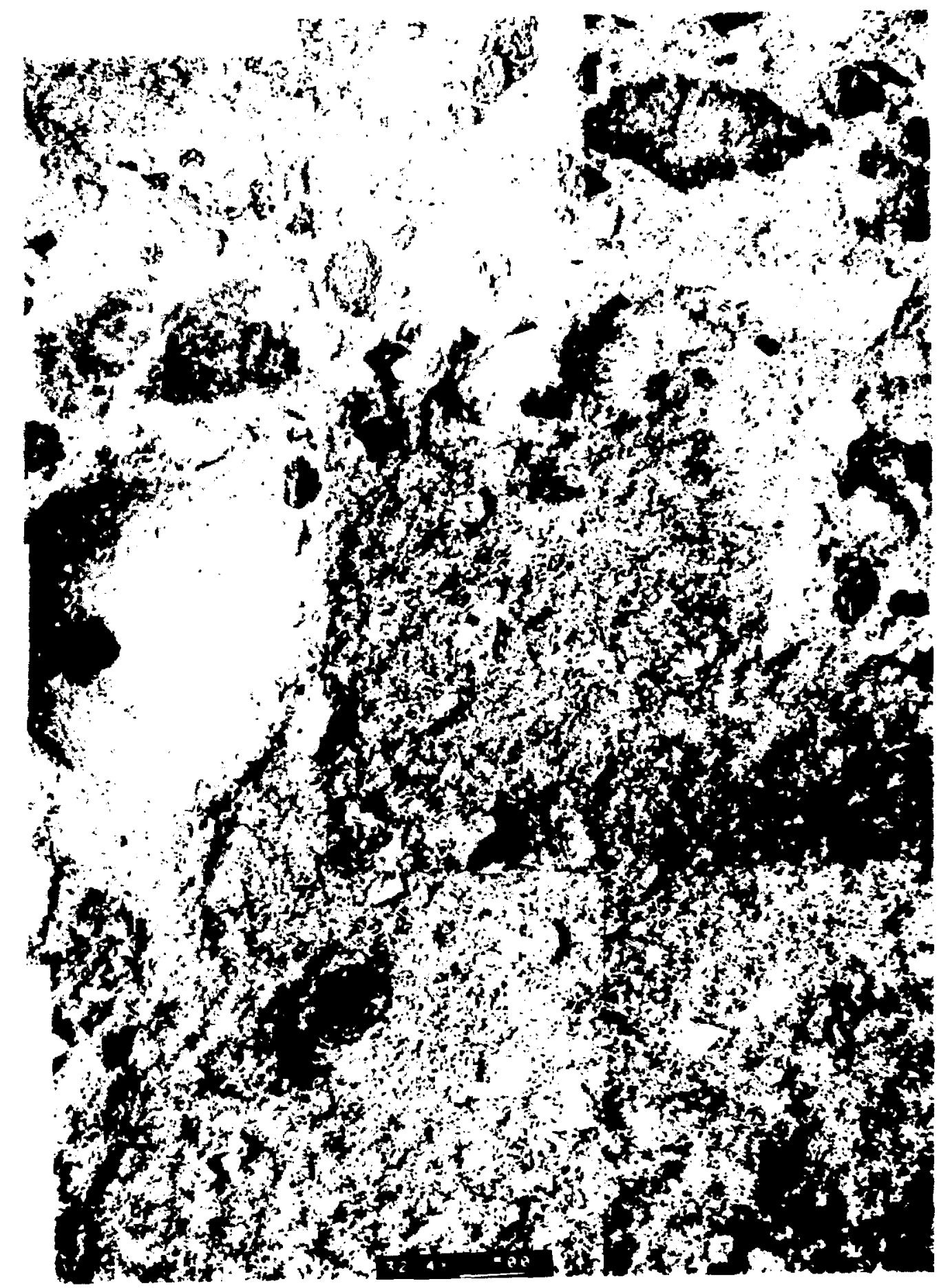

Fig. 11(b). An EBS photomosaic of disc $1 B$ after 2 wecks of hydrothermal treatment. 


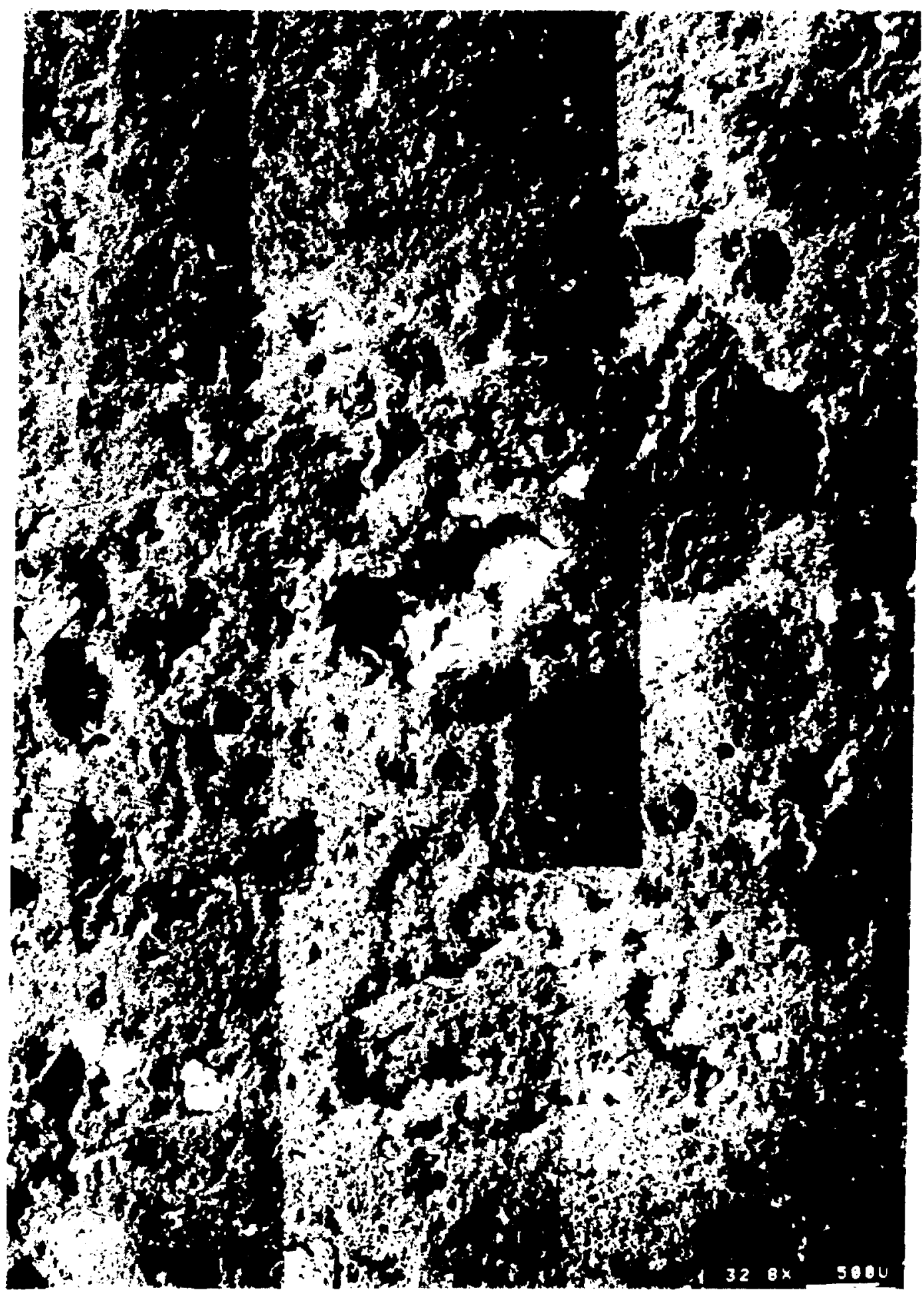

Fig. 12(a). An EBS photomosaic of clisc 1C before hyclrothermal treatment. 


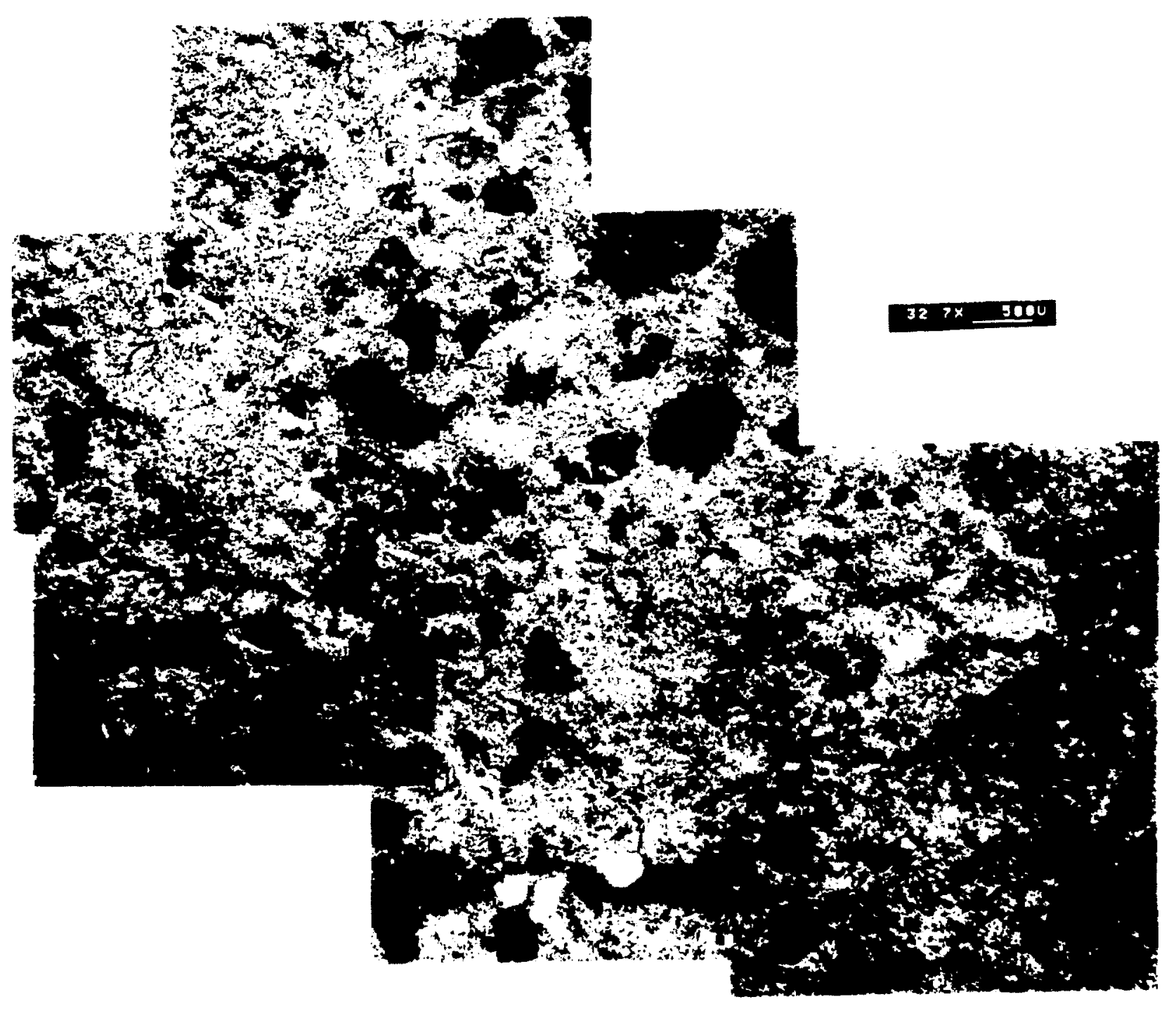

Fig. 12(b). An EBS photomosaic of disc $1 \mathrm{C}$ after 3 wecks of lydrothermal treatment. 


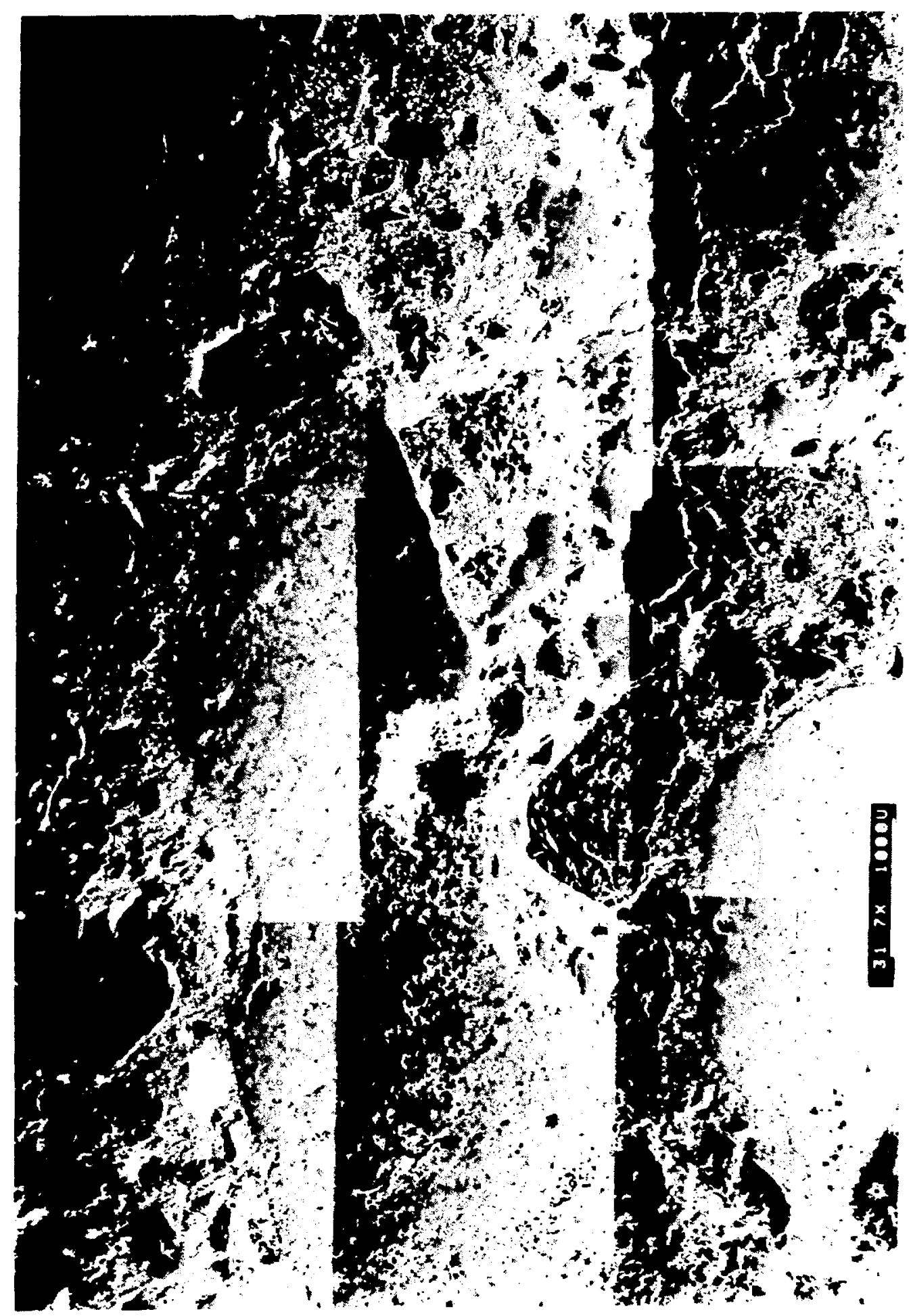

Fig. 13(a). An EBS photomosaic of disc 1D before hydrothermal treatment. 


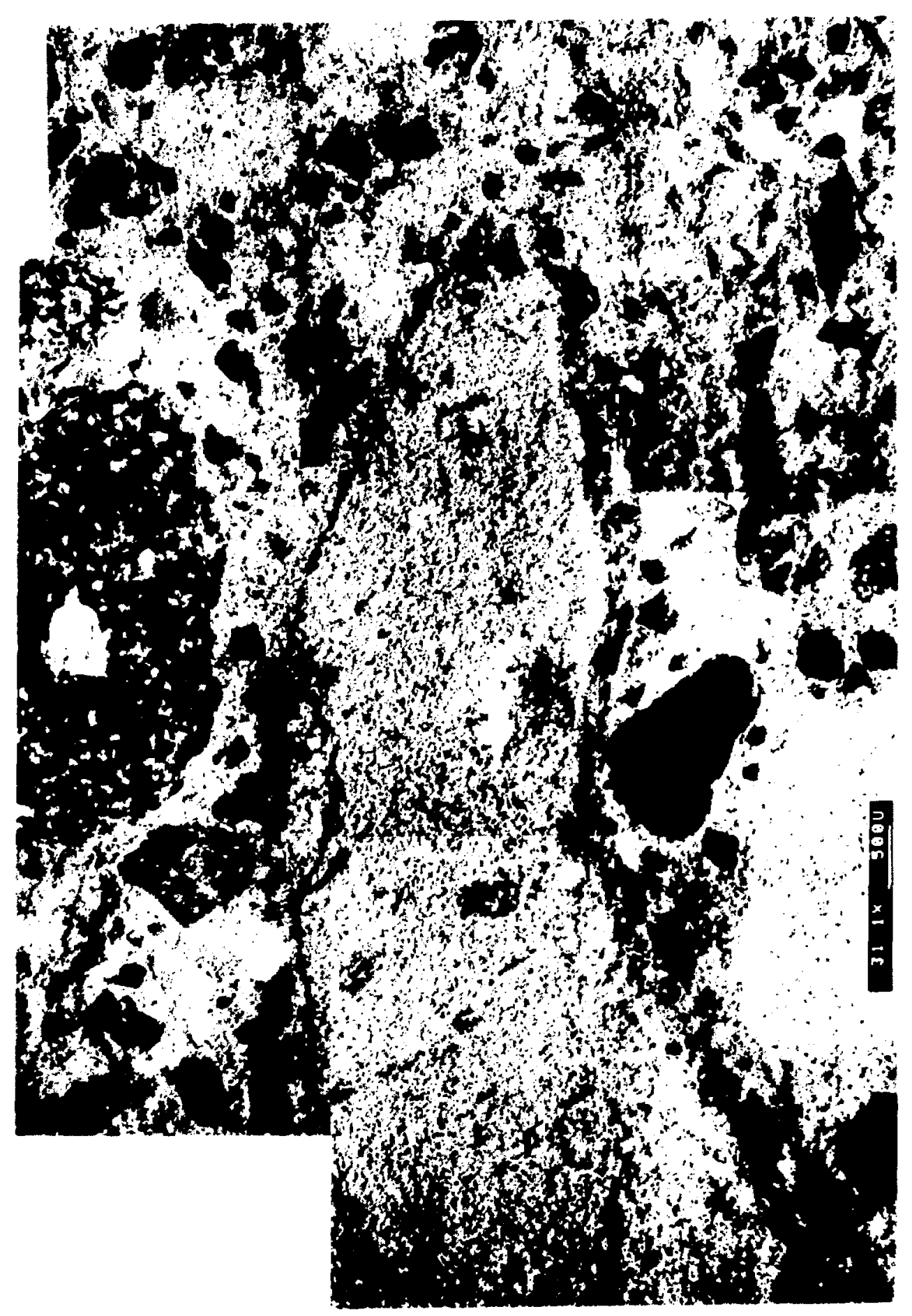

Fig. 13(b). An EBS photomosaic of disc 1D after 4 weeks of hydrothermal treatment. 
samples. The average of approximately 60 to 70 data points obtained from the matrix shows an average calcium/silicon ratio of 5.7 and an aluminum/silicon ratio of 1.2. These values agree with values anticipated from the knowledge of the cement and aggregate bulk chemical compositions and proportions used in the mixture. (The $\mathrm{Al}$ is somewhat higher than the initial ratio in the cement, suggesting enrichment from the tuff component.)

Rectangular prisms of the hydrothermally treated CON-14 were cut from the centers of the reacted disc specimens. The direction of the cut was chosen to allow for the maxinum sample length. Chemical profiling was conducted along the length of the specimen and inward from both the top and the bottom surfaces approximately $900 \mu \mathrm{m}$ to the core of the disc. Top is defined as the external surface from which the photomosaic was prepared. The data collected from profiling of specimen 1A (Fig. 15) (exposed 1 week to hydrothermal conditions) give an aluminum/silicon ratio of approximately 1.1 averaged for both top and bottom surfaces, a value in good agreement with the starting materials, and a calcium/silicon ratio of approximately 14.8 averaged for the top and bottom of the specimen. This latter value represents some depletion of silicon relative to calcium. Figure 15 details one such chemical profile through the surface of the disc that was hydrothermally treated for 1 week (see Appendix $\mathrm{E}$ for raw data).

Examination of the specimen that was exposed to the hydrothermal fluids for the maximum duration of time is reported in a similar fashion in Fig. 16. Chemical profilings from both surfaces support an equivalent removal of material from both sides of the sample. The aluminum/silicon ratios average to 1.0 , showing a slight depletion in silicon relative to aluminum. The calcium/silicon ratio of 3.5 represents a slight depletion of calcium relative to silicon.

The chemical profiling data and the surface characterization studies combine to support a model of alteration of the CON-14 concrete that is composed of dissolution of the matrix and aggregate to the hydrothermal fluids and a diffusional process that is depleting the surface material qualitatively, much like the "Phantom Diffusion Model" presented by Richardson (1981). With this model, the leachant is assumed to remove the leached constituents as if they were dissolved from the surface of a "phantom" solid that decreases in size with time as leaching proceeds. Unlike most traditional leaching models that treat 

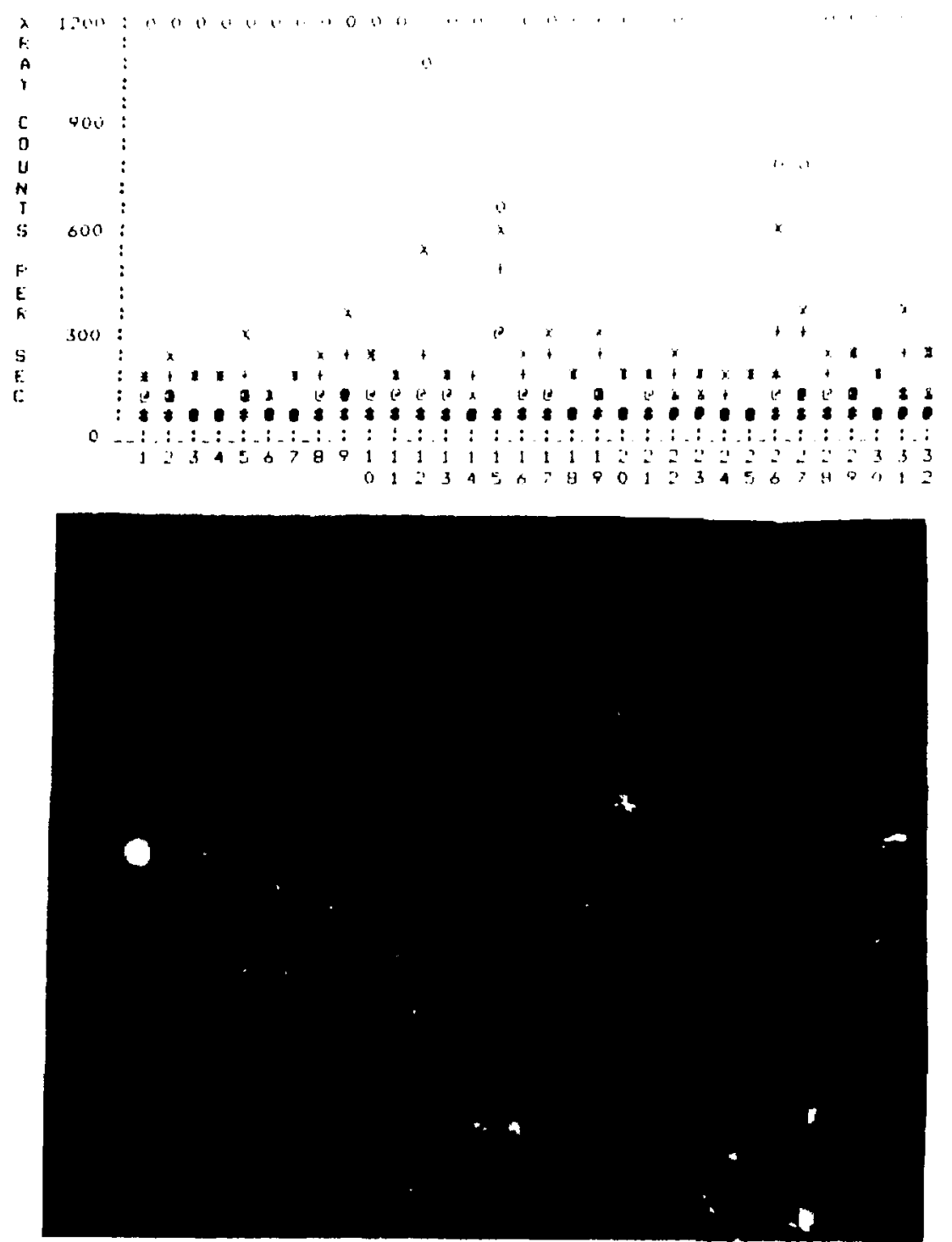

SLALE FALIIIK =

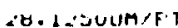

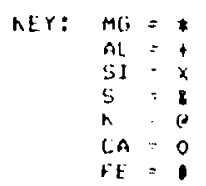

Fig. 14. Chemical profile across the surface of disc 1A starting material. 

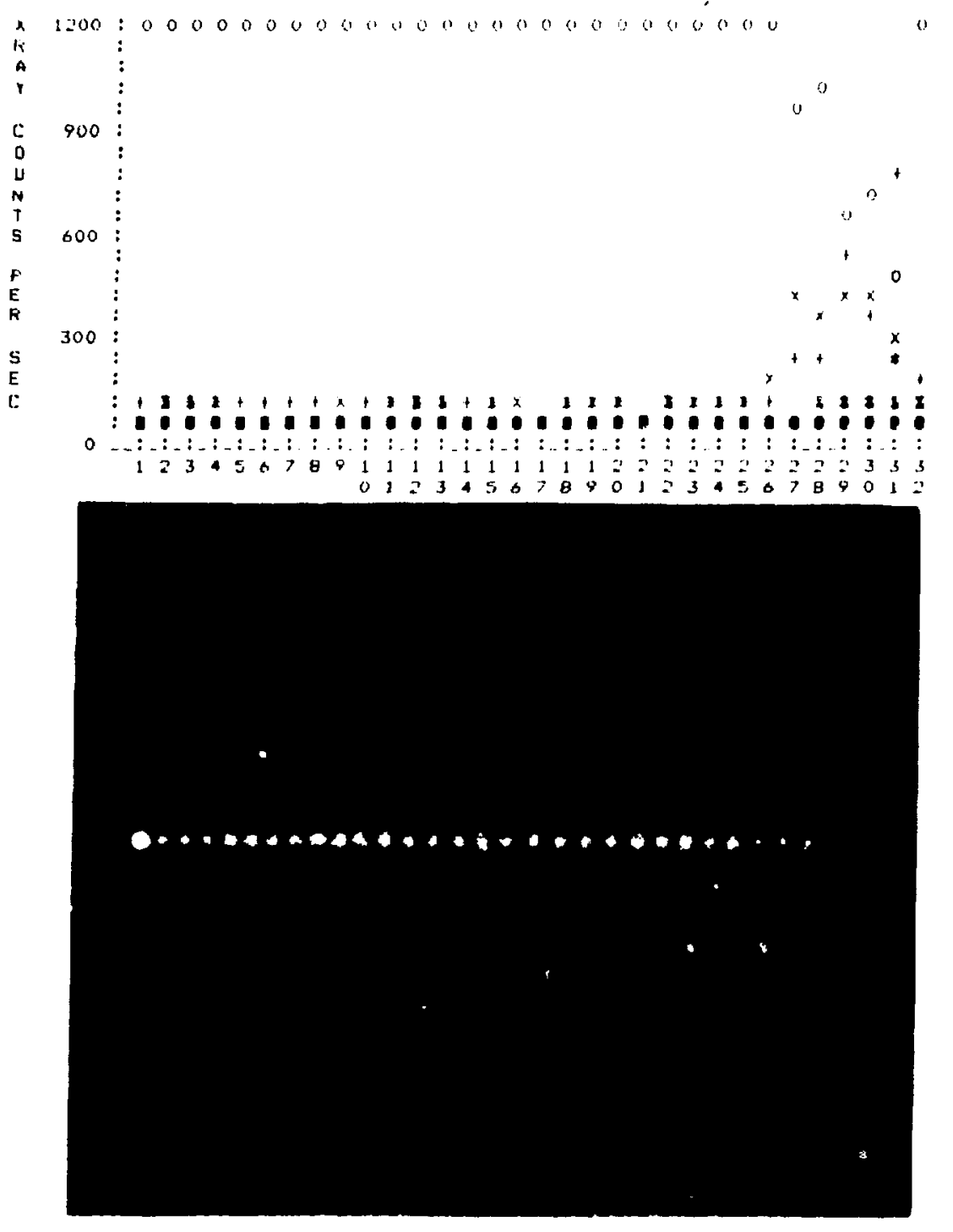

SCALE FACTOF $=\quad 28.1250 U M / F T$

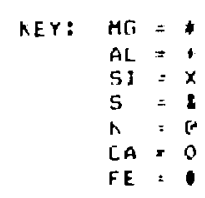

Fig. 15. Chemical profile of disc $1 \mathrm{~A}$ after 1 week of hydrothermal treatment. 


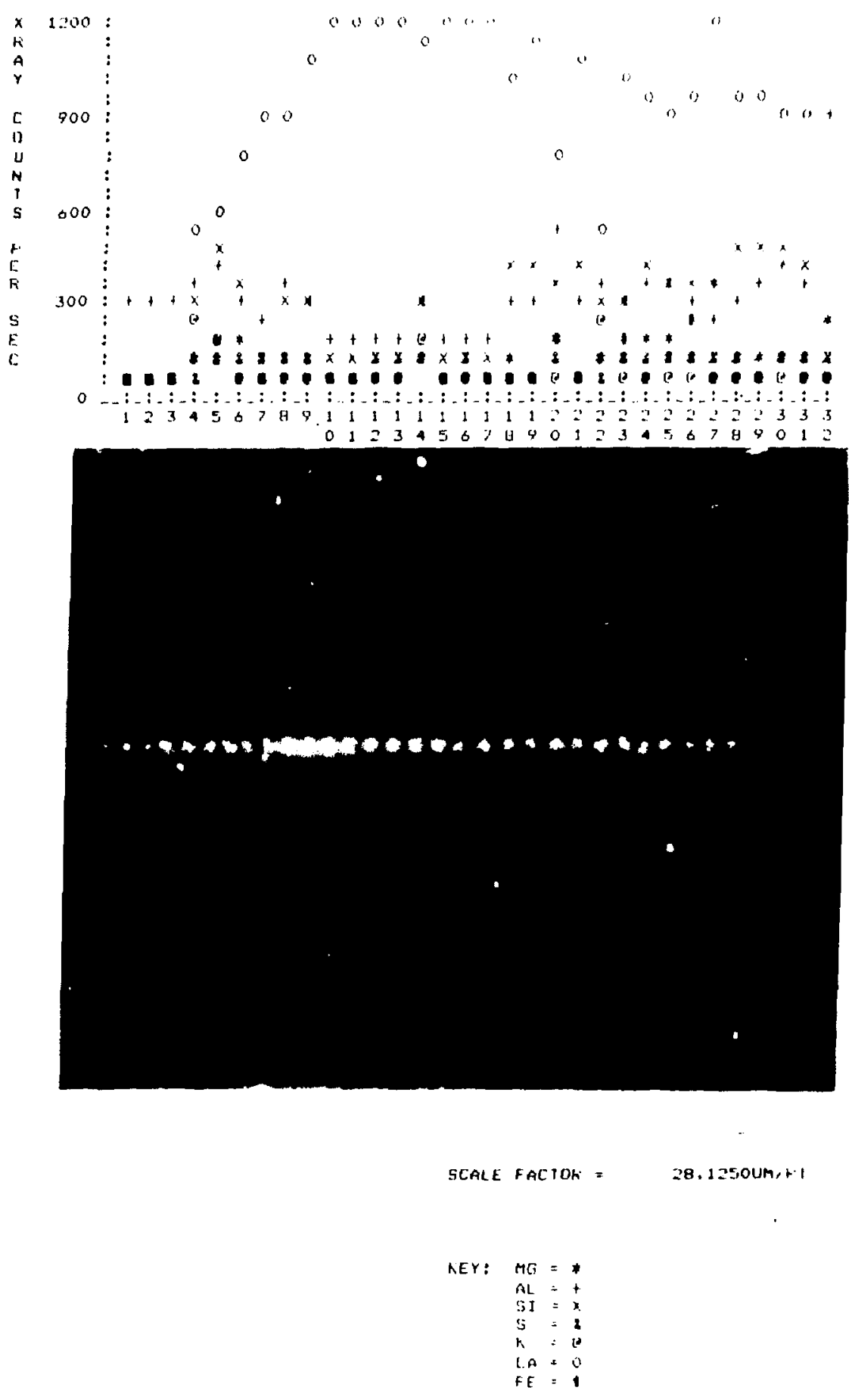

Fig. 16. Chemical profile typical of disc $1 \mathrm{D}$ after $>4$ weeks of hydrothermal treatment. 
the surface-area-to-volume-of-solid, S/V, ratio as a constant, the phantom dissolution leach model treats this volume of the solid as a variable.

\subsubsection{Aggregate/Matrix Alterations}

The rclative ratios of elements in the large aggregate grains were examined both before and after hydrothermal exposure for the $>4$-werk experiments. The large, dark brown grains that exhibited the most dissolution are poorly welded tuff particles, as shown in Fig. 17. In this EBS image, the characteristic shape of the remnant glass shards is clearly visible. The elements in the grains in this sample appear to be highly partitioned. The light rims on the individual grains indicate an average higher atomic number than do the interior darker gray portions. The enrichment in both calcium and iron is responsible for the brighter rim areas.

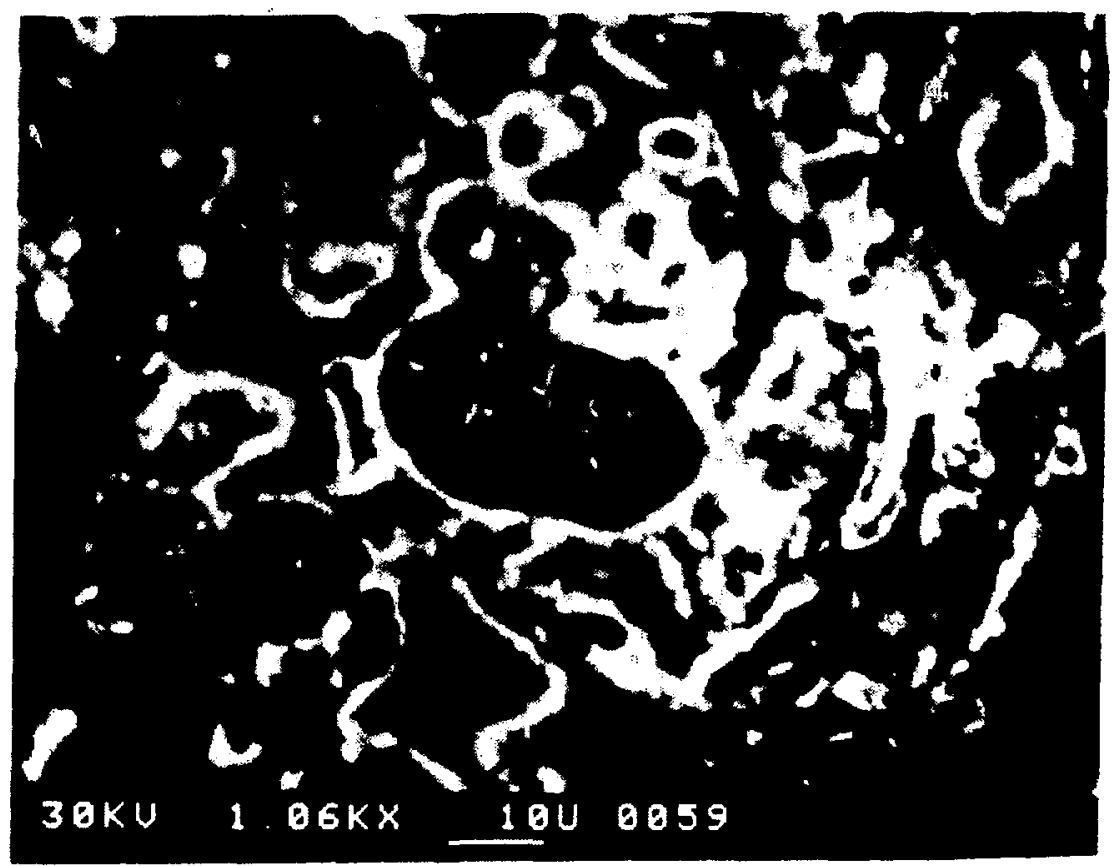

Fig. 17. An EBS image of poorly welded, dark brown tuff aggregate before hydrothermal treatment. 
Chemical profiling across a dark brown tuff particle/matrix interface and contrasting the aluminum/silicon ratios to a similar profile after 4 weeks of hydrothermal treatment [Fig. 18 (before) and Fig. 19 (after)] show a slight depletion in silicon in the matrix; however, little difference can be recognized in the calcium/silicon ratio in the matrix before and after samples. This latter suggests the congruent dissolution of the heterogeneous grain, as suggested in the visual examinations (see also Appendix F).

\subsubsection{Solution Characterization}

Aliquots of the solution phase in contact with the discs were sampled at each time interval in the experiment. The solutions were obtained after the vessel had been cooled to room temperature. Table XII summarizes the DCP analyses of these solutions.

\section{TABLE XII}

CHEMICAL ANALYSES OF SOLUTIONS FROM AGITATED CON-14 HYDROTHERMAL EXPERIMENTS ${ }^{* a}$

\begin{tabular}{|c|c|c|c|c|c|}
\hline Element & 1 week & 2 weeks & \multicolumn{2}{|c|}{3 weeks } & 4 weeks $^{b}$ \\
\hline $\mathrm{Al}$ & $1.0 \pm 0.1$ & $0.1 \pm 0.1$ & 0.02 & \pm 0.02 & $0.16 \pm 0.02$ \\
\hline $\mathrm{Ca}$ & $27 \pm 1$ & $54 \pm 2$ & 33 & \pm 2 & \pm 2 \\
\hline $\mathrm{Fe}$ & $0.2 \pm 0.1$ & $0.7 \pm 0.1$ & 0.6 & \pm 0.1 & $0.23 \pm 0.02$ \\
\hline K & $50 \pm 2$ & $61 \pm 2$ & 68 & \pm 2 & $50 \quad \pm 2$ \\
\hline $\mathrm{Mg}$ & $0.4 \pm 0.1$ & $<0.1$ & $<0.1$ & & $0.02 \pm 0.02$ \\
\hline $\mathrm{Na}$ & $80 \pm 5$ & $100 \pm 5$ & 105 & \pm 5 & $85 \quad \pm 5$ \\
\hline$P$ & $0.8 \pm 0.1$ & $0.8 \pm 0.1$ & 0.8 & \pm 0.1 & $0.25 \pm 0.02$ \\
\hline $\mathrm{Si}$ & $105 \pm 5$ & $120 \pm 5$ & 105 & \pm 5 & \pm 10 \\
\hline $\mathrm{Sr}$ & $0.3 \pm 0.1$ & $0.3 \pm 0.1$ & 0.3 & \pm 0.1 & $0.27 \pm 0.02$ \\
\hline F & $-^{c}$ & $-^{c}$ & - & $c$ & $<0.1$ \\
\hline $\mathrm{SO}_{4}$ & $-^{c}$ & $-^{c}$ & - & & $220 \pm 10$ \\
\hline
\end{tabular}

${ }^{*} \mathrm{Li}, \mathrm{Cu}, \mathrm{Ba}, \mathrm{Cr}, \mathrm{Mn}, \mathrm{Ni}, \mathrm{Ti}, \mathrm{Zr}$ were typically $<0.2 \mathrm{mg} / \mathrm{L}$ (ppm). ${ }^{a} \mathrm{mg} / \mathrm{L}$. Solutions sampled after cooling to room temperature. ${ }^{b}$ Sample not acidified.

${ }^{c}$ Not determined. 


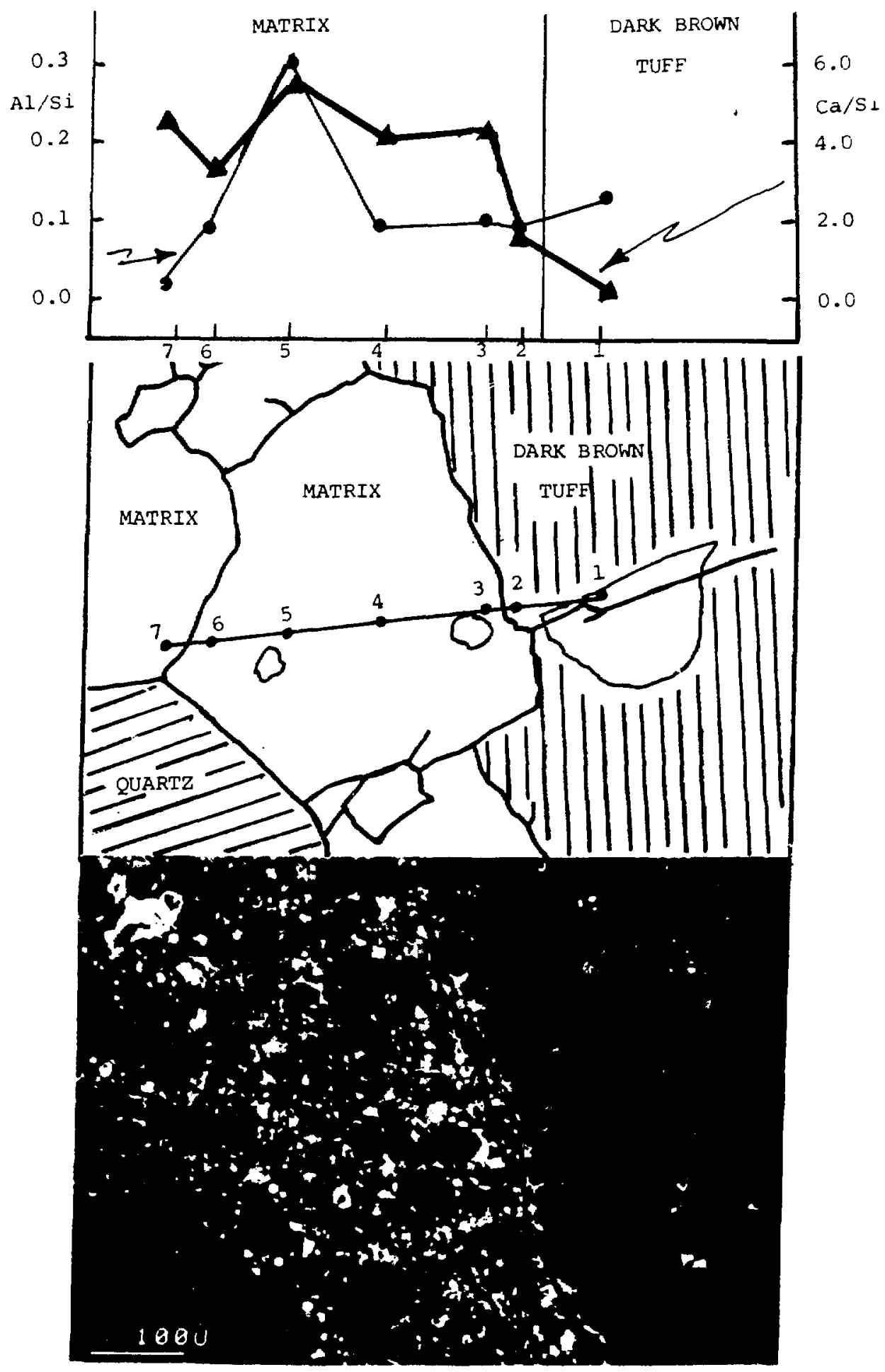

Fig. 18. Chemical profile across dark brown tuff aggregate before hydrothermal treatment. 


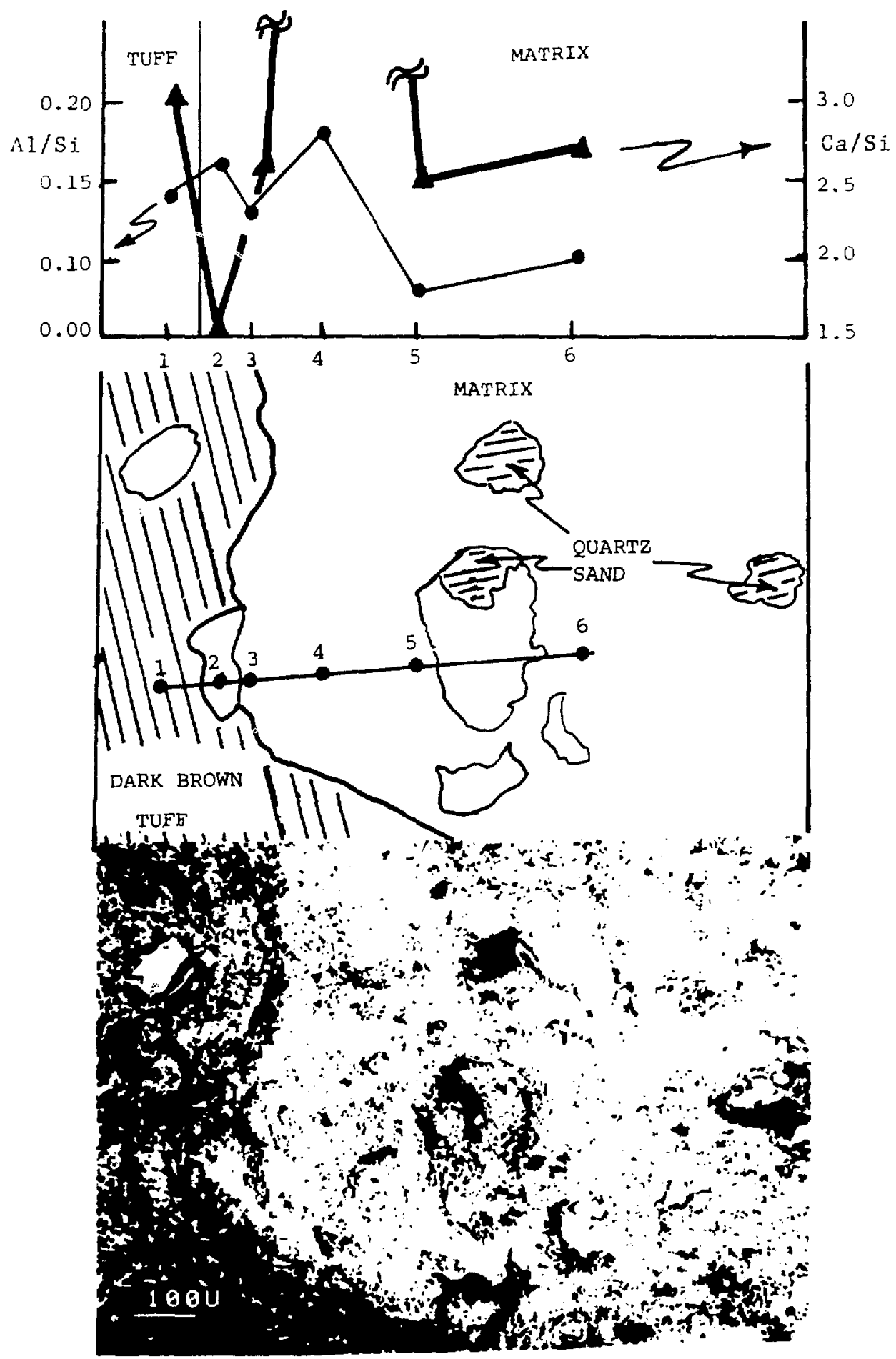

Fig. 19. Chemical profile across dark brown tuff aggregate after $>4$ weeks of hydrothermal treatment. 


\subsection{Vapor Phase Alteration of $\mathrm{CON}-14$}

Four dises were prepared in a fashion similar to the description for hydrothermal experiments in Sect. 2.2.1. All four discs, one cach to be sampled at monthly intervals, were suspended with chromel $(80 \% \mathrm{Ni}: 20 \% \mathrm{Cr})$ wire in the vapor phase region of a Bridgmanstyle autoclave. The fluid used in these experiments was deionized water. The conditions were saturated steam pressure at $200^{\circ} \mathrm{C}$.

\subsubsection{Characterization of Solid Surfaces by Optical and SEM Microscopy}

Visual examination at $40 \mathrm{X}$ of the individual surfaces revealed only minor etching (the reflective polished surfaces of grains were no longer evident) on the 1-month sample. For each of the remaining three samples, a scale formed on the surfaces of the discs. The details of the surface alteration of the discs were more clearly revealed by EBS imaging capabilities of the SEM. Figures $20(a, b)$ through $23(a, b)$ are photomosaics prepared from the EBS images. Figure 20(a) is an image of the sample before treatment for 1 month. The details of the disc are identical to those previously described; notably cracking developed at the aggregate/matrix interfaces. Post-treatment examination of the disc [Fig. 20(b)] clearly shows the presence of the cracks, but the most prominent feature of the posttreatment mosaic is the spongy nature of some of the large aggregate grains [upper left and right, 20(b)]. These grains were identified as the dark brown, poorly welded tuff aggregates. Presumably the glassy fraction of these particles is sufficiently reactive to account for this texture. Remnant small crystals are still prominent in the aggregate. The remaining, more densely welded tuff aggregate [bottom right of mosaic, 20(b)] does not appear to be substantially affected, nor does the quartz or the feldspar grains. The 2-month sample [Figs. 21(a) and (b)] is similar to the 1-month sample.

The 3-month sample was so heavily encrusted with scale that identification of the "before" area was not possible [Fig. 22(a,b)]. Long exposure to the lrot condensing vapors can cause significant alteration [Figs. 22(a,b) and 23(a,b)]. Etching of some larger crystal grains and deposition of scale in other arcas are observed after 4 months [Fig. 23(b)]. The magnitude of the observed alteration/dissolution, however, is not as great as in the immersion hydrothermal experiments where significant amounts of material were removed. 


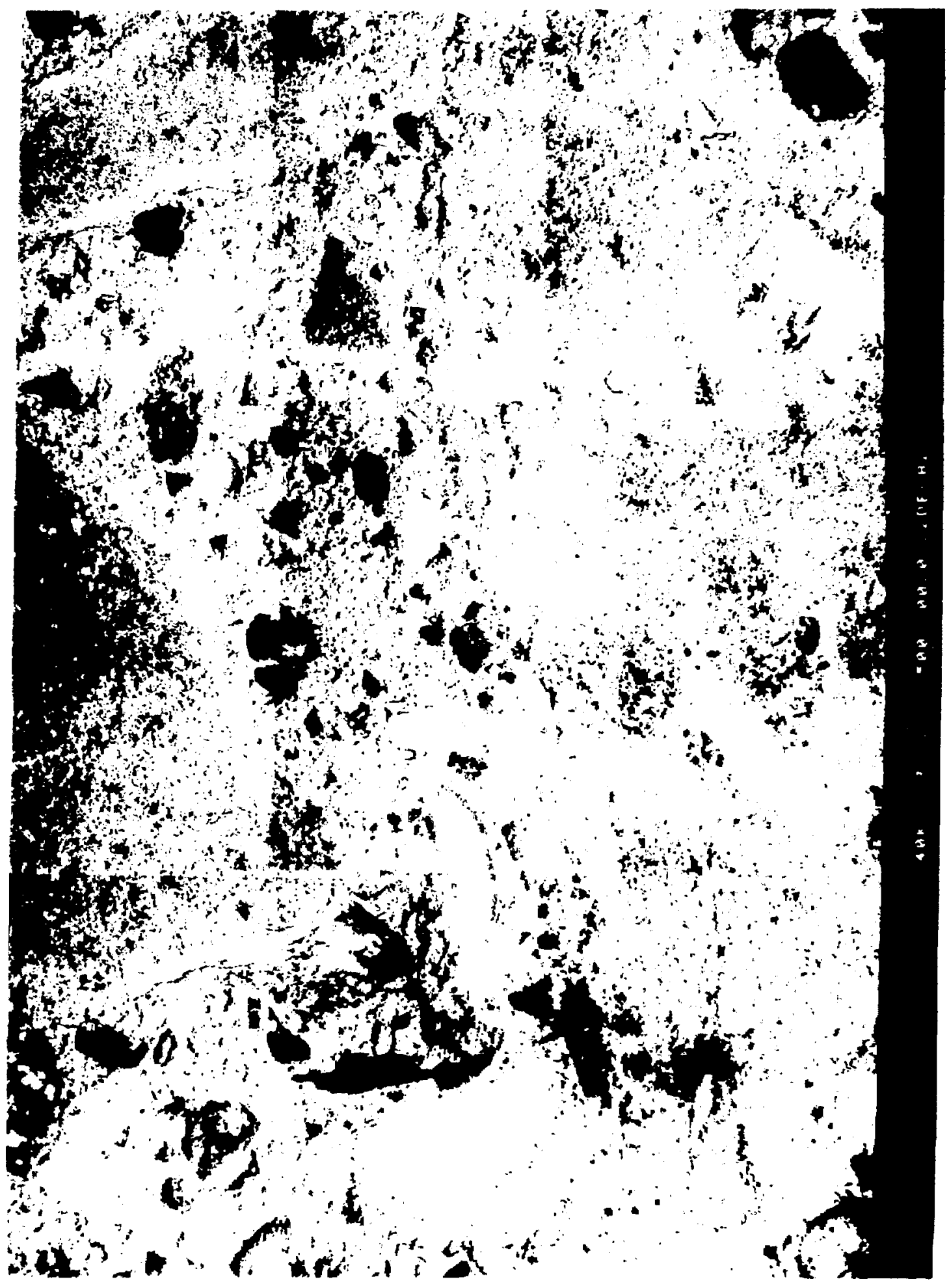

Fig. 20(a). An EBS photomosic of disc 2B bofore 1 month of hydrothemal treatment. 




Fig. 20(b). An EBS photomosaic of disc 2B after 1 month of hydrothermal treatment. 


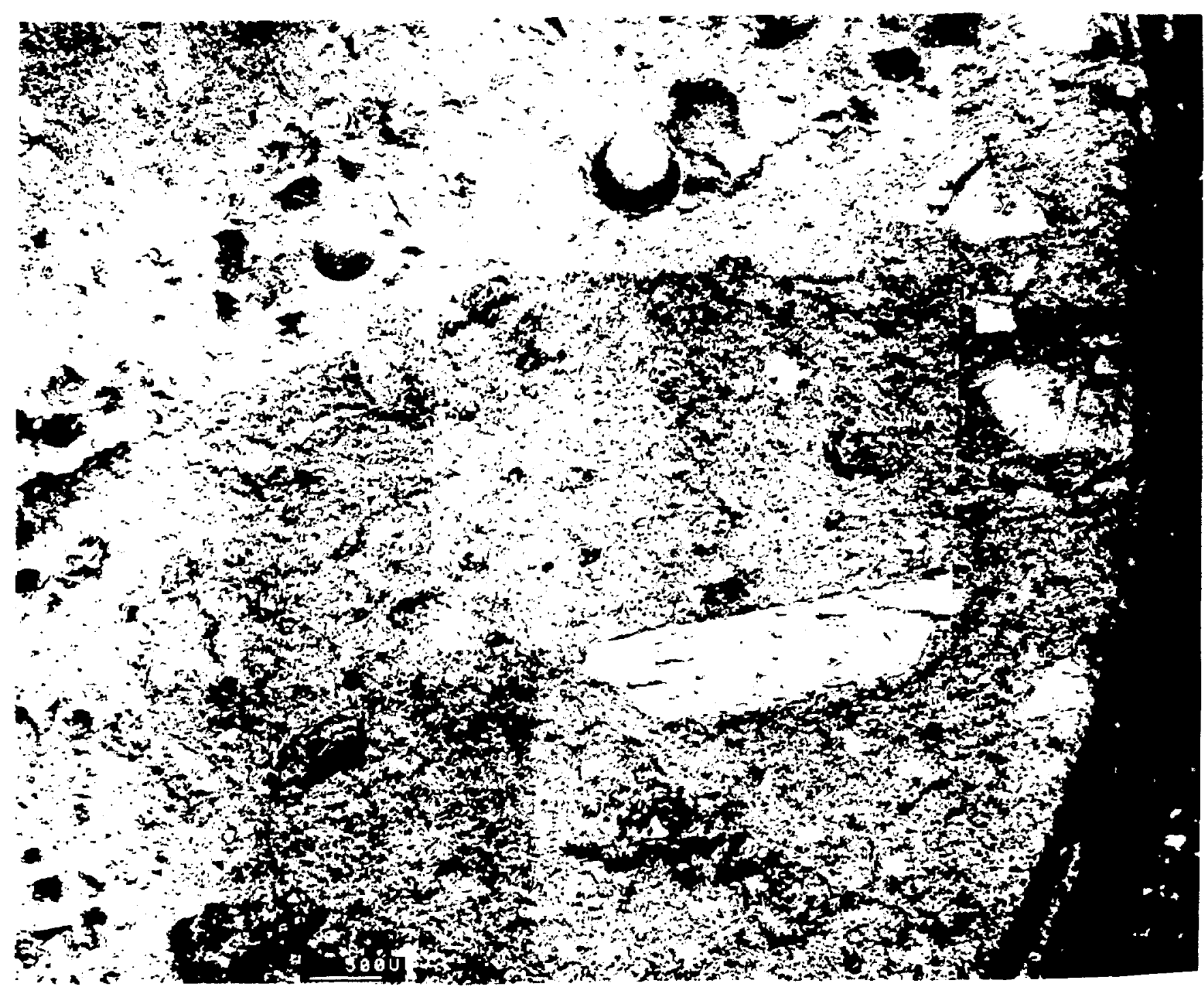

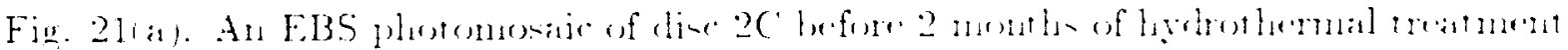




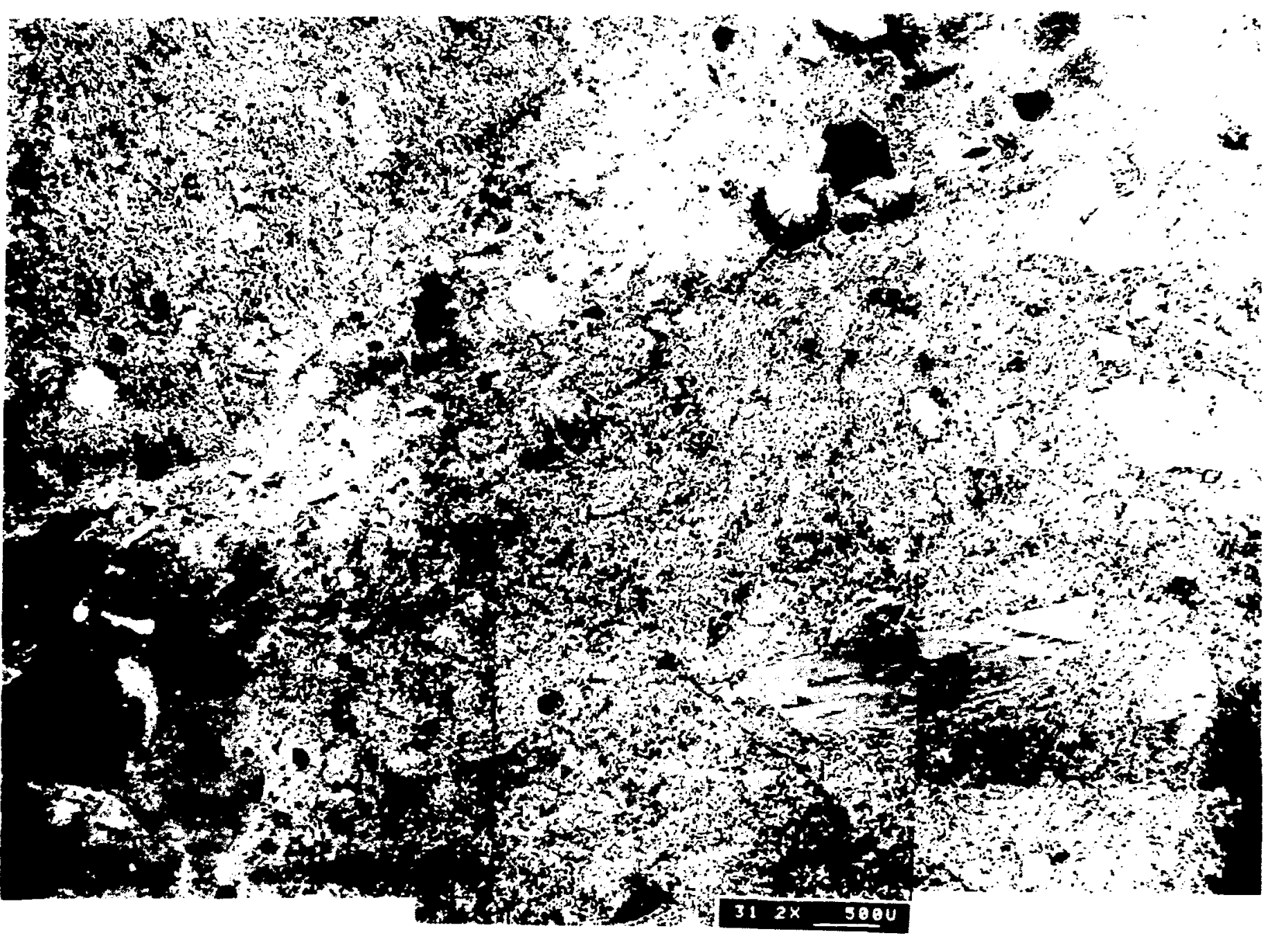

Fig. 21(b). An EBS plirtomositic of disc $2 C^{\prime}$ after 2 mont lis of hydrothemal treatment. 


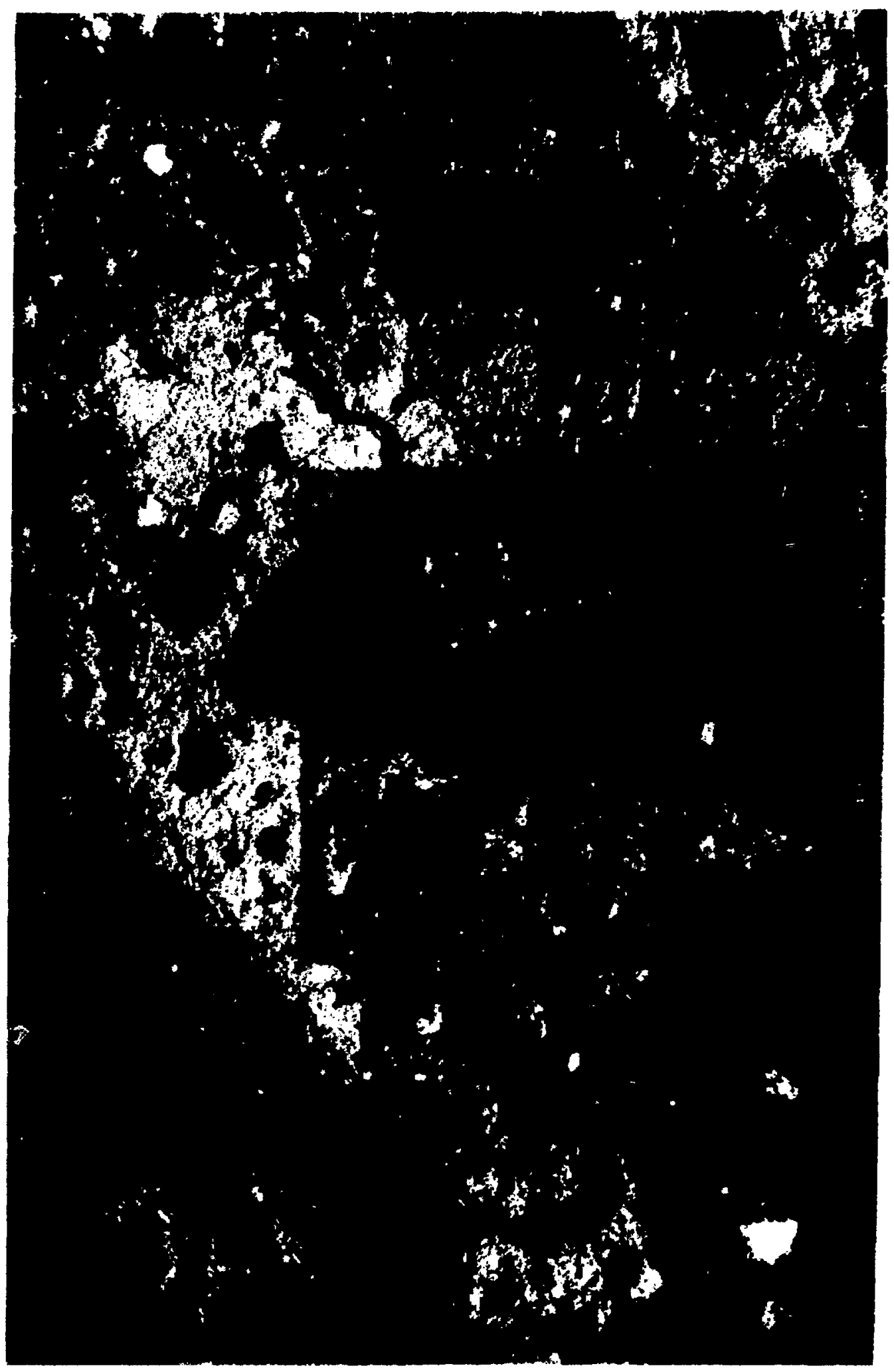

Fig. 22(a). An EBS photomosaic of disc 2D before 3 months of hydrothermal treatment. 


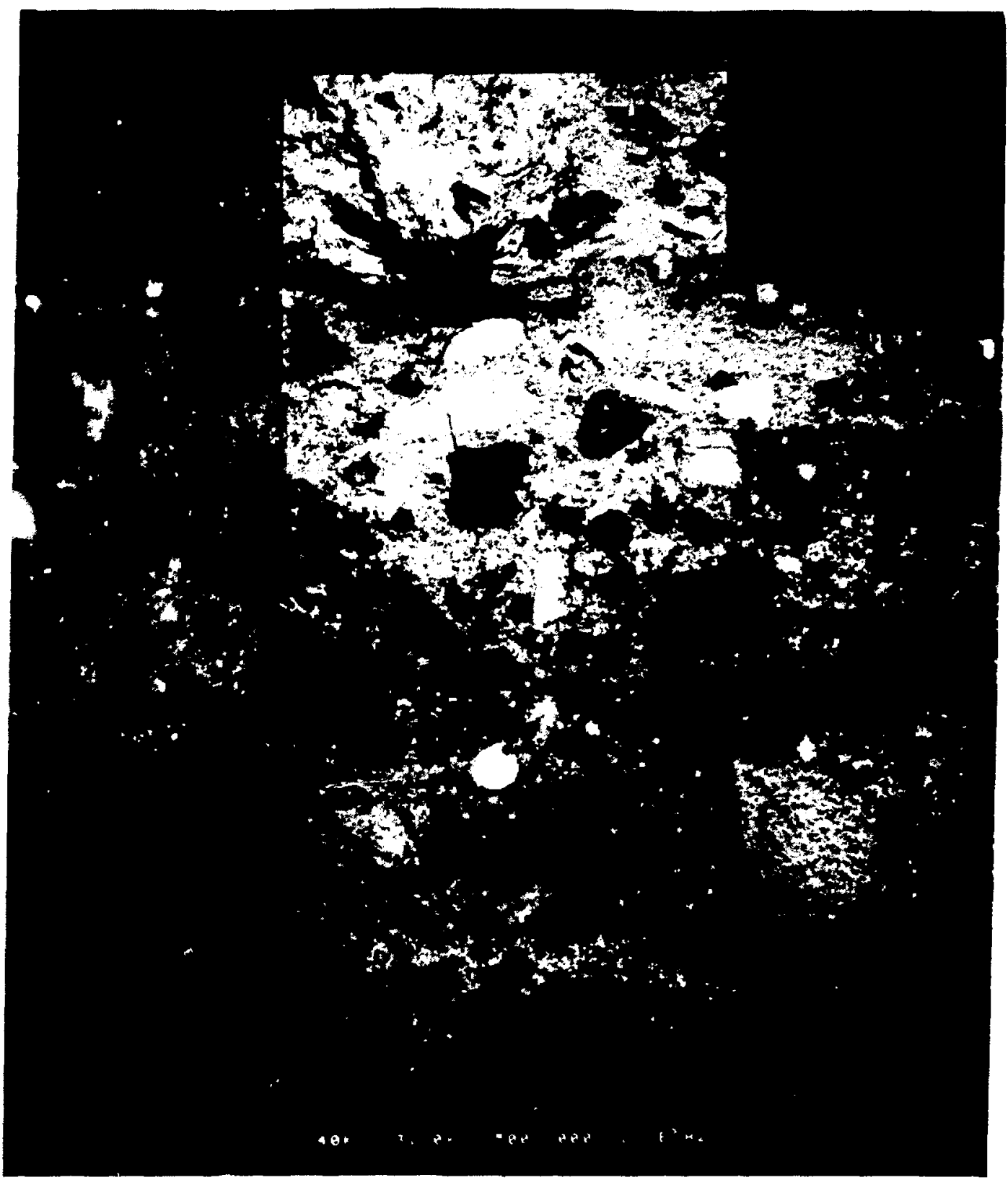

Fig. 23(a). An EBS photomosaic of disc 2A before $<4$ months of hydrothermal treatment. 


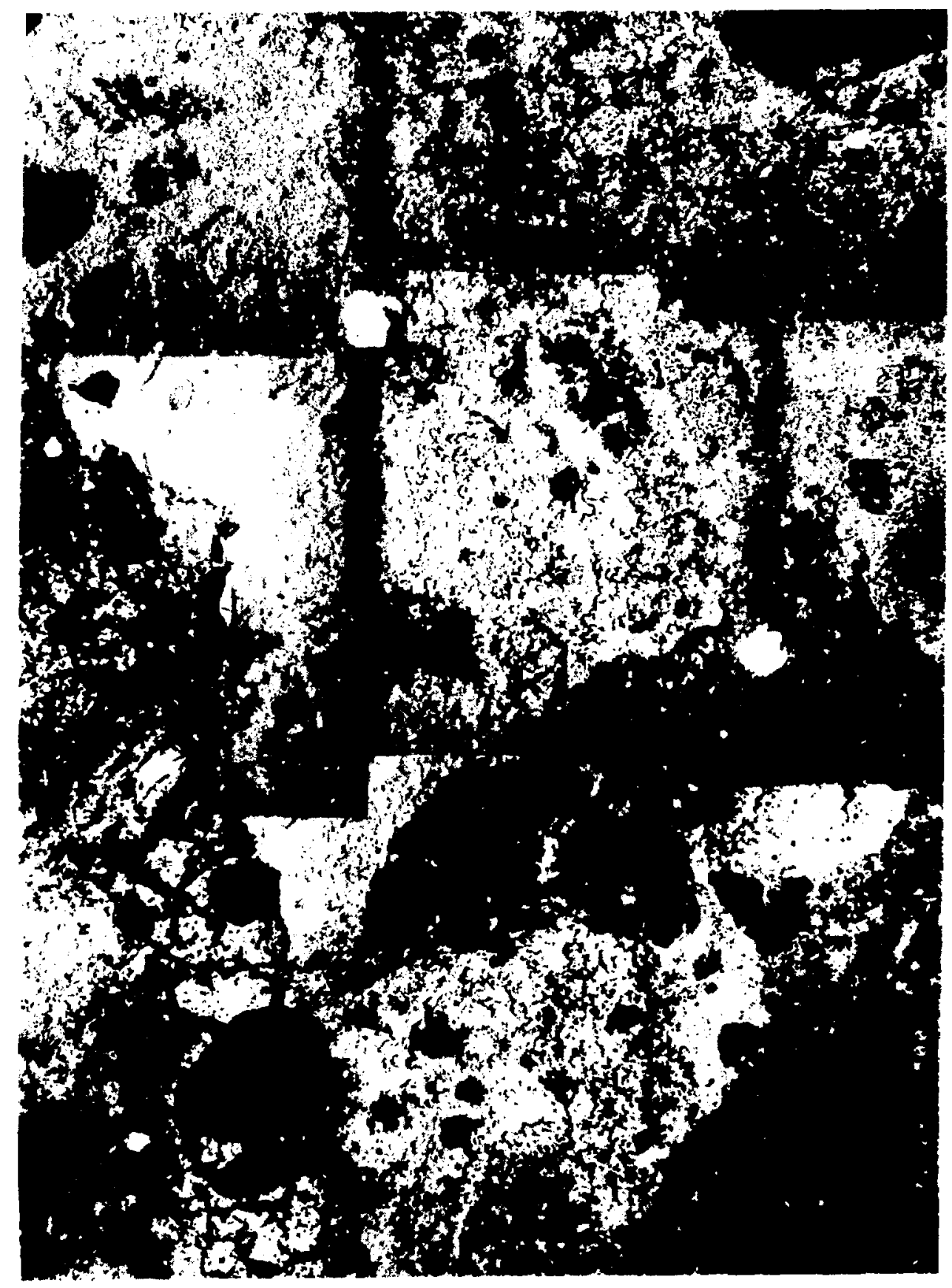

Fig. 23(b). An EBS photomosaic of disc $2 \mathrm{~A}$ after $<4$ months of hydrothermal treatment. 
The SEM/EDX analysis of the scale material on the three samples indicated that similar materials had formed on all of the samples but to varying extents. Extensive well-formed crystals of calcium sulfate are represented by the crystal in Fig. 24.

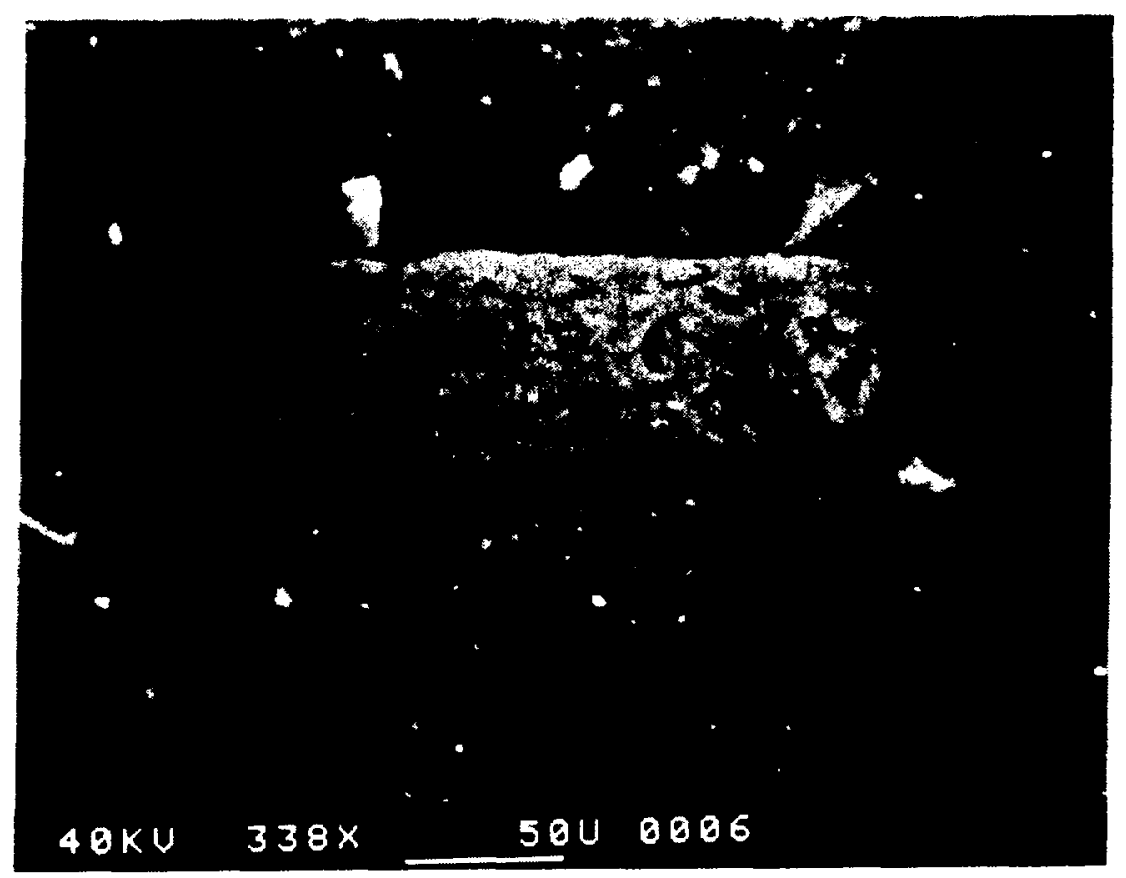

Fig. 24. An EBS image of calcium sulfate crystal from vapor phase experiments.

Satava and Veprek (1975) reported the decomposition of ettringite by hydrothermal differential thermal analyses (DTA) (pressure not specified) in the temperature interval between 190 and $280^{\circ} \mathrm{C}$ to produce anhydrite $\left(\mathrm{CaSO}_{4}\right)$ and hydrogarnet, $\mathrm{Ca}_{3} \mathrm{Al}_{2}(\mathrm{OH})_{12}$. Ogawa and Roy (1981) reported the reaction, under static conditions in contact with water at $\sim 200 \mathrm{psi}$, to take place at lower temperatures and to yield anhydrite and tetracalcium aluminate monosulfate hydrate. The presence of extensive amounts of euhedral crystals of anhydrite suggests that these crystals represent a recrystallization product from the decomposition of ettringite.

A number of other alteration products were observed in these overgrowths. These included an occasional cluster of crystals containing only iron, as detected by EDX, possibly siderite (Fig. 25), as suggested by the crystal morphology. Figure 26(a,b) shows the 
varied morphologies that developed in the alteration products on the discs. All of the morphologies represented in Fig. 26(b), with the exception of the spherical clusters, are calcium silicates in which the silicon signal is much more intense than the calcium; see Fig. 27. The spherical clusters in the center of Fig. 26(b) and the upper left-hand portion possess a similar chemistry but with the addition of minor potassium and subordinate amounts of aluminum. No positive phase identifications have yet been made for these clusters, although the entire mass of surface scale from sample $2 \mathrm{C}$ was removed and bulk $x$-ray diffraction attempted. The results of this analysis gave only an $\mathrm{x}$-ray amorphous diffractogram.

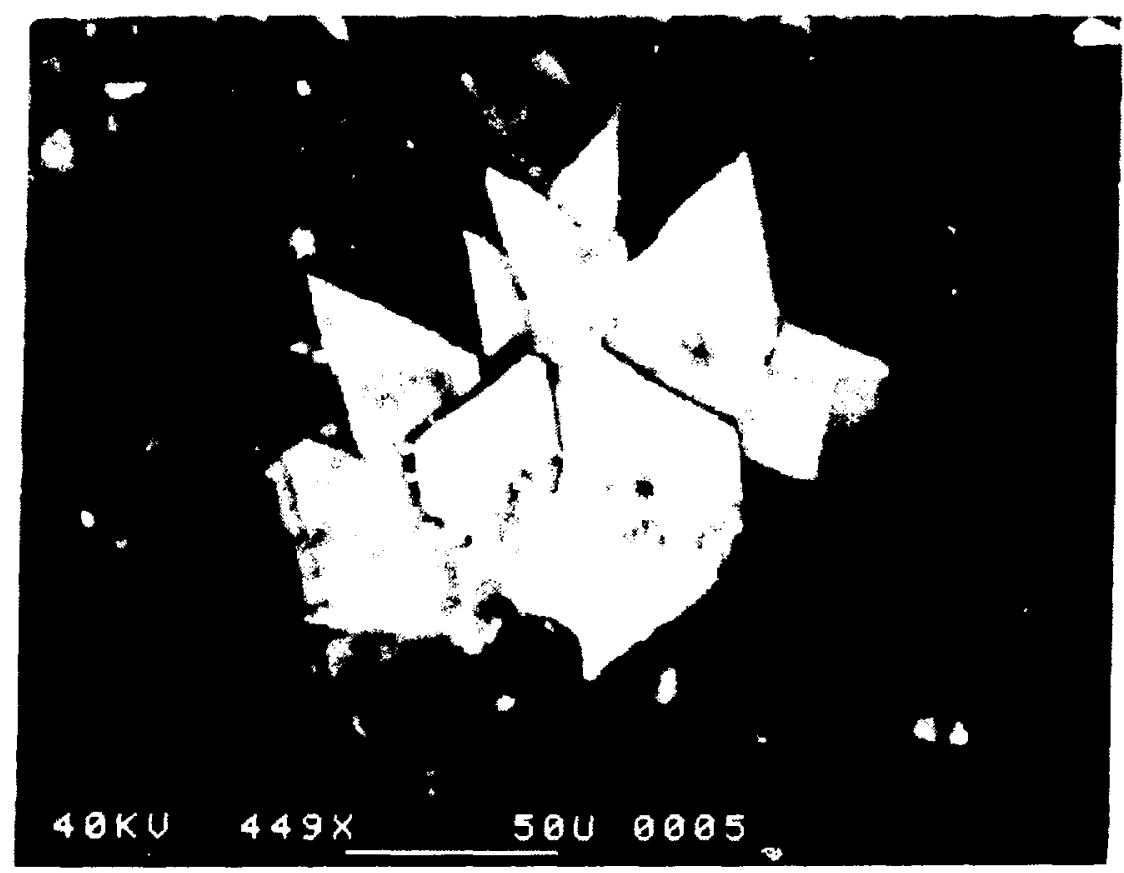

Fig. 25. An EBS image of a cluster of crystals rich in iron from vapor phase experiments.

A comparison can be made between those disc samples exposed to condensing vapors and those submerged in J-13 groundwater. The discs in the "vapor phase" experiments were exposed to a limited volume of leachate, which was initially distilled water. The highly undersaturated leachate would promotc rapid dissolution, the magnitude of which was limited by the amount of liquid water available and the proxtmity to an equilibrium 

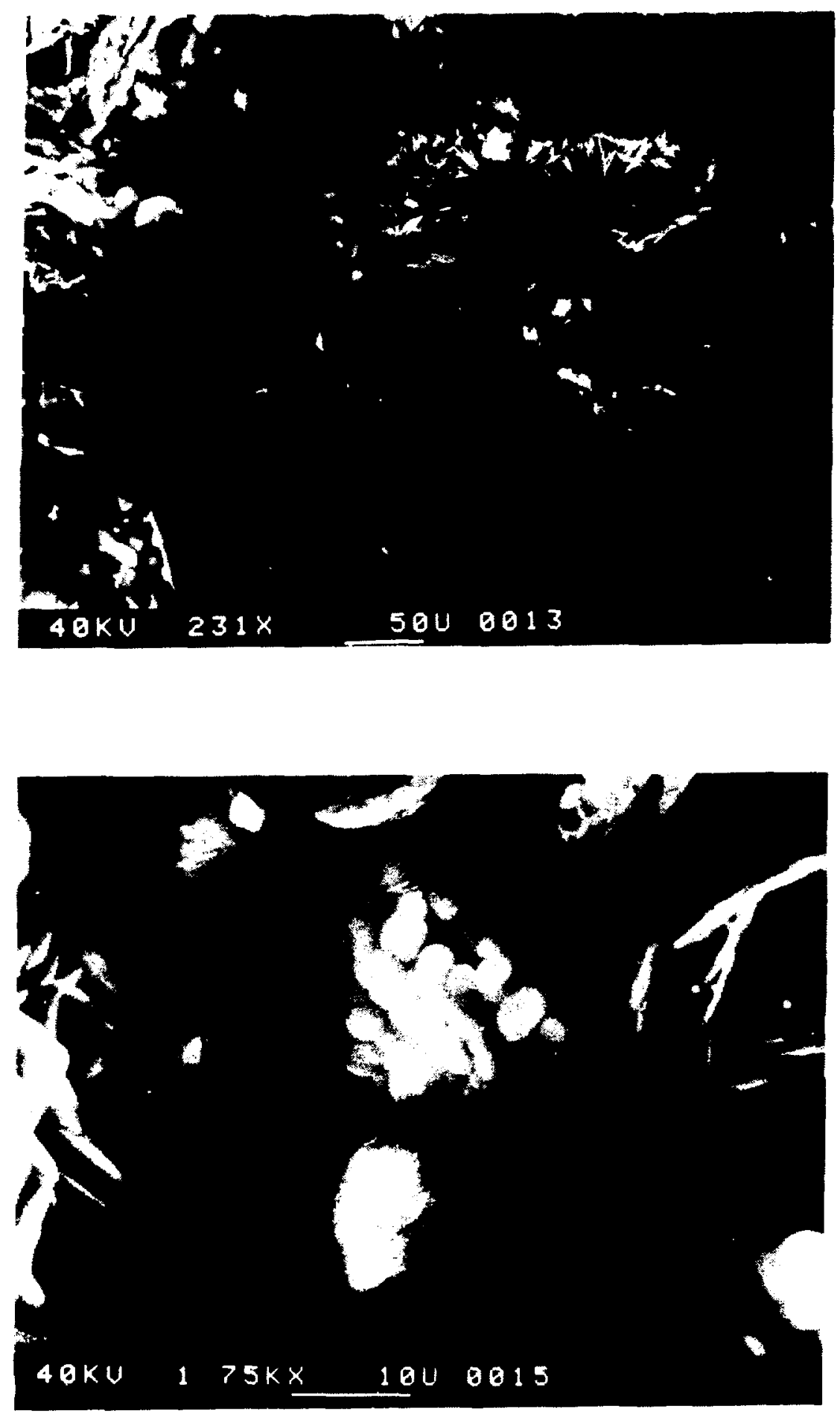

Fig. 26(a). An SEM image of crystal growth on surface of disc from vapor phase experiments. 

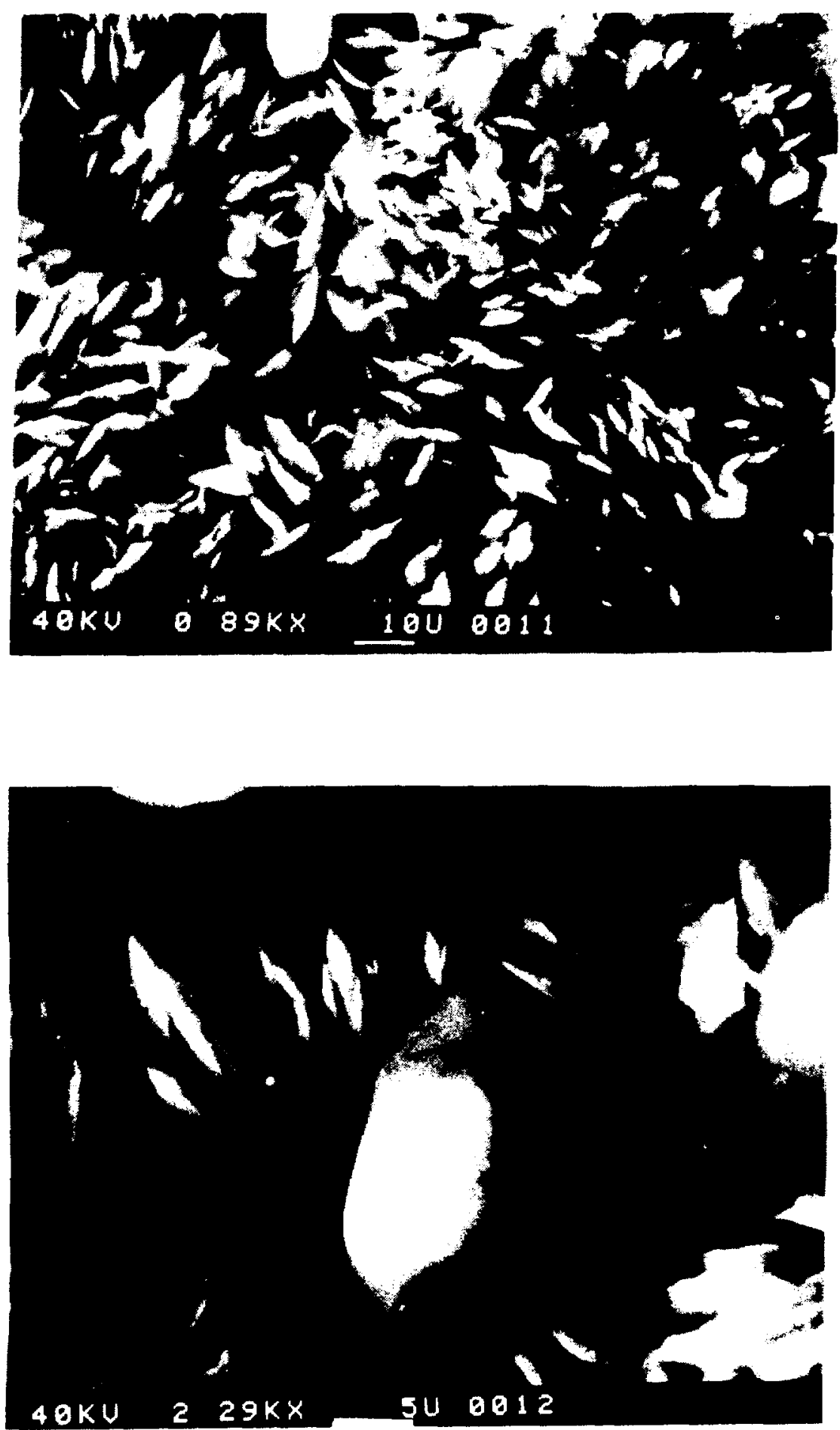

Fig. 26(b). An SEM image of calcium silicate crystal growth on surface of disc from vapor phase experiments. 


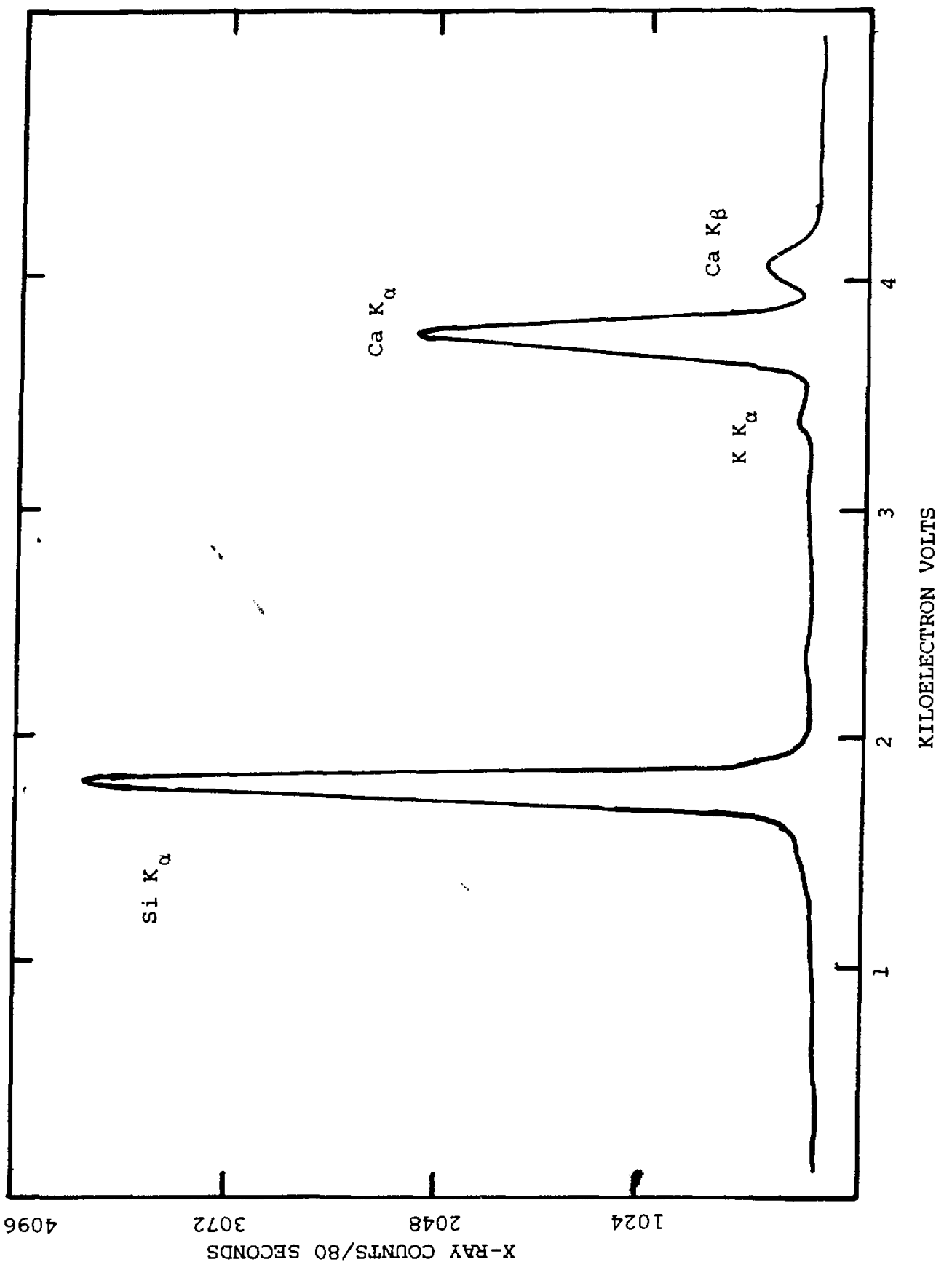

Fig. 27. Energy spectrum of crystals from Fig. 26(b). 
state. Although only an anorphous $x$-ray pattern was obtained from the surface scale, the morphology suggests that it was crystalline. The appearance of relatively large crystalline growths on the surface of these samples suggests growth from a solution at or alsove saturation, either from a thin film of concentrated solution or resulting from evaporation of droplets.

By contrast, those discs that were submerged in groundwater exhibited removal of material from the specimen by dissolution and clid not exhibit buildup of overgrowths. The macroscopic appearance of these two types of dises suggests extensive alteration of the latter type (exposed to vapor phase) even though more material was removed from the former type (submerged), because of the crusty buildup remaining on the surface of the vapor phase samples.

\section{CONCLUSIONS}

The detailed geochemical/hydrothermal experiments reported here show that reaction has taken place in the concrete tested under the elevated temperature conditions. While the specimens were not grossly damaged in periods of a few months, the results point to areas of concern. The vitreous component of the tuff may alter to produce unpredictable mechanical properties. In spite of the potential advantage of chemical compatibility between the tuffaccous concrete in general and the host rock, the enhanced chemical reactivity of glassy tuff components in the aggregate might result in changes in physical properties of the tuff that are difficult to predict. In contrast, a welded devitrified tuff would be more resistant to reaction.

Studies reported here suggest that alteration of the seal may occur in the unsaturated environment at elevated temperature. Because of the relatively small amount of leachant condensed on the disc in the vapor phase studies, less dissolution/alteration has occurred than in the parallel studies of immersed specimens.

The liydrothermal experiments using fine fraction crushed material achieved a more advanced state of alteration because of the acceleration caused by exposure of larger sample surface areas. The products contained crystalline calcium silicates, such as tobermorite, truscottite, or gyrolite, but the calcium sulfoaluminate hydrate, ettringite, was no longer 
present. The resultant phase assenblages do not directly correlate with those formed by "vapor pliase" growth experinents and those formed in the static liguid experinents. nor do the reported solution analyses correspond with the static and agitated reaction vessel runs. These results represent different data points in a continuum of water-tosolids ratios, for which the degree of saturation of the leaching fluid phase will control the reaction rate and the amount of matcrial removed from the solids. At low water/solid ratios and static condition, the leacling fluids will approach saturation very quickly with a subsequent reduction in the reaction rates and amount of material dissolved. In contrast, large water/solid ratios represent a departure from steady state (or equilibrium conditions) with more rapid reaction rate and the capacity to take larger amounts of material into solution. The results of stirred and rapilly agitated ressel experiments simulate longterm leaching or reaction with moving groundwater, while the "vapor phase" and coldseal studies represent reactions nearer those expected in a more static environment with limited access to groundwater. Both types of information are useful for bracketing possible repository exposure conditions and for making prudent selections of sealing materials.

The observations that ettringite, the matrix phase responsible for the expansion of the concrete, is unstable and decomposes to yield anlyydrite and an $x$-ray amorphous component at the high temperature has potential impact upon the stability of the seal. Initially; the transformation of ettringite would cause the release of sulfate to the groundwater, which has a relatively low concentration of sulfate and causes an imbalance in the chemical activity between the concrete, rock, and the groundwater. This would enhance the potential for alteration of the concrete/rock seal system and might increase permeability, although the rate and full consequences of such reaction are not known.

Additionally, the alteration at elevated temperatures of ettriagite (tetracalcium aluminate trisulfate hydrate) to tetracalcium aluminate monosulfate hydrate and anhydrite (calcium sulfate) plus water may result in the development of increased porosity. The magnitude of this por sity increase could be as much as $40-50 \%$ of the initial rolume of ettringite present. If the total ettringite $(<3-5 \%$ of the concrete) decomposed, it could develop up to $2.5 \%$ additional porosity (or greater if it were leached out). It is possible that ettringite formed in concrete as a three-dimensional growth of needle- 
like crystals would result in intercomected porosity, which could serve as a conduit for fluid transfer through the seal. The concrete discs in the present study actually appear sound macroscopically after hychrothermal treatnent. with no apparent development of catastrophic failure mechanisms during the course of the geoclenical tests. Detailed mechanical properties studies would be necessary to deternine the actual naginitude of the observed alteration and its mechanical consequences.

The alteration data that were collected from these experiments support a model for the dissolution of the sealant that involves a two-step process, one for which the contacting leachates are removing cations (anions) from the scalant bot $h_{1}$ by a diffusional mechamism from the interior of the solid to the surface and from surface removal of the sealant in such a fashion that the surface area of the sealant is continually changing.

\section{ACKNOWLEDGEMENTS}

Assistance of S. Komarneni, L. D. Wakeley, and D. Cattell in this research is gratefully acknowledged. These studies were supported by the Nevada Nuclear Waste Storage Investigations Project, which is managed by the Waste Management Project Office of the US Department of Energy:

\section{REFERENCES}

A. A. Ballman and R. A. Laudise, "Hydrothermal Growth," in The Art and Science of Growing Crystals, J. J. Gilman, Ed. (John Wiley and Sons, New York, 1963).

J. A. Fernandez and S. Wong, "Evaluation of Concrete L'sing Tuff as a Coarse Aggregate for the NNWSI Repository Sealing Program," Sandia National Laboratories report SANDST1374 (in preparation).

M. Fleischer, Glossary of Mineral Species (The Mineral Record, Inc., Tucson, Arizona, 19S3).

S. Fomarneni, D. M. Roy, and R. Roy, "Al-Sulsstituted Tobermorite: Shows Cation Exchange," Cem. Concr. Res. 12, 773-780 (19:2).

K. Ogawa and D. M. Roy, " $\mathrm{C}_{4} \mathrm{~A}_{3} \overline{\mathrm{S}}$ Hydration, Ettringite Formation, and Its Expansion Mechanism: I. Expansion; Ettringite Stability;" Cem. Concr. Res. 11, T41-750 (1981). 
G. L. Richardson, "The Phantom Dissolution Leach Model," Nuel. Chem. Waste Manage. 2, 237-241 (1981).

D. M. Roy, C. A. Langton, M. W. Grutzeck, and E. L. White, "Hydrothermal High Temperature Cements for Potential Geothermal Applications," SPE International Symposium on Oilfield and Geothermal Chemistry, May 28-30, 1980, Paper No. 8994, pp. $18 \bar{\imath}-198$.

V. Satava and O. Veprek, "Thermal Decomposition of Ettringite under Hydrothermal Conditions," J. Am. Ceram. Soc. 58, 357-350 (1975).

B. E. Scheetz, "Characterization of the Physical Parameters and Sampling Procedure of a Modifed Rocking Autoclave Apparatus," Rockwell report RHO-BWI-G-65. Rockwell International, Richland, Washington (April 1980).

B. E. Scheetz, D. W. Strichler, M. W. Grutzeck, and D. M. Roy, "Physical and Chemical Behavior of Selectively Etched Fly Ashes," S. Diamond, Ed., in Proceedings, Symposium N, Effects of Fly Ash Incorporation in Cement and Concrete, 1981 (Materials Research Society, Secretariat, 110 Materials Research Laboratory, University Park, PA 16802, 1982), pp. 24-33. 


\section{APPENDIX A}

Chemical Analysis of Three Tuff Samples 


\section{CHEMICAL ANALYSIS OF THREE TUFF SAMPLES}

(by Waterways Experiment Station)

Sample CL-40G

Oxides and

Ignition Loss ${ }^{a}$

(\%)

$-1 \quad-1 b \quad \begin{gathered}\text { Analysis } \\ -1 \mathrm{c}\end{gathered}$

Method $^{b}$

$\mathrm{Fe}_{2} \mathrm{O}_{3}$

$\mathrm{Na}_{2} \mathrm{O}$

3.17

2.90

3.38

3.84

3.50

1.76

AA

$\mathrm{K}_{2} \mathrm{O}$

6.10

5.38

5.51

$A A$

0.05

0.04

0.23

A.A

$\mathrm{MgO}$

71.15

73.50

64.03

AA

$\mathrm{SiO}_{2}$
$\mathrm{Al}_{2} \mathrm{O}_{3}$

12.70

11.94

13.65

0.19

0.15

0.19

Gravimetric

$\mathrm{Mn}_{2} \mathrm{O}_{3}$

0.35

0.34

0.48

Plasma

Plasma

$\mathrm{TiO}_{2}$

0.35

0.32

4.34

Plasma

$\mathrm{CaO}$

0.03

0.03

0.03

Plasma

$\mathrm{BaO}$

$\mathrm{SrO}$

$\mathrm{P}_{2} \mathrm{O}_{5}$

$<0.01$

$<0.01$

0.01

Plasma

0.05

0.06

0.09

Plasma

Ignition Loss

0.66

0.66

6.49

Total

98.64

98.82

100.19

${ }^{a}$ Included determination for $\mathrm{SO}_{3}$ but none was detected.

${ }^{b} \mathrm{AA}=$ atomic absorption; plasma = plasma emission. 


\section{APPENDIX B}

XRD Pattern of CL-40 CON-14 Before Geochemical Testing 


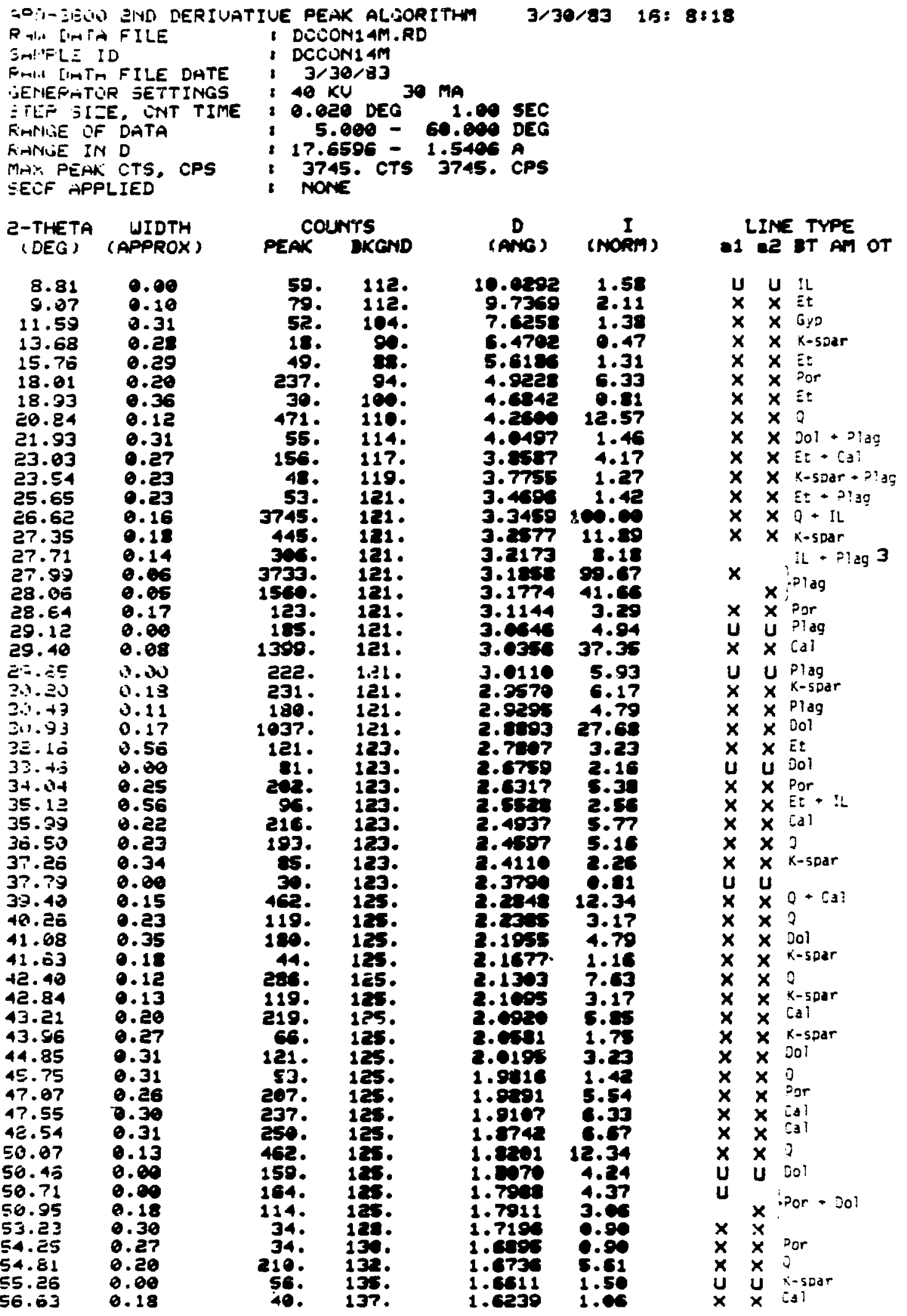




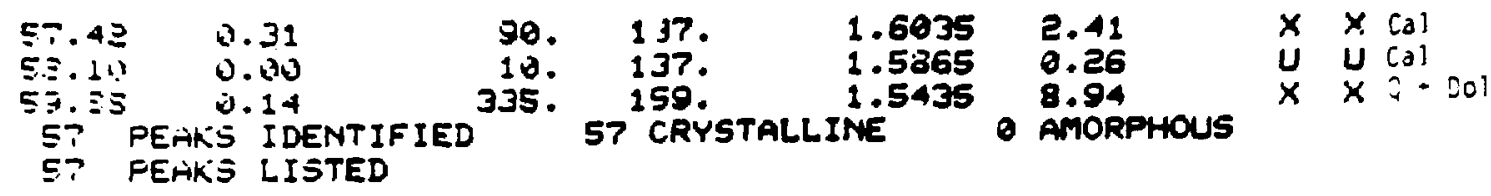

Key to Phases

\begin{tabular}{lll} 
Phase & PDF No. & Abbrev. \\
\cline { 2 - 2 } orthoclase & $19-1227$ & K-spar \\
plagioclase & $20-548$ & Plag \\
illite & $24-495$ & IL \\
Calcite & $5-586$ & Cal \\
dolomite & $11-078$ & Dol \\
ettringite & $9-414$ & Et \\
portlandite & $25-144$ & Por \\
quartz & $5-490$ & 0 \\
gypsum & $6-46$ & Gyp
\end{tabular}

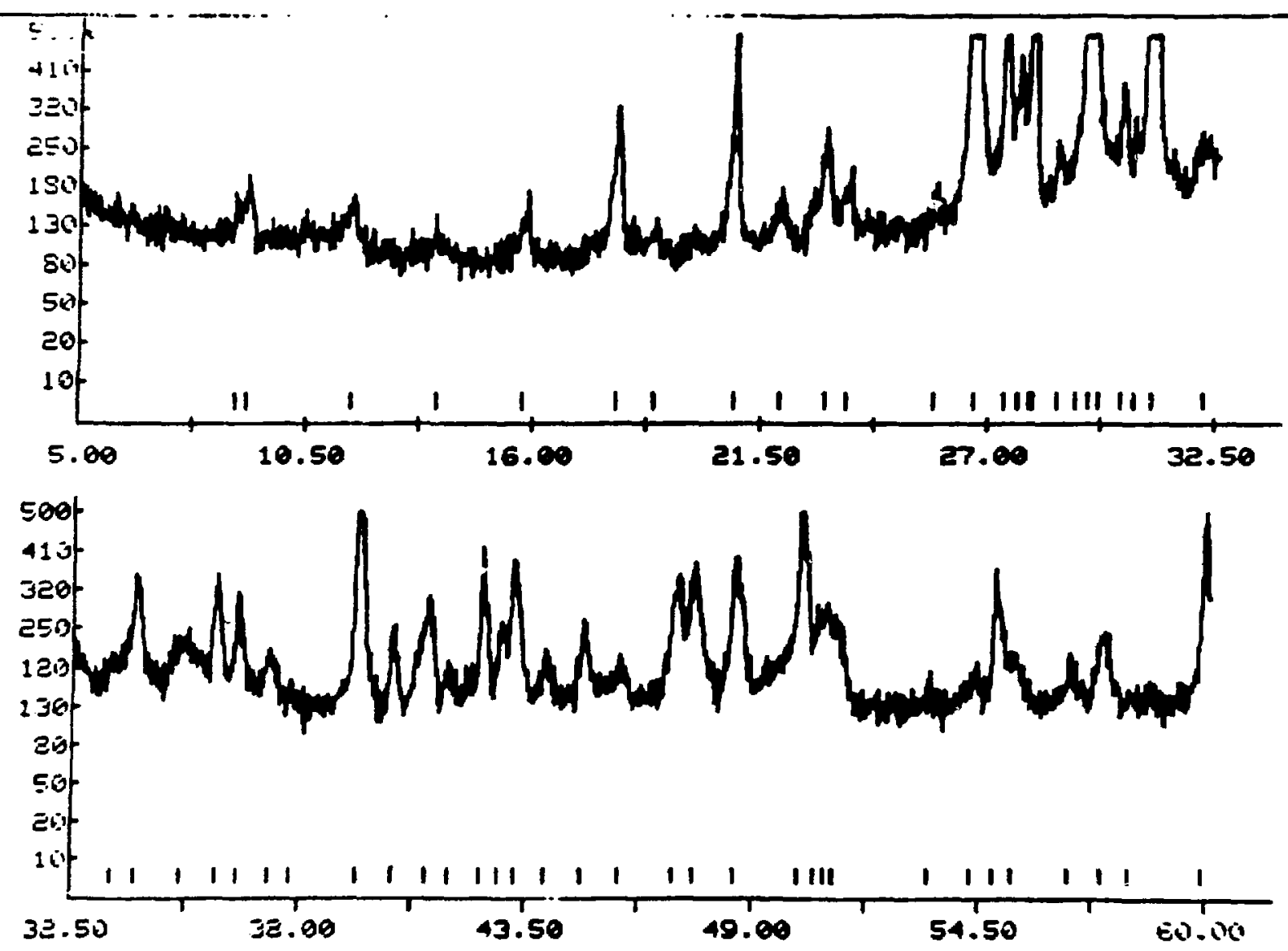




\section{APPENDIX C \\ XRD of CL-40 CON-14 After Geochemical Testing DCLASLT1 (LANL-T-1), 76 hours, Rocking Autrrlave}




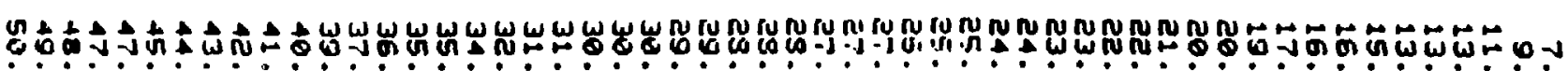

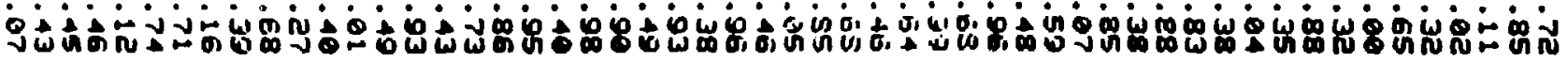

000000000000000000000000000000000000000000000000000000 ding 8 क w

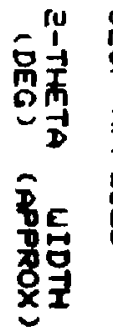

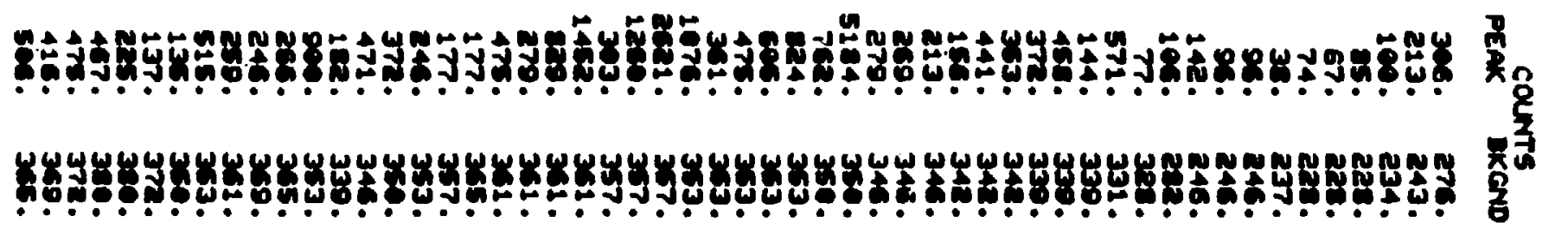

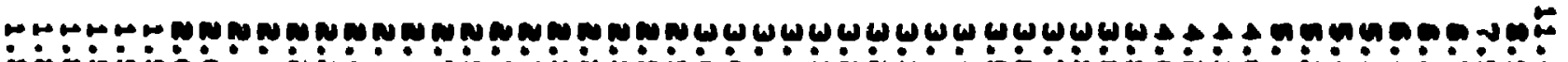

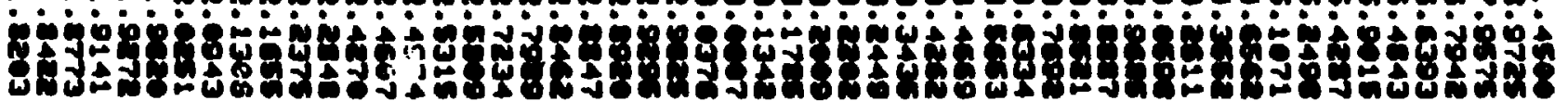

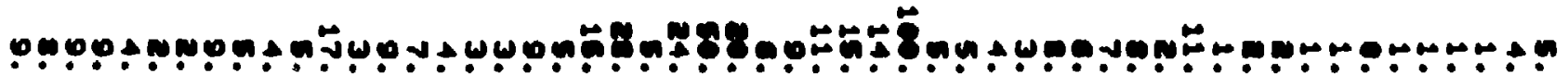
J日

\section{恿}
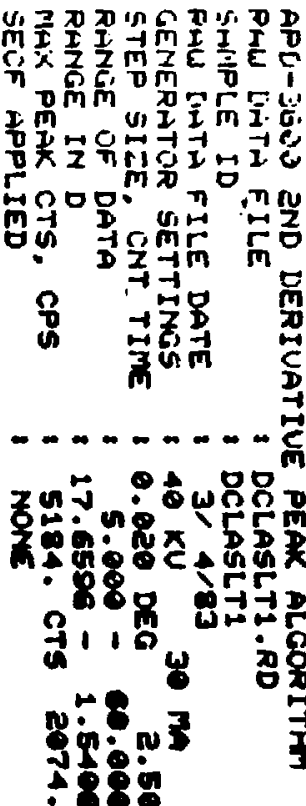

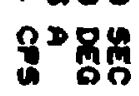

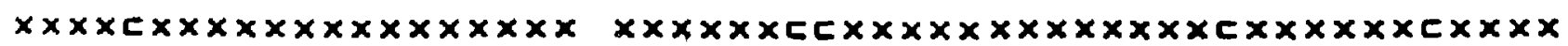

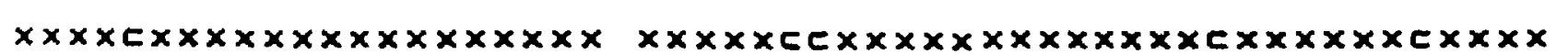

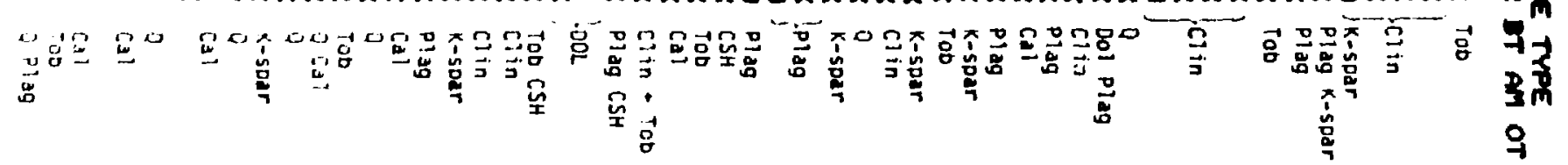




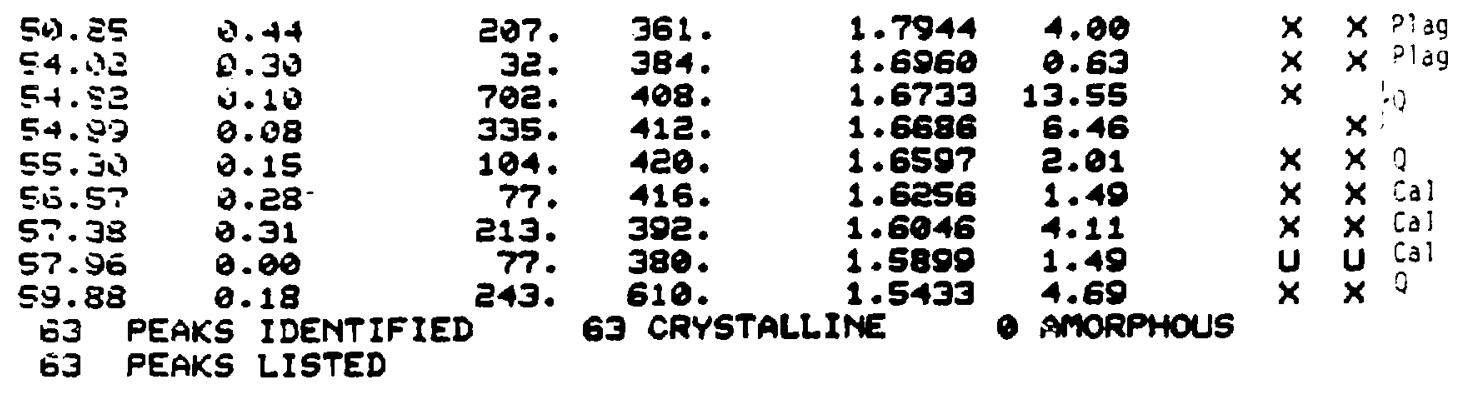

Key to Phases

$\begin{array}{lll}\text { Phase } & \text { POF No. } & \text { Abbreviation } \\ \text { quartz } & 5-490 & \\ \text { Clinoptilolite } & 25-1349 & \text { Clin } \\ \text { calcite } & 24-27 & \text { Cal } \\ \text { plagioclase } & 20-548 & \text { Plag } \\ \text { tobermorite } & 19-1364 & \text { Tob } \\ \text { CSH } & 29-374 & \text { CSH } \\ \text { orthoclase } & 19-1227 & \text { K-5par } \\ \text { dolomite } & 11-78 & \text { Dol }\end{array}$

T:.EHAI!E: LNLASLT1.RD SAMPLE! D:LASLT1 3/4/83

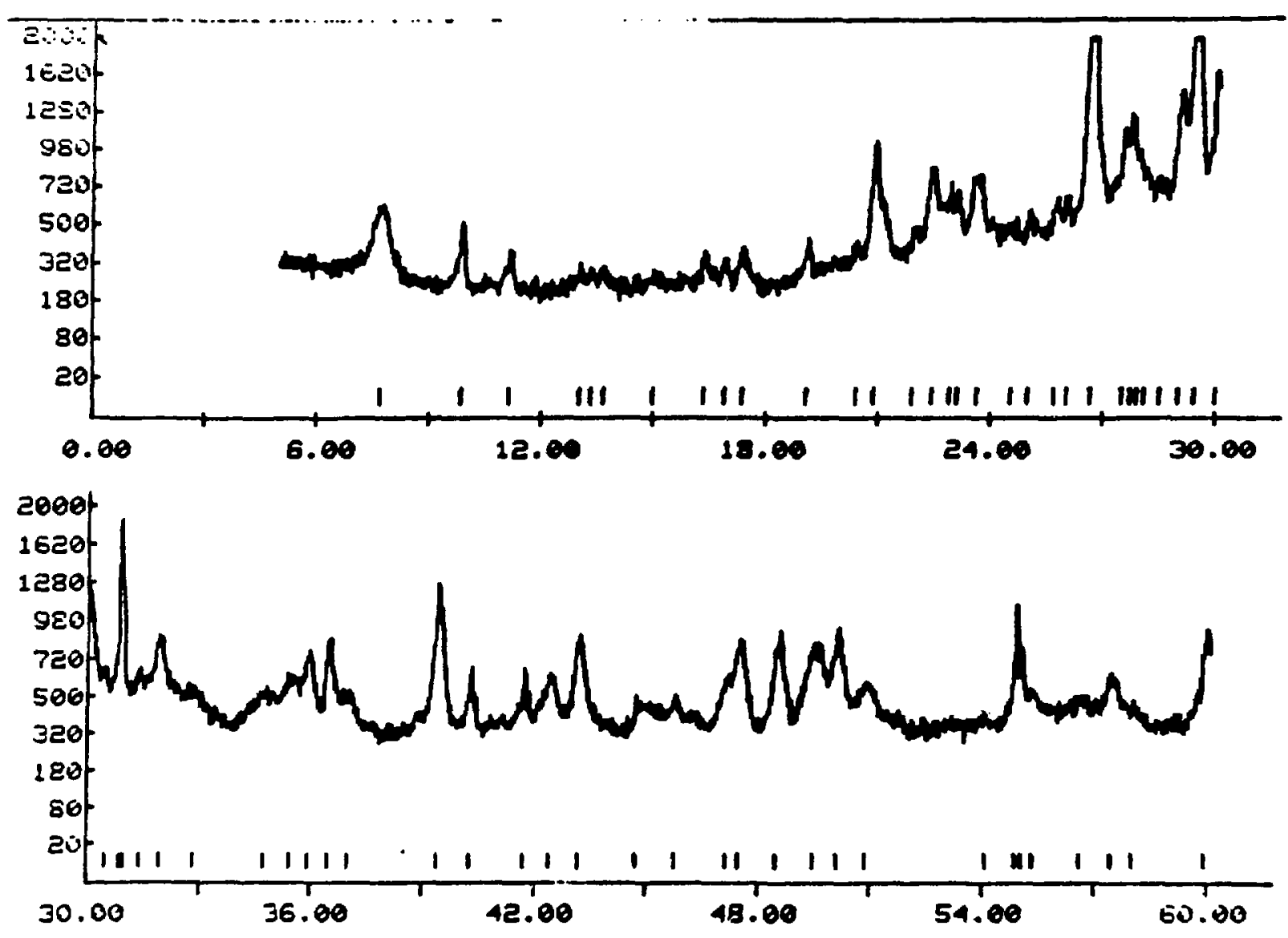




\section{APPENDIX D}

X-ray Data (Energy-Dispersive Counts) for Chemical Profile Across Surface of Starting Material (CON-14) 


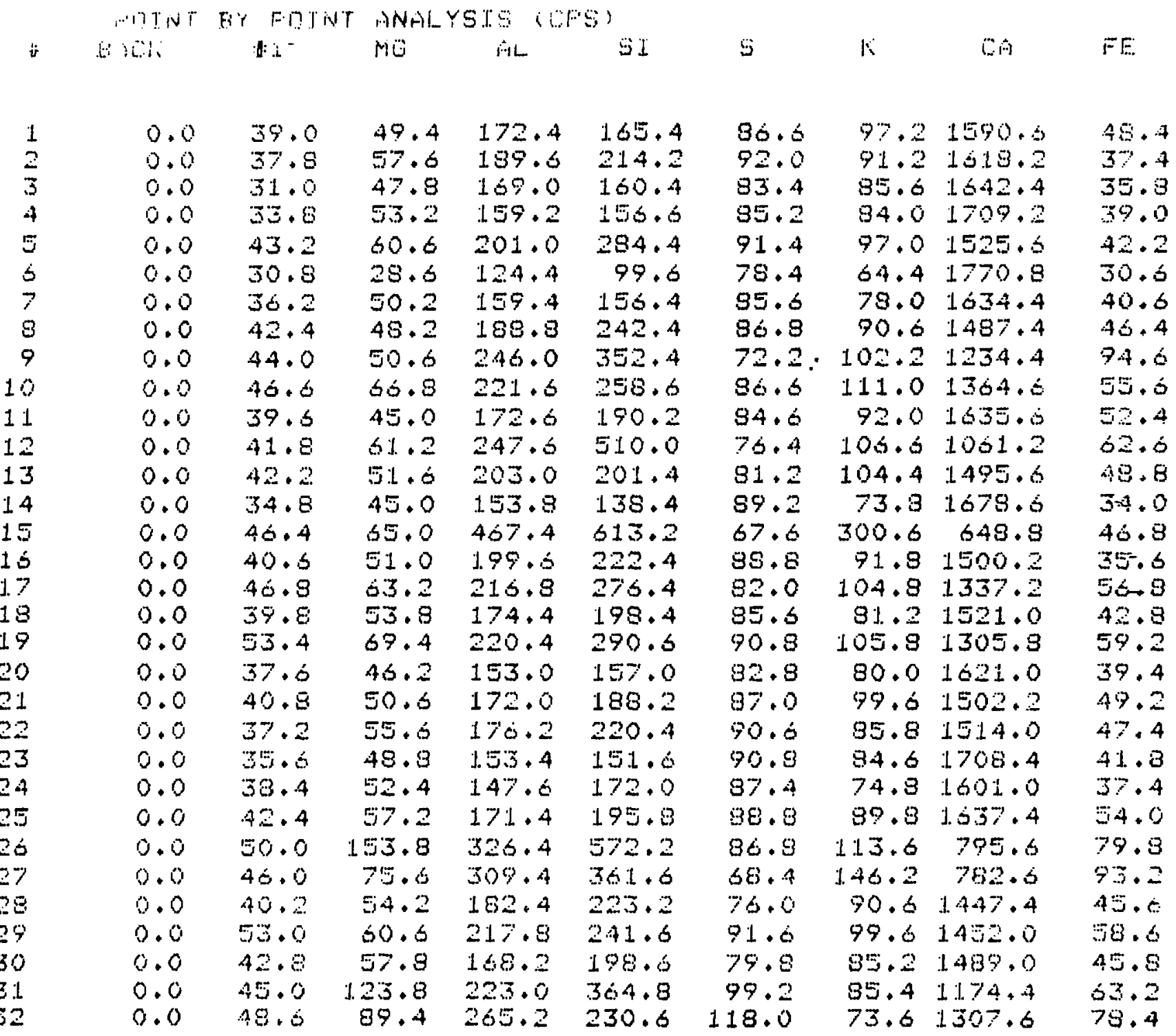

FARMS. FOF THIS FUN:

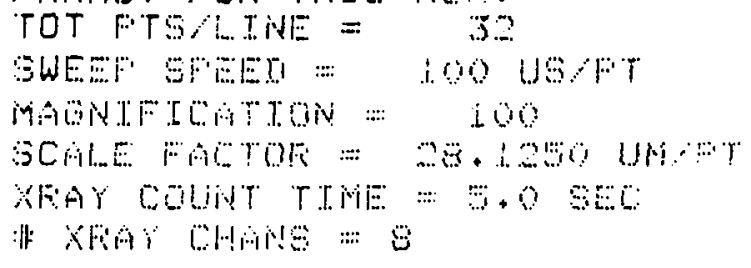




\section{APPENDIX E}

$\mathrm{X}$-ray Data (Energy-Dispersive Counts) for Representative

Chemical Profile Through Disc 1A Treated Hydrothermally for 1 Week 


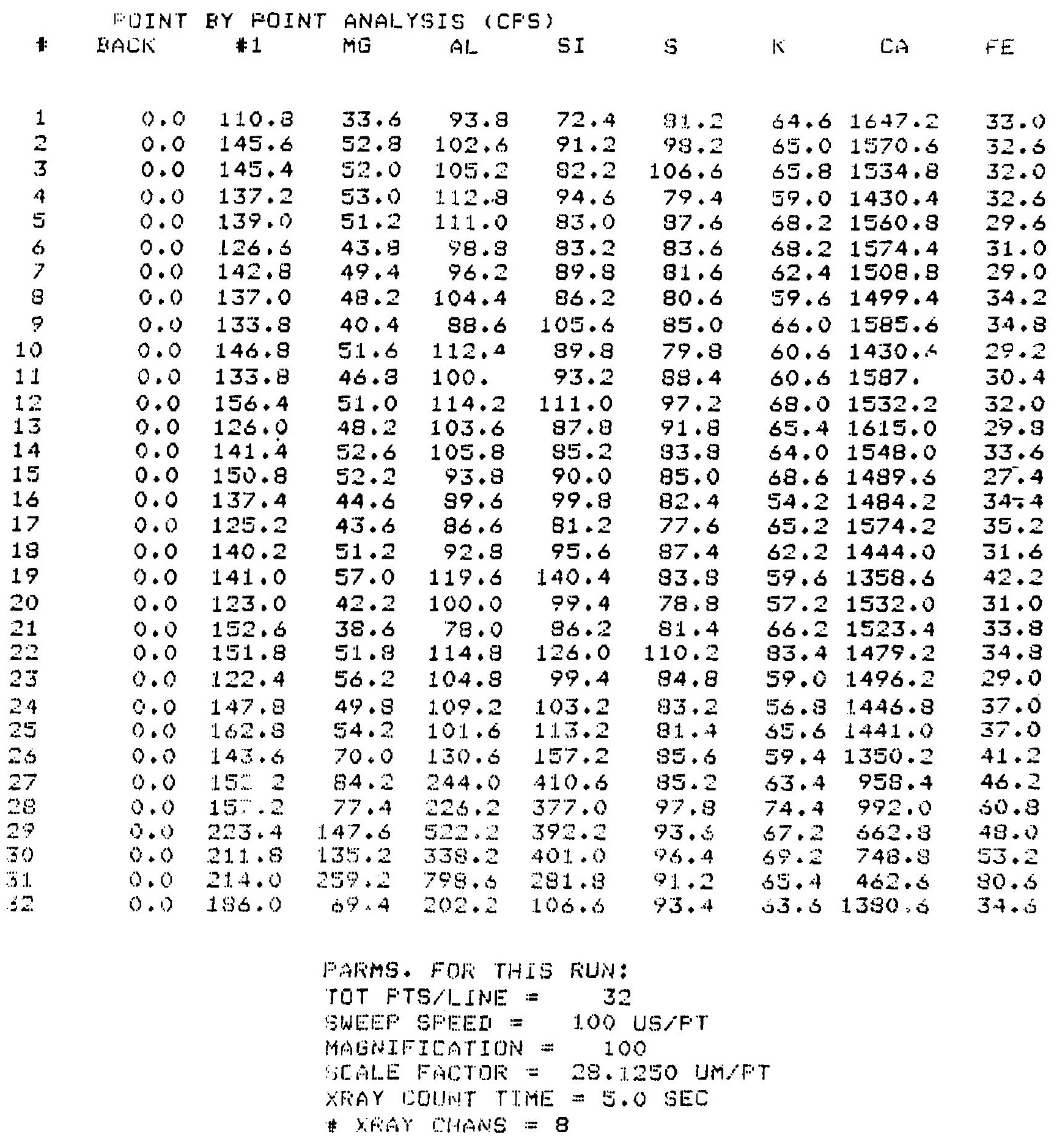




\section{APPENDIX F}

$\mathrm{X}$-ray Data (Energy-Dispersive Counts) for Representative Chemical Profile Through Disc 1D Treated Hydrothermally for $>4$ Weeks 


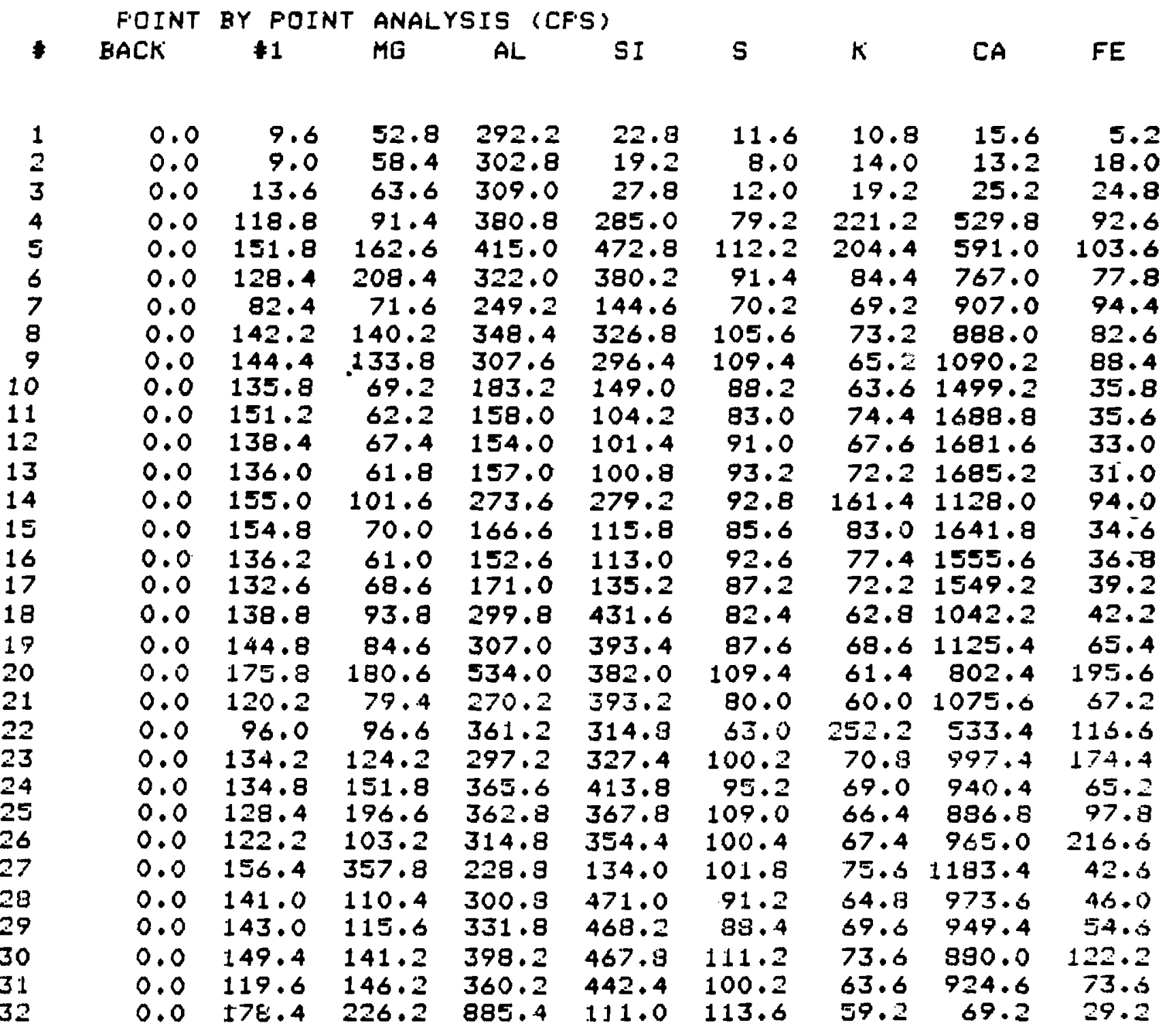

PARMS. FOF THIS RUN:

TOT F'TS/LINE = 32
SWEEF SFEEII $=100$ US/F'T
MAGNIFICATION $=100$
SCALE FACTOF $=28.1250 \mathrm{UM} / \mathrm{F} \cdot \mathrm{T}$
XFAY COUNT TIME $=5.0 \mathrm{SEC}$
XFAY CHANS $=8$


APPENDJX G

Symbols and Formulas 
TABLE G-1

CEMENT CHEMIST NOTATION

$$
\begin{aligned}
\mathrm{C} & =\mathrm{CaO} \\
\mathrm{S} & =\mathrm{SiO}_{2} \\
\mathrm{H} & =\mathrm{H}_{2} \mathrm{O} \\
\mathrm{F} & =\mathrm{Fe}_{2} \mathrm{O}_{3} \\
\mathrm{~N} & =\mathrm{Na}_{2} \mathrm{O} \\
\mathrm{K} & =\mathrm{K}_{2} \mathrm{O} \\
\overline{\mathrm{C}} & =\mathrm{CO}_{2} \\
\overline{\mathrm{S}} & =\mathrm{SO}_{3}
\end{aligned}
$$

TABLE G-2

IDEALIZED CHEMICAL FORMULAS FOR MINERAL

$$
\text { AND RELATED CEMENTITIOUS PHASES }{ }^{a}
$$

$$
\begin{aligned}
& \mathrm{C}_{2} \mathrm{~S} \quad=\mathrm{Ca}_{2} \mathrm{SiO}_{4} \\
& \mathrm{C}_{3} \mathrm{~S} \quad=\mathrm{Ca}_{3} \mathrm{SiO}_{5} \\
& \text { C-S-H = poorly crystalline hydrous calcium silicate } \\
& \text { Ettringite } \quad=\mathrm{Ca}_{6} \mathrm{Al}_{2}\left(\mathrm{SO}_{4}\right)_{3}(\mathrm{OH})_{1} 2 \cdot 26 \mathrm{H}_{2} \mathrm{O} \\
& \text { Portlandite } \quad=\mathrm{Ca}(\mathrm{OH})_{2} \\
& \text { Quartz }=\mathrm{SiO}_{2} \\
& \text { Brownmillerite }=\mathrm{Ca}_{4} \mathrm{Al}_{2} \mathrm{Fe}_{2} \mathrm{O}_{10} \\
& \text { Calcite } \quad=\mathrm{CaCO}_{3} \\
& \text { Anhydrite } \quad=\mathrm{CaSO}_{4} \\
& \text { Gypsum } \quad=\mathrm{CaSO}_{4} \cdot 2 \mathrm{H}_{2} \mathrm{O} \\
& \text { Periclase } \quad=\mathrm{MgO} \\
& \text { Illite } \quad=\left(\mathrm{K}, \mathrm{H}_{3} \mathrm{O}\right)(\mathrm{Al}, \mathrm{Mg}, \mathrm{Fe})_{2}(\mathrm{Si}, \mathrm{Al})_{4} \mathrm{O}_{10}\left[(\mathrm{OH})_{2}, \mathrm{H}_{2} \mathrm{O}\right] \\
& \text { Chamosite }=\left(\mathrm{Fe}^{+2}, \mathrm{Mg}, \mathrm{Fe}^{+3}\right)_{5} \mathrm{Al}\left(\mathrm{Si}_{3} \mathrm{Al}\right) \mathrm{O}_{10}(\mathrm{OH}, \mathrm{O})_{8} \\
& \text { Orthoclase } \quad=\mathrm{KAlSi}_{3} \mathrm{O}_{8} \\
& \text { Dolomite } \quad=\mathrm{CaMg}\left(\mathrm{CO}_{3}\right)_{2} \\
& \text { Magnetite } \quad=\mathrm{Fe}_{3} \mathrm{O}_{4} \\
& \text { Heulandite }=(\mathrm{Na}, \mathrm{Ca})_{2-3} \mathrm{Al}_{3}(\mathrm{Al}, \mathrm{Si})_{2} \mathrm{Si}_{13} \mathrm{O}_{36} \cdot 12 \mathrm{H}_{2} \mathrm{O} \\
& \text { Gyrolite } \quad=\mathrm{Ca}_{2} \mathrm{Si}_{3} \mathrm{O}_{7}(\mathrm{OH})_{2} \cdot \mathrm{H}_{2} \mathrm{O} \\
& \text { Reyerite } \quad=(\mathrm{Na}, \mathrm{K})_{4} \mathrm{Ca}_{14}\left(\mathrm{Si}, \mathrm{Al}_{24}\left(\mathrm{Al}_{4} \mathrm{Si}_{2}\right) \mathrm{O}_{60}(\mathrm{OH})_{5} \cdot 5 \mathrm{H}_{2} \mathrm{O}\right. \\
& \text { Truscottite } \quad=\mathrm{Ca}_{14} \mathrm{Si}_{24} \mathrm{O}_{58}(\mathrm{OH})_{8} \cdot 2 \mathrm{H}_{2} \mathrm{O} \\
& \text { Tobermorite }=\mathrm{Ca}_{5} \mathrm{Si}_{6} \mathrm{O}_{16}(\mathrm{OH})_{2} \cdot 4 \mathrm{H}_{2} \mathrm{O} \\
& \text { Wairakite } \quad=\mathrm{CaAl}_{2} \mathrm{Si}_{4} \mathrm{O}_{12} \cdot \mathrm{H}_{2} \mathrm{O} \\
& \text { Smectite } \quad=\mathrm{X}_{0.33} \mathrm{Y}_{2-3} \mathrm{Z}_{4} \mathrm{O}_{10} \cdot \mathrm{nH}_{2} \mathrm{O}(\mathrm{X}=\mathrm{Na}, \mathrm{K}, \mathrm{Ca} / 2)(\mathrm{Y}=\mathrm{Al}, \mathrm{Fe}, \mathrm{Mg})(\mathrm{Z}=\mathrm{Si}, \mathrm{Al}) \\
& \text { Siderite } \quad=\mathrm{FeCO}_{3}
\end{aligned}
$$

${ }^{a}$ After Fleischer (1983). 